\title{
MODELING AND DESIGN OF RIGID CONNECTIONS BETWEEN COLUMNS AND FLAT SLABS
}

\author{
by \\ Jasmin Jenger \\ B.Eng., Karlsruhe University of Applied Sciences, Germany, 2016 \\ A master's research project \\ presented to Ryerson University and \\ Karlsruhe University of Applied Sciences \\ in partial fulfillment of the \\ requirements for the degree of \\ Master of Engineering \\ in the program of \\ Civil Engineering
}

Toronto, Ontario, Canada, 2018

(C) Jasmin Jenger, 2018 


\section{AUTHOR'S DECLARATION}

I hereby declare that I am the sole author of this project. This is a true copy of the project, including any required final revisions.

I authorize Ryerson University to lend this project to other institutions or individuals for the purpose of scholarly research.

I further authorize Ryerson University to reproduce this project by photocopying or by other means, in total or in part, at the request of other institutions or individuals for the purpose of scholarly research.

I understand that my project may be made electronically available to the public. 


\title{
MODELING AND DESIGN OF RIGID CONNECTIONS \\ BETWEEN COLUMNS AND FLAT SLABS
}

\author{
Master of Engineering, 2018
}

Jasmin Jenger

Civil Engineering

Ryerson University and Karlsruhe University of Applied Sciences

\begin{abstract}
When it comes to the statical calculation and the design of the connection between reinforced concrete flat slabs and columns, the usual practice is to assume a hinged connection. However, in many cases this assumption does not reflect the actual behavior of the connection and a rigid design should be targeted in order to transfer the moments from the slab into the column.

This project aims to develop adequate strut-and-tie models in order to find practical solutions on how to transfer the moments from flat slabs into their supporting columns or in other words how to design a rigid slab-column connection. Special emphasis is devoted to solutions for the use of precast columns because the arrangement of the reinforcement is often limited.
\end{abstract}




\section{ACKNOWLEDGEMENTS}

First and foremost, I would like to express my sincere gratitude and appreciation to my supervisor, Dr. Jan Akkermann (Karlsruhe University of Applied Sciences), for his encouragement, guidance and support during the development of this project. I have been extremely lucky to have had a supervisor who cared so much about my work, who could always give me good advice and answered all my questions carefully and promptly.

Moreover, I would like to thank my co-supervisor, Dr. Reza Kianoush (Ryerson University), who had already supervised former projects of mine and who guided me towards the topic of strutand-tie models, providing the basis for the present project.

The Double-Degree Program between Karlsruhe University of Applied Sciences in cooperation with Ryerson University was a unique and enriching experience and I am all the more delighted to conclude this journey with the completion of this project. 


\section{TABLE OF CONTENTS}

AUTHOR'S DECLARATION .................................................................................... ii

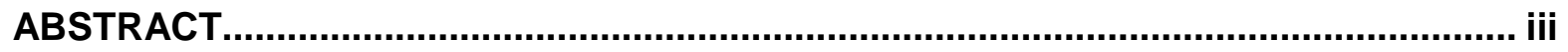

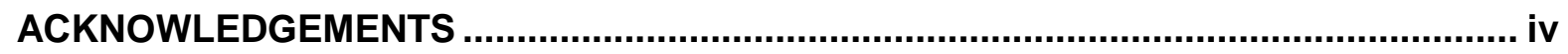

LIST OF TABLES ....................................................................................................... vii

LIST OF FIGURES........................................................................................... viii

1 INTRODUCTION AND RELEVANCE OF THE TOPIC ............................................... 1

1.1 Source of Moments and Consequences ....................................................... 2

1.1.1 Definition of the Transfer Moment ................................................................ 2

1.1.2 Consideration of Moment Transfer ...................................................................... 3

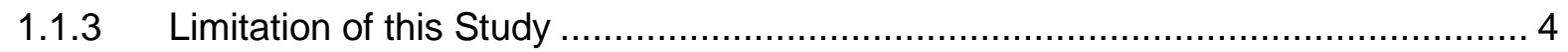

1.2 Slab-Column Connections in Monolithic Structures .......................................... 5

1.3 The Use Of Precast Columns ......................................................................... 5

2 CURRENT STANDARDS AND APPROACHES FOR THE DIMENSIONING OF SLABCOLUMN CONNECTIONS...................................................................................... 7

2.1 Punching Shear Design According to Building Codes ........................................ 7

2.1.1 Influence of Additional Moments............................................................. 8

2.2 Effects of Transmission of Large Column Loads ........................................... 9

3 DETERMINATION OF INTERNAL FORCES AND MAGNITUDE OF MOMENTS...... 12

3.1 Distribution and Flow of Internal Forces ...................................................... 12

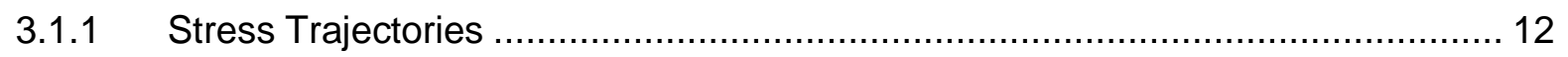

3.1.2 Distribution and Calculation of Internal Forces ............................................ 14

3.2 Estimation of the Magnitude of Moments ................................................... 15

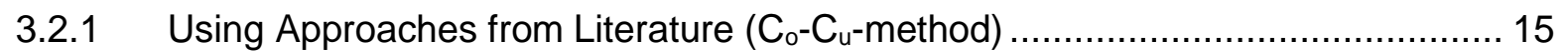

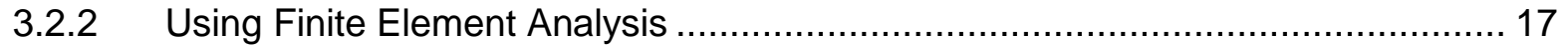

3.3 Comparison and Evaluation of the Methods............................................... 18

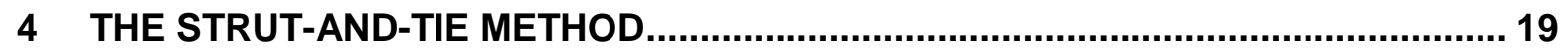

$4.1 \quad$ Introductory and General Remarks ........................................................ 19

4.2 Components of Strut-and-Tie Models and Design Rules .................................. 20

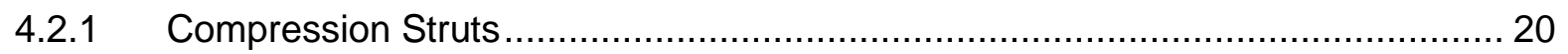

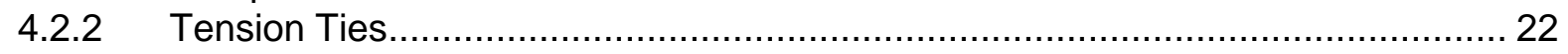

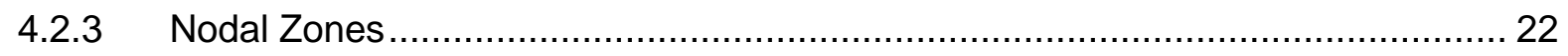

4.3 Related Strut-and-Tie Models ............................................................ 24 


\section{DEVELOPMENT OF STRUT-AND-TIE MODELS ADAPTED FOR RIGID SLAB-}

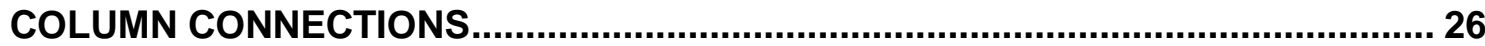

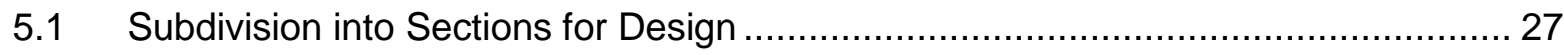

5.2 Successive Development of Valid Strut-and-Tie Model....................................... 29

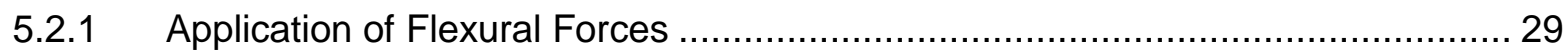

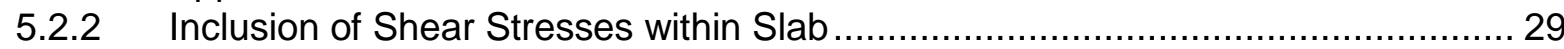

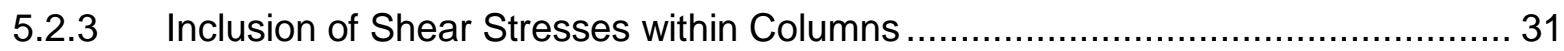

5.3 Development of Three-Dimensional Models ..................................................... 32

6 POSSIBLE REINFORCEMENT DESIGN SOLUTIONS …........................................... 35

6.1 General Rules for Reinforcement Design ....................................................... 35

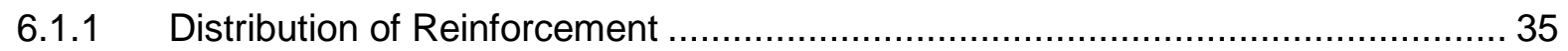

6.1.2 Minimum Mandrel Diameter to Avoid Damage to Reinforcement........................ 36

6.1.3 Confinement by Surrounding Concrete or by Reinforcement............................... 37

6.1.4 Anchorage of Reinforcing Bars.............................................................. 38

6.1.5 Transverse Tension Resulting from Reinforcement Arrangement........................ 40

6.2 Reinforcement Design Solutions .............................................................. 41

6.2.1 Design Solutions for a Simple Model Charged with Moment and Shear .............. 41

6.2.2 Design Solution with Horizontal Reinforcement Loop ........................................ 43

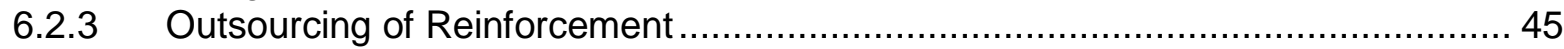

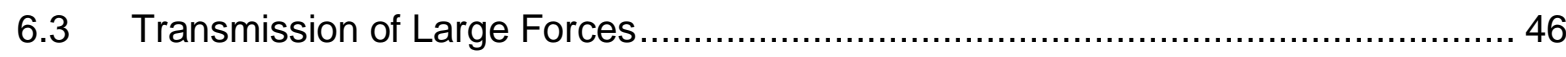

7 PARAMETRIC STUDY AND RECOMMENDATIONS …........................................... 47

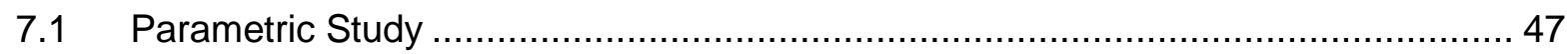

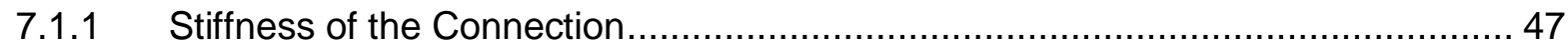

7.1.2 Dimensions of the Column and Slab Thickness.......................................... 47

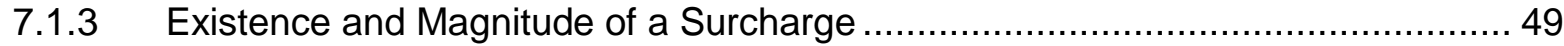

7.1.4 Concrete Strength ................................................................................... 49

7.1.5 Existence and Length of a Slab Overhang.................................................. 50

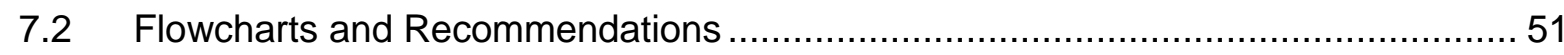

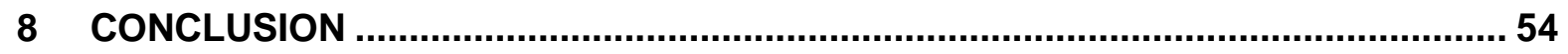

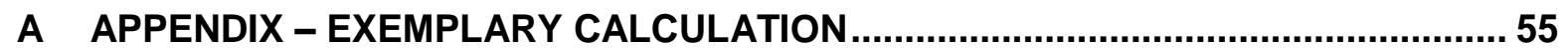

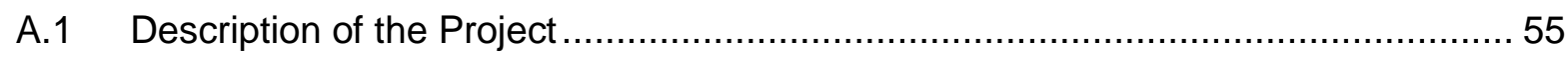

A.2 Estimation of the Magnitude of Moments ……............................................. 57

A.3 Strut-and-Tie Models and Dimensioning of Reinforcement ............................... 61

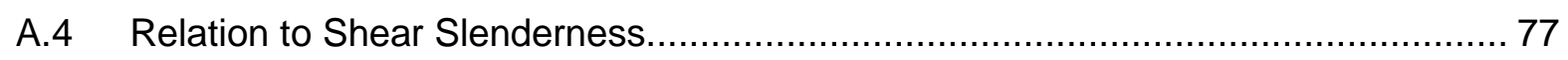

REFERENCES 


\section{LIST OF TABLES}

Table 4-1 - Value of $k$ parameters according to EC2 including National Annex......................23

Table 6-1 - Minimum mandrel diameter for diagonal and other bent bars ............................. 36

Table 6-2 - Minimum mandrel diameter for hooks, loops, and stirrups ................................. 36

Table 7-1 - Values of compression and tensile forces for different strut angles.....................48

Table A-1 - Collection of calculated moments and shear forces..................................... 61

Table A-2 - Different reinforcement arrangements, required cross sectional area and width....78 


\section{LIST OF FIGURES}

Figure 1-1 - Load balance within column-slab connection joint [1] ......................................

Figure 1-2 - Definition of the transfer moment resulting from lateral and vertical loading ........... 3

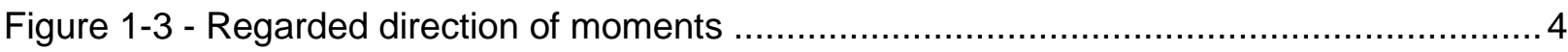

Figure 1-4 - Reinforcement design recommendations for monolithic connections by $\mathrm{ACl}$ [2] .....5

Figure 1-5 - Screwed reinforcement connection for spun-concrete columns (Europoles) [3]...... 6

Figure 2-1 - Failure mechanisms leading to punching failure [4] .................................... 7

Figure 2-2 - Values for increasing factor $\beta$ according to EC [6] ..................................... 8

Figure 2-3 - Shear distribution along the critical section under the influence of moments [7] f....9

Figure 2-4 - Stress-strain relationship for concrete subjected to multiaxial loadings [9]........... 10

Figure 2-5 - Transmission of large column loads through the connection [10]...................... 10

Figure 2-6 - Strain distribution of the specimens at maximum loading [11] .......................... 11

Figure 3-1 - Idealised flow of internal forces and common reinforcement arrangement [12]..... 12

Figure 3-2 - Eccentrically loaded edge column, FE mesh, and stress trajectories.................. 13

Figure 3-3 - Different views of the pathway of stress trajectories .................................... 13

Figure 3-4 - Internal forces and resulting distribution of forces and moments [14] ................ 14

Figure 3-5 - Analogy to a short beam, deformation characteristic crack formation [14] ............ 15

Figure 3-6 - $\lambda$ and $\psi$ and for calculating the effective width and clamping moment [17] ..........16

Figure 3-7 - Equations for calculation of moments in edge and corner columns [17]............. 16

Figure 3-8 - Different default column support conditions offered by RFEM .........................17

Figure 4-1 - Discontinuity regions in different structures [20] ...................................... 19

Figure 4-2 - Components of strut-and-tie models [21] ................................................ 20

Figure 4-3 - Different types of struts in a strut-and-tie model [21] ....................................20

Figure 4-4 - Determination of transverse tensile forces in a compression field [6]..................21

Figure 4-5 - Design strength of concrete struts with and without transverse tension [6] ..........21

Figure 4-6 - Different types of nodes and design parameters according to the EC [6]............23

Figure 4-7 - Different examples of frame nodes [22] ............................................... 24

Figure 4-8 - Superposition of opening and closing corner joint [23] ................................ 24

Figure 4-9 - Strut-and-tie models for a frame corner, corbel and a frame node [24] ...............25

Figure 5-1 - Modelling of the strut-and-tie models with RSTAB ......................................26

Figure 5-2 - Realistic flow of internal forces within frame end nodes [24] ...........................27

Figure 5-3 - Subdivision of the connection into different B- and D-regions [24] ..................... 28

Figure 5-4 - Adjoining forces of B- and D-regions [24] .............................................. 28

Figure 5-5 - Simple model with and without upper column charged with bending moment......29

Figure 5-6 - Strut-and-tie model with shear forces ................................................ 30

Figure 5-7 - Splitting of trusses to point out different D-sections ...................................... 30

Figure 5-8 - Including shear stresses at the interface of the columns .............................. 31 
Figure 5-9 - Simple 3D-strut-and-tie model charged with pure bending ............................... 32

Figure 5-10 - Different strut-and-tie models in three-dimensional space ............................... 33

Figure 6-1 - Distribution of reinforcement according to EC [6] ........................................ 35

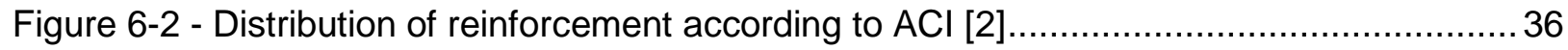

Figure 6-3 - Confinement by concrete or by reinforcement [25] .................................... 37

Figure 6-4 - Definitions of areas of 'good' and 'poor' bond conditions [6]............................. 38

Figure 6-5 - Methods of anchorage other than by a straight bar [6] .................................. 38

Figure 6-6 - Welded anchor heads [14] and anchor heads as a screw connection [26]........... 39

Figure 6-7 - Ultimate load $\mathrm{T}$ in dependence on the anchor types [14] ............................... 39

Figure 6-8 - Transverse tensile forces resulting from redirecting or anchoring forces [16]....... 40

Figure 6-9 - Simple model charged with bending moment and shear .................................4 41

Figure 6-10 - Reinforcement design solution for simple model $\left(90^{\circ}\right.$ bent bars) [27] ...............42

Figure 6-11 - Reinforcement design solution for simple model (anchorage of bars) ................42

Figure 6-12 - Strut-and-tie model with horizontal reinforcement loop ................................. 43

Figure 6-13 - Model for the distribution of forces and strut-and-tie model [28]..................... 43

Figure 6-14 - Reinforcement design solution with horizontal reinforcement loop................... 44

Figure 6-15 - Outsourcing of reinforcement ............................................................. 45

Figure 6-16 - Reinforcement design solutions with the outsourcing of reinforcement bars ....... 46

Figure 6-17 - Additional stirrups to ensure confinement .............................................. 46

Figure 7-1 - Influence of angle of compression strut on internal force distribution.................. 48

Figure $7-2$ - Influence of magnitude of a surcharge ..................................................... 49

Figure 7-3 - Spalling of the concrete as a result of the non-existent overhang [1] .................50

Figure $7-4$ - Necessity of considering moments and calculation methods ...........................51

Figure 7-5 - Reinforcement design solution depending on different parameters ....................52

Figure A-1 - Plan view of the first floor of an institutional building ..................................55

Figure A-2 - Dimensions of the regarded exemplary slap stripe ......................................56

Figure A-3 - Definition of lengths $I_{1}$ and $I_{2}$ according to "Heft 240" ....................................57

Figure A-4 - Calculation of moments by the Co-Cu-method ........................................... 58

Figure A-5 - Definition of support conditions and estimated values for replacement spring ......59

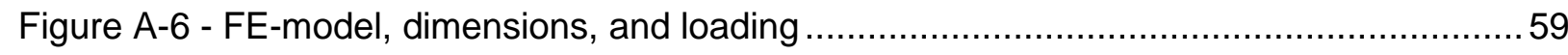

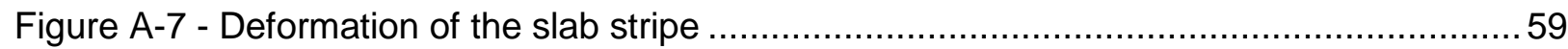

Figure A-8 - Moment diagram in the longitudinal direction and support reactions .................60 60

Figure A-9 - Shear diagram in the longitudinal direction ............................................. 60

Figure A-10 - Explanations of symbols in strut-and-tie models .......................................61

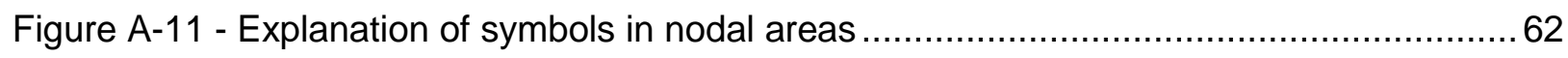

Figure A-12 - Moment and shear distribution in a simply fixed end beam [29] .................... 77 


\section{INTRODUCTION AND RELEVANCE OF THE TOPIC}

Reinforced concrete flat slabs supported by columns are currently one of the most common structural elements for multi-story buildings like apartments, offices and institutional buildings. At the same time, the connection between slab and column is an area that is subjected to a complex loading state and therefore needs to be designed properly (Figure 1-1).

Typically, the weak point of flat slabs is their resistance against punching, a special case of shear failure which occurs close to the supporting columns. However, when the column-slab connection is exposed to supplementary moments, as it will always be the case for edge and corner column supports, the current codes and literature do not provide many practical and detailed design solutions. Therefore, particular attention must be paid when it comes to the design of the reinforcement that ensures the transfer of the moment within the connection. The usual practice to assume the slab-column connection to be an articulated joint, in order to avoid the occurrence of moments respectively the necessity of transfer reinforcement, is not always justified as will be shown in the following.
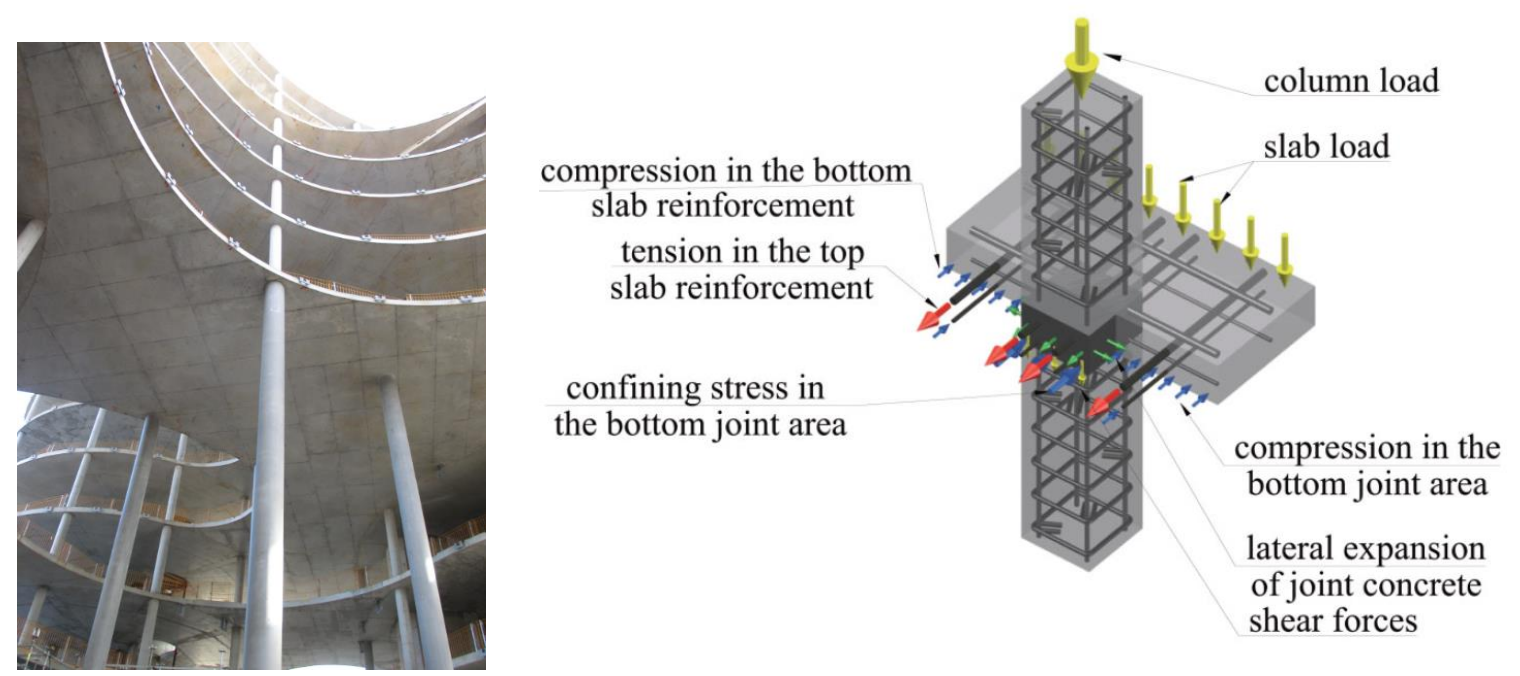

Figure 1-1 - Load balance within column-slab connection joint [1]

It has to be mentioned that this issue of moment transfer not only arises in the field of building construction and flat slab-column connections. Moment transfer also plays a significant role when it comes to the design and construction of structural connections like pile caps or bridge piers. However, this paper will only concentrate on flat-slab column connections, especially on edge column supports subjected to moments acting in a simplified way perpendicular to the edge. 


\subsection{SOURCE OF MOMENTS AND CONSEQUENCES}

The occurrence of moments at slab-column connections is due to various reasons:

- unsymmetrical load distribution

- accidental or unintended restraint (connections under high pressure)

- moments due to horizontal loads (e.g. earthquakes, wind)

Normally, interior columns are only little affected, provided that the span width at each side of the column is more or less equal and the load is uniformly distributed. Edge and corner columns, however, are always exposed to one-sided or unilateral loads and therefore an additional moment transfer between the slab and the column must be considered in design.

Of course, it may be argued that once the slab-column connection contains no additional fixedend reinforcement and the concrete becomes cracked in that area, the connection can be considered as an articulated joint for design. This assumption, obviously, results in larger deformations and moments of span, whereas the clamping moment is completely neglected and assumed to be zero. It is well known that a reinforced concrete connection can never be assumed to act as a perfect articulated joint as there will always occur some partial fixing. In addition, cracking of the concrete may be limited by the choice of the concrete strength and the existence of a surcharge resulting from the weight and loads of the supporting columns standing above (accidental or unintended restraint).

This paper will only cover the moments resulting from vertical loading of the slab. Moments resulting from horizontal loads e.g. from earthquakes or wind are assumed to be transferred into the stiffening elements of the building such as the staircase core or walls. In other words, it is assumed that the columns do not take part in the bracing system and that the moments resulting from horizontal loads do not have to be considered in the design of the connection.

\subsubsection{Definition of the Transfer Moment}

When talking about the transfer moment in the following, this means the portion of the slab total moment which is transferred to the supporting element at a connection, in our case the supporting column. The transfer moment is identical in meaning to the unbalanced moment as defined in current literature and standards. 

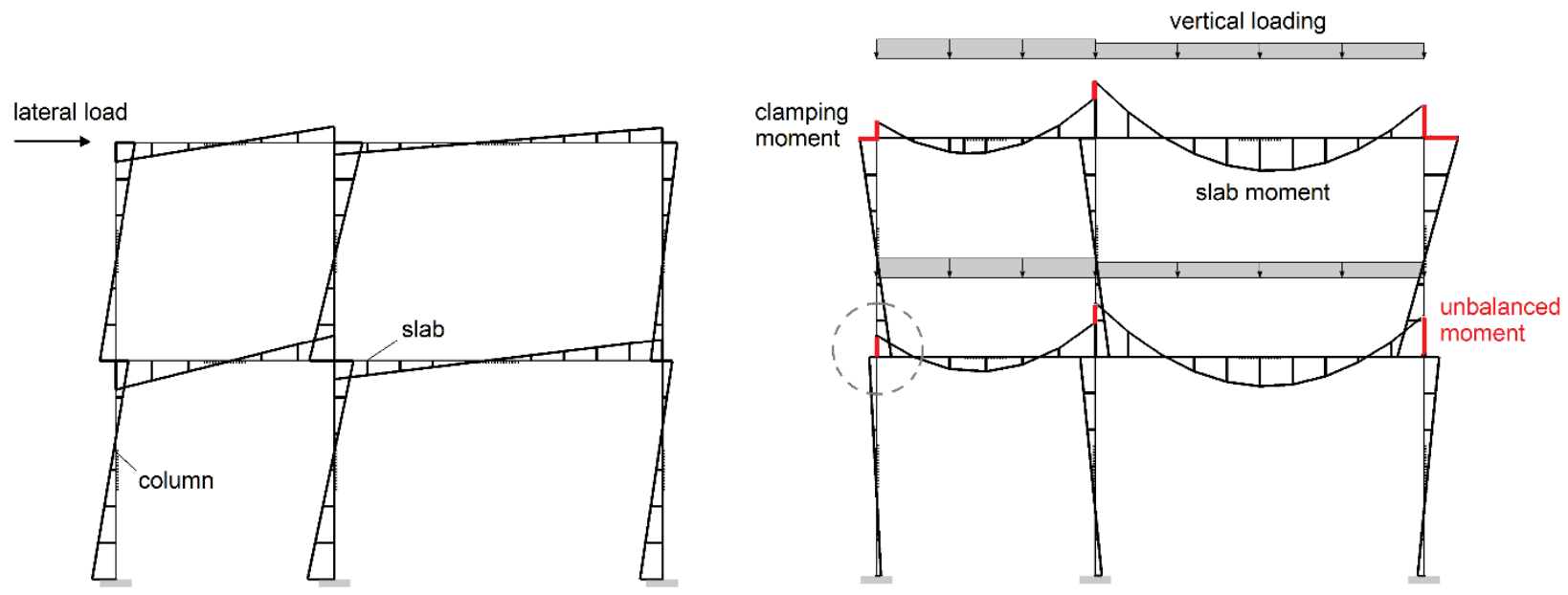

Figure 1-2 - Definition of the transfer moment resulting from lateral and vertical loading

As shown in Figure 1-2 the unbalanced moment corresponds to the leap in the moment diagram in the axis of the column support (marked in red). The transfer moment gets larger the stiffer the connection is. At the same time, the slab moment decreases. The proportional distribution of the slab moment into the upper and lower column is, in turn, dependent on their individual stiffness.

\subsubsection{Consideration of Moment Transfer}

In its recommendation for the design of slab-column connections in monolithic reinforced concrete structures (352.1R-89) from 1989 the ACI-ASCE Committee states that moment transfer should be included in evaluating the resistance of the slab-column connection if the ratio between the factored transfer moment and factored slab shear at the slab critical section exceeds the value of $0.2 d$, where $d$ is the effective depth of the slab [2]:

$$
M_{d} V_{d}>0,2 d
$$

This limitation is also valid for biaxial moments, whereby both principal axes of the connection must be checked independently. In any case, it should be assumed that the moment acts at the geometric centroid of the slab critical section.

The general valid EC does not provide any detailed information on the question at what point moment transfer must be considered in the design of slab-column connections. However, in the National Annex of Germany an additional paragraph ${ }^{1}$ gives instructions on how to calculate

\footnotetext{
${ }^{1}$ DIN EN 1992-1-1 including German National Annex, (NA.6) and (Table NA.6.1.1)
} 
minimal values of moments acting in the area of columns which are to be taken into consideration for design unless the values resulting from the determination of internal forces are greater.

\subsubsection{Limitation of this Study}

To keep this paper concise, several limitations and simplifications need to be specified. At the beginning of this chapter, the scope of this paper was already restricted to the consideration of moments resulting from vertical loading of the slab. Moments resulting from lateral loading are not taken into consideration. Therefore, the resulting moments only act in a downward direction, as indicated in red color in Figure 1-3.

To specify the content further, only edge columns and only moments acting perpendicular to the slab edge (about an axis parallel to the slab edge) are considered. Lastly, and to simplify the calculations conducted in the Appendix, a rectangular column shape was chosen.
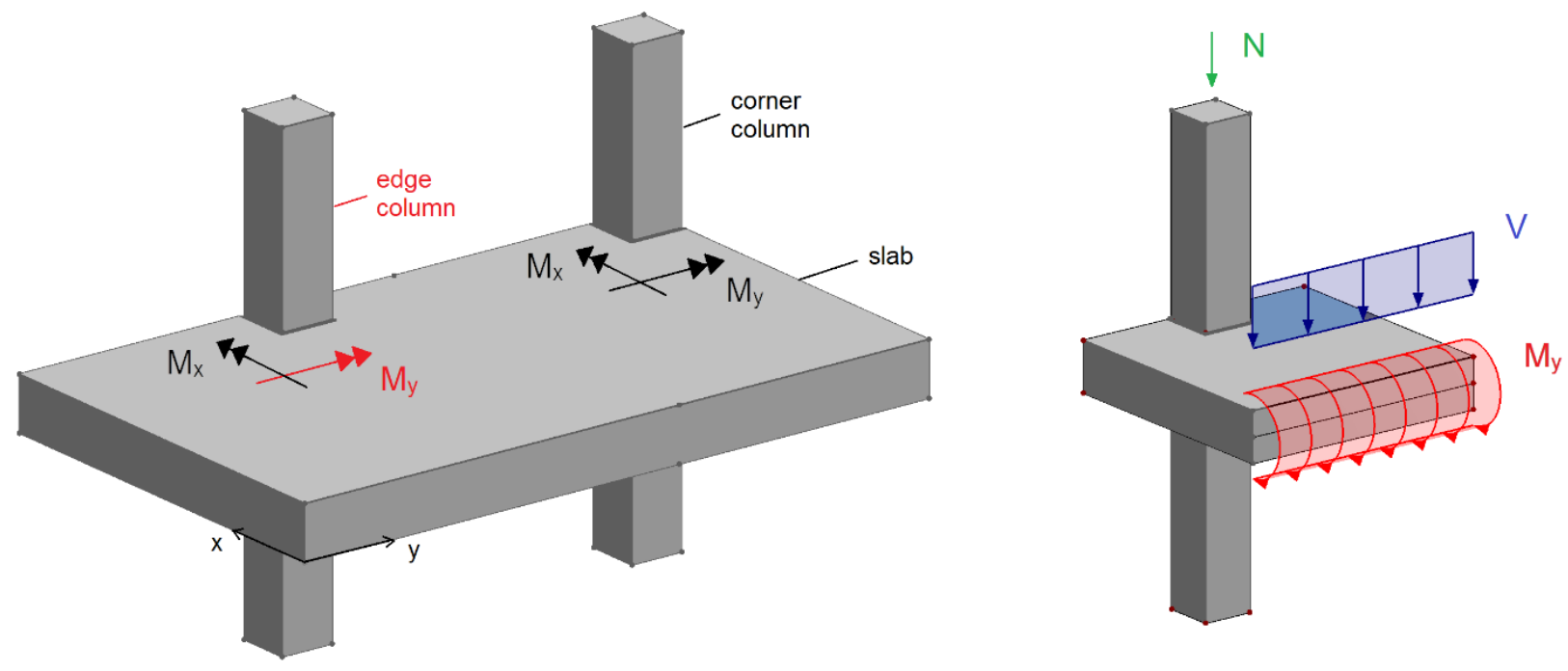

Figure 1-3 - Regarded direction of moments

Besides all these limitations, it should be kept in mind that the direction of the moment acting on the connection is not restricted to the illustrated $x$ and $y$-axis. This is only a simplification, as the moments can basically act in every imaginable direction. 


\subsection{SLAB-COLUMN CONNECTIONS IN MONOLITHIC STRUCTURES}

When it comes to the design of reinforcement, slab-column connections may be related to slabwall connections or rather frame corners. The most simple and common way is to add $90^{\circ}$ bent bars perpendicular to the adjoining wall or support element (in the axis of the acting moment), as shown in Figure 1-4. In dependence on the direction of the moment and the location of tensile stresses, the bars have to be located at the top or at the bottom of the slab and bent accordingly.
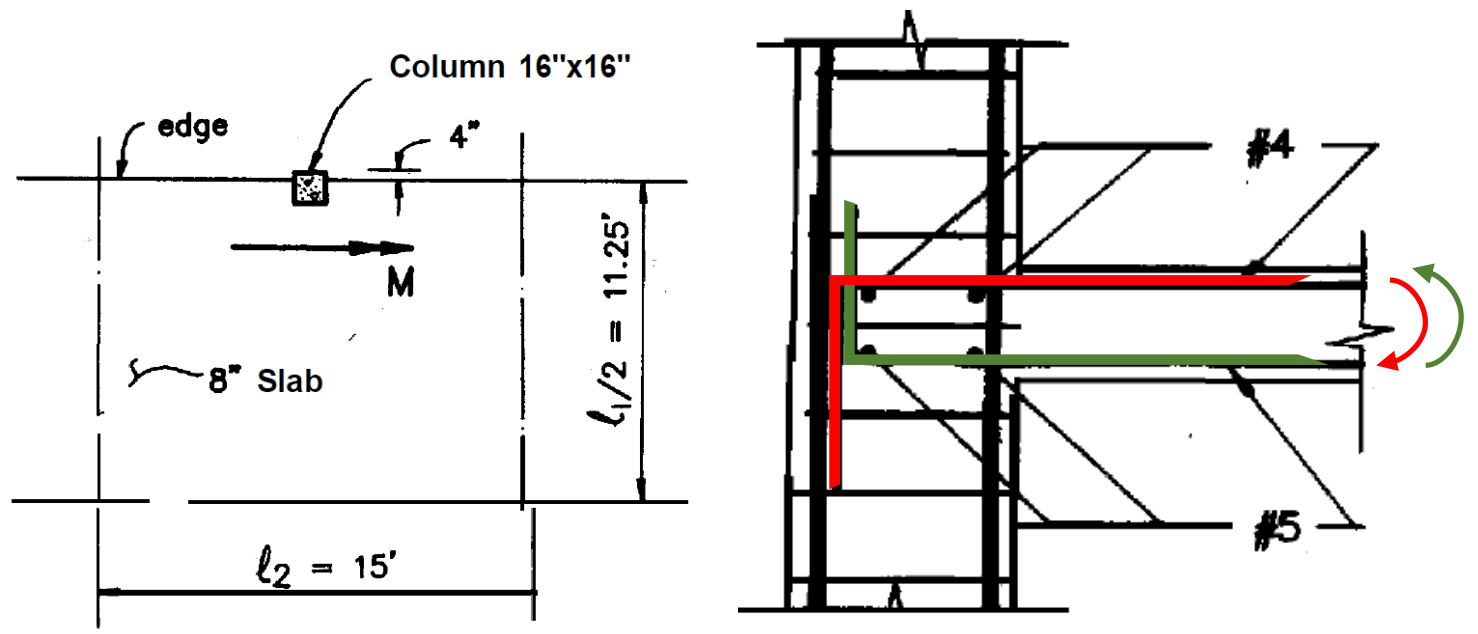

Figure 1-4 - Reinforcement design recommendations for monolithic connections by $\mathrm{ACl}$ [2]

Although this seems to be a simple and effective solution in the first place, the installation of this bent bar is difficult to reconcile with the sequence of construction as column and slab are usually concreted separately. The bent bar would need to be installed in the course of the concreting of the column, disturbing the following construction process.

\subsection{THE USE OF PRECAST COLUMNS}

In order to reduce expenses in time, costs and labor precast columns are often the preferred solution to columns cast in situ. Moreover, when it comes to the design of very slim and long column elements, cast-in-place columns are often limited in their shape and dimensions. Though advantageous in terms of construction, the use of precast columns introduces new challenges when it comes to the design of rigid slab-column connections that enable moment transfer. Limited by the means of transportation and their handling it is likely not possible to adopt the reinforcement solutions from the cast-in-place elements and therefore other solutions must be found to transfer the moments from the slab into the column. 


\section{Current Solutions for Precast Column-Slab Connections}

The German company Europoles, for example, proposes a solution using screwed reinforcement connections to enable the transfer of moments. As shown in Figure 1-5 the reinforcement bars are already bent in position and equipped with a screw connection at their ends which can be connected to the upper slab reinforcement.
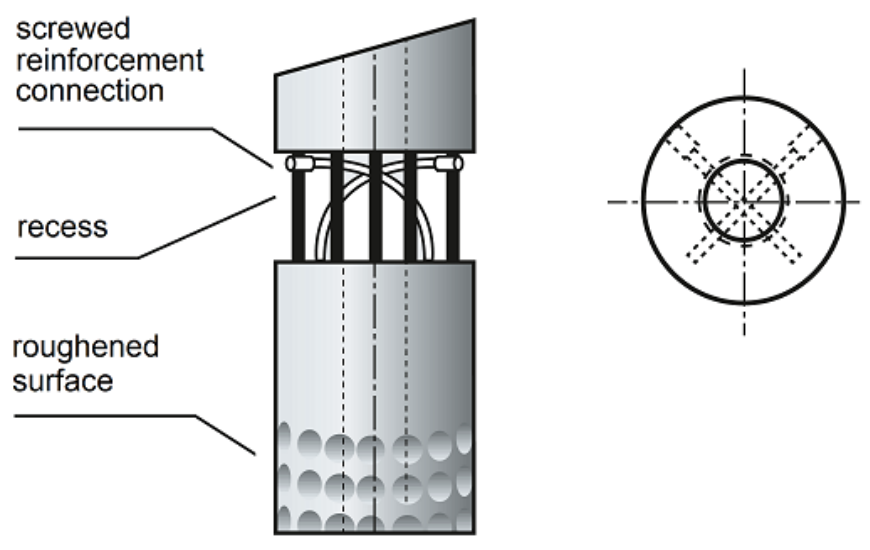

Figure 1-5 - Screwed reinforcement connection for spun-concrete columns (Europoles) [3]

At the bottom, the surface of the column is roughened to improve adhesion to the cast-in-place concrete. This is necessary to guarantee the transfer of the diagonal compressive strut into the nodal zone, which will be further explained in the following chapters.

Although the proposed solution allows an uncomplicated flow of forces similar to that of the castin-place connection, it is also a very cost-intensive variant. Besides the fact that screwed reinforcement connections are expensive special care has to be taken during the construction as this very sensitive type of connection needs to be constructed with a high degree of accuracy to ensure its proper functioning.

In light of this, this paper aims to find more simple and economical solutions on how to design rigid connections between flat slabs and their supporting columns, at best, a solution that avoids the installation of a $90^{\circ}$ bent bar. 


\section{CURRENT STANDARDS AND APPROACHES FOR THE DIMENSIONING OF SLAB-COLUMN CONNECTIONS}

This chapter shall give a general overview of current standards and approaches on how to dimension and design slab-column connections with special regard to the influence of additional moments acting on the connection.

\subsection{PUNCHING SHEAR DESIGN ACCORDING TO BUILDING CODES}

Decisive for dimensioning and design of flat slabs is commonly their resistance to punching which is a very brittle and sudden failure and therefore should be avoided. Punching failure, which is closely related to and pictures a special case of shear failure, can be traced back to two main failure mechanisms which are illustrated in Figure 2-1.

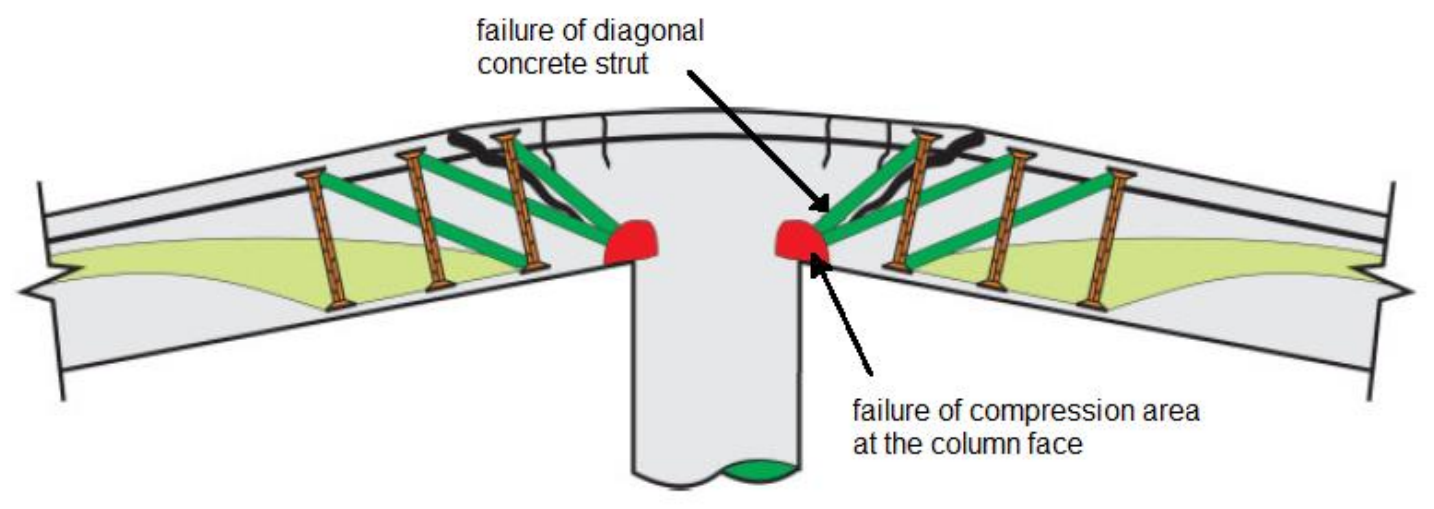

Figure 2-1 - Failure mechanisms leading to punching failure [4]

Analogous to a simple beam subjected to shear the bearing capacity of the diagonal compression strut next to the support is relevant for the design. Due to transverse tensile stresses along the strut the concrete cracks resulting in the typical diagonal crack pattern shown in Figure 2-1 (bold black line). However, further investigations and tests have shown that for very flat slabs it is not the failure of the compression strut but rather the failure of the small concrete area next to the face of the column at the bottom of the slab that gets relevant for design (red marked area). This second failure mechanism, which may occur prior to the failure of the compressive strut, shows up by spalling of the concrete in this area. It is due to the small size of the concrete compression zone at the interface of the support area as well as to insufficient confinement of the column by stirrups [4]. 


\subsubsection{Influence of Additional Moments}

If there are no bending moments transferred from the slab into the supporting column we can assume a rotationally symmetrical shear force distribution along the critical section. As already mentioned in the previous chapters, this is an ideal case that is only given for inner columns which are uniformly charged and have approximately equal spans.

In case that a moment is transferred, moment-shear-interaction must be considered leading to an uneven distribution of shear along the critical section (Figure 2-3) and therefore to locally increased punching shear stresses. To consider moment-shear-interaction in punching shear design, different codes offer different solutions which are, in turn, based on different approaches.

For a more detailed description and comparison of the different approaches, reference is made to Soares et al. [5]. Basically, most of the approaches are based on increasing the shear loads by a factor $\beta$. This factor can either be read from the given values (Figure 2-2) or be calculated more precisely by using the formulas provided by the codes (Figure 2-3).

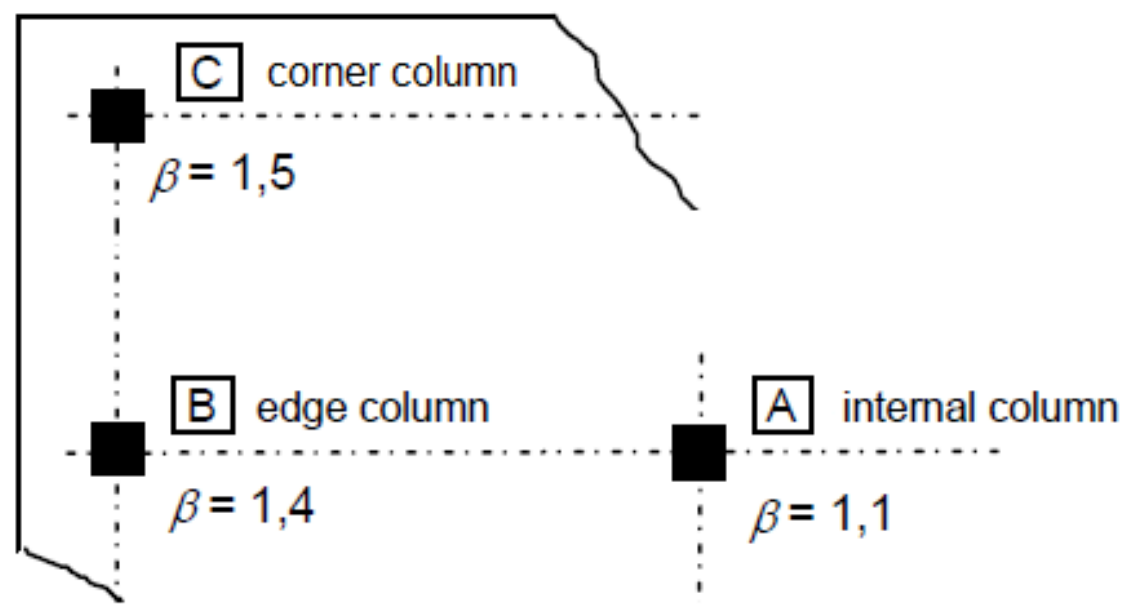

Figure 2-2 - Values for increasing factor $\beta$ according to EC [6]

In order to use the given values for $\beta$ according to the EC, several thresholds must be fulfilled. These include that the adjacent span lengths do not differ by more than $25 \%$ and that the stability against lateral loads is not dependent on frame action between the slabs and the columns ${ }^{2}$.

2 DIN EN 1992-1-1 including German National Annex, 6.4.3 (6) 

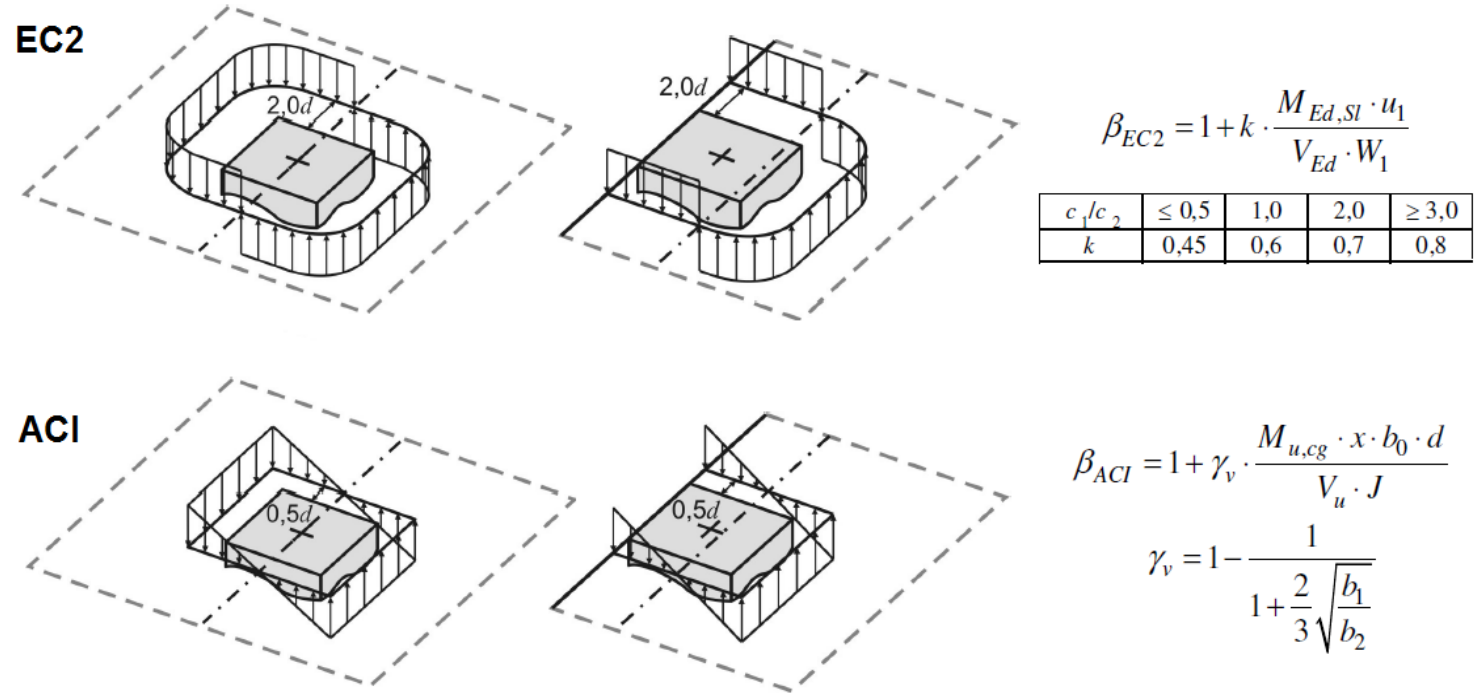

$$
\begin{gathered}
\beta_{A C I}=1+\gamma_{v} \cdot \frac{M_{u, c g} \cdot x \cdot b_{0} \cdot d}{V_{u} \cdot J} \\
\gamma_{v}=1-\frac{1}{1+\frac{2}{3} \sqrt{\frac{b_{1}}{b_{2}}}}
\end{gathered}
$$

Figure 2-3 - Shear distribution along the critical section under the influence of moments [7]

As this paper concentrates on the transfer of moments through the slab-column connection and not on the punching shear design itself, this shall only serve as background information. In addition to the reinforcement for moment transfer, which is elaborated in the following, punching shear reinforcement will likely be required.

\subsection{EFFECTS OF TRANSMISSION OF LARGE COLUMN LOADS}

As columns are often limited in their size due to architectonical reasons but still need to transfer large loads, it is nowadays usual practice to use high strength concrete for the columns, whereas concrete of normal strength is used for the slabs. An extreme example for this are spun concrete columns, which are characterized by very high concrete strengths (up to $140 \mathrm{~N} / \mathrm{mm}^{2}$ characteristic cylindrical compressive strength) combined with a very small cross-sectional area. In this case, it is likely that the high compressive stresses at the relatively small support areas of the columns exceed the uniaxial compressive strength of the concrete of the slab. Given that the surrounding concrete of the slab provides confinement and therefore prevents transverse expansion it is still possible to transfer the high loads through the slab area of the joint. This is due to the higher compressive strength of concrete in a multiaxial stress state (see Figure 2-4). It is reported in [8] that the concrete compressive strength in such joint areas may exceed the uniaxial compressive strength by more than three times. Though, it has to be noted that this state is combined with large deformations of the joint which may do not satisfy the verification of the serviceability. 

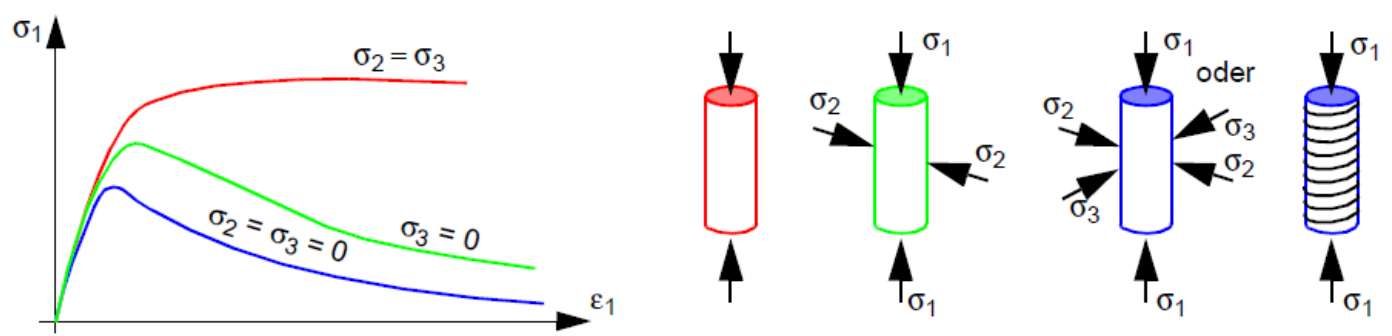

Figure 2-4 - Stress-strain relationship for concrete subjected to multiaxial loadings [9]

However, when it comes to the design of edge and corner columns confinement by surrounding concrete may not be existent or at least not sufficient. It is stated in [1] that the existence of a small slab overhang beyond the column edge increases the actual strength of the joint significantly (besides having positive effects on the punching shear resistance of the slab). Nevertheless, it may be necessary to ensure sufficient confinement by adding adequate reinforcement such as stirrups in the joint region of the column (see also Chapter 6.1.3).

Insufficient confinement may lead to the unfavorable distribution of forces illustrated by the strutand-tie model in Figure 2-5. If the transverse tensile forces $\left(Z_{2}\right)$ arising from the vertical loading of the column are not or only insufficiently covered by reinforcement, they may result in additional diagonal compressive struts (marked in yellow color). These struts, in turn, lead to an increase of tensile stresses in the upper slab reinforcement, larger deformations and unfavorable effects on the ultimate load capacity of the connection as a whole [10].

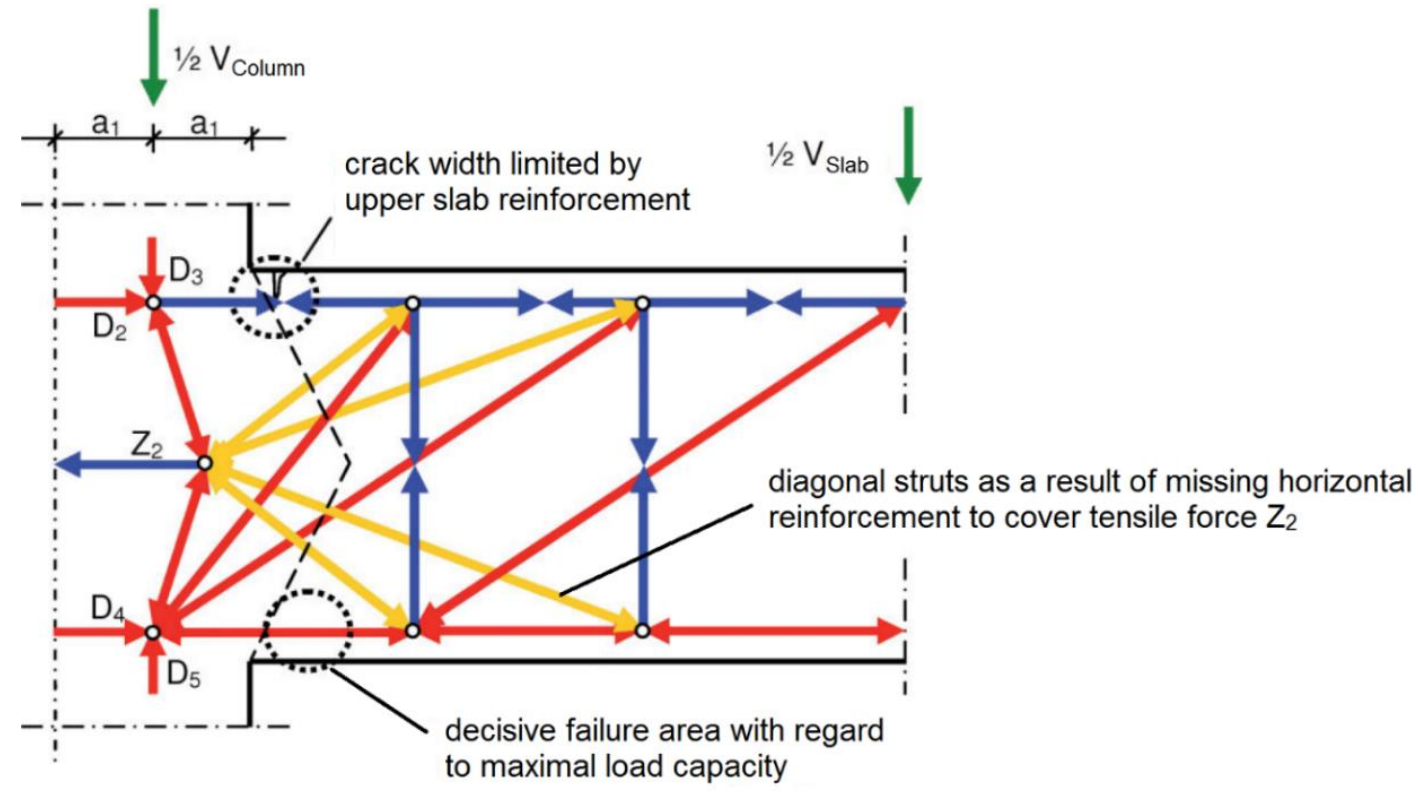

Figure 2-5 - Transmission of large column loads through the connection [10] 


\section{Additional Bending Moments}

Additional bending moments in the area of the slab-column joint may further reduce the confinement effect of the surrounding concrete. Cracks on the upper side of the slab near the joint may lead to loss of the multiaxial state and therefore have an adverse effect on the loadbearing capacity of the joint.
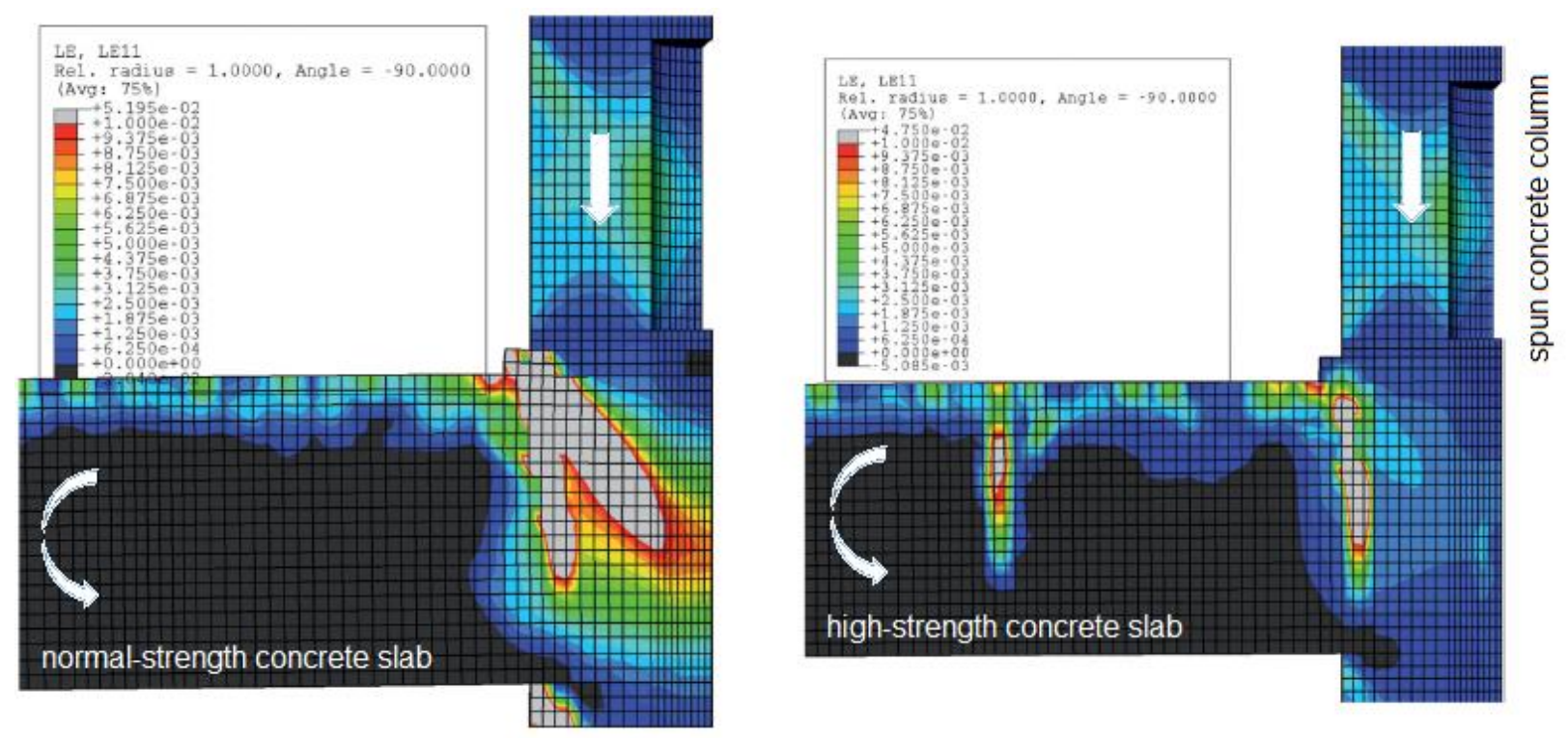

Figure 2-6 - Strain distribution of the specimens at maximum loading [11]

The effect of additional bending moments on slab-spun column joints was investigated by Rinnhofer et al. [11], with the result that the specimens containing a slab out of high-strength concrete still showed sufficient bearing capacities. Although being charged with an additional moment, the high-strength core could ensure sufficient confinement. On the contrary, the specimens which contained a slab out of normal-strength concrete failed earlier as a result of the lacking multiaxial compressive state. 


\section{DETERMINATION OF INTERNAL FORCES AND MAGNITUDE OF MOMENTS}

Before presenting different methods on how to calculate the magnitude of the bending moments, general remarks concerning the flow of internal forces within a slab-column connection are given.

\subsection{DISTRIBUTION AND FLOW OF INTERNAL FORCES}

In order to develop an adequate strut-and-tie model, we need to understand the flow of forces within the connection in the first place. Therefore, we can resort to the flow of forces of a simple frame end node subjected to the corresponding moments.
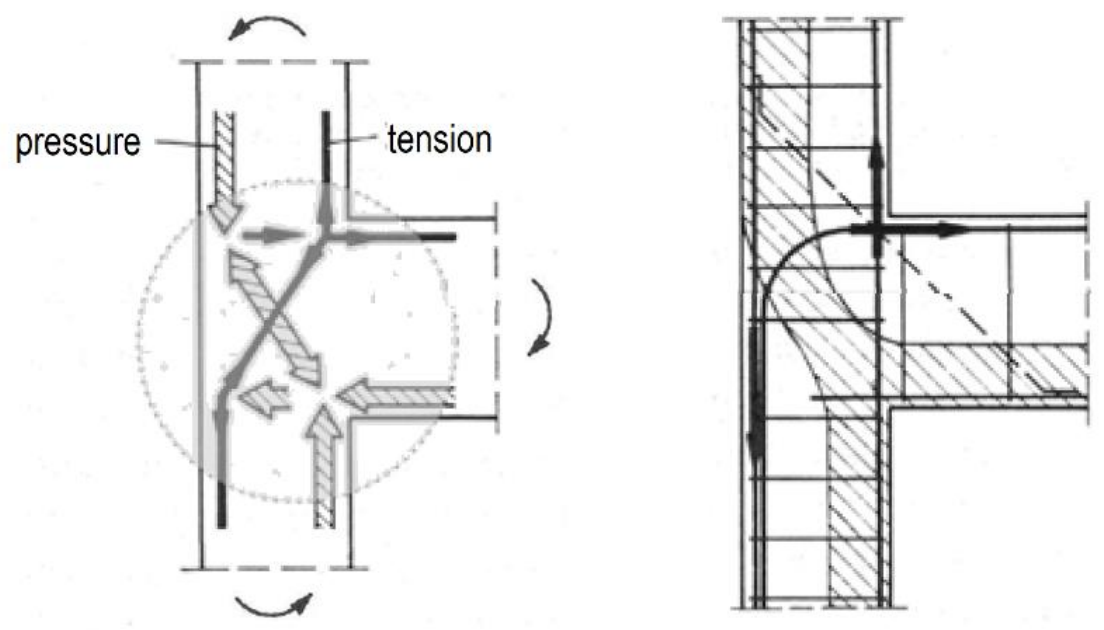

Figure 3-1 - Idealised flow of internal forces and common reinforcement arrangement [12]

The left picture in Figure 3-1 shows the simplified flow of forces within a frame end node, which can also be applied for the slab-column connection charged with a bending moment parallel to the slab edge. It can be seen that the compressive and tensile forces due to the column moments change side within the connection. This idealized flow of forces is also confirmed by the pathway of stress trajectories presented in the following.

\subsubsection{Stress Trajectories}

Developing an adequate strut-and-tie model is much simplified if the elastic stresses and principal stress directions are known. Such an elastic analysis can be performed by any suitable finite element software. For the following illustrations of the stress trajectories in an eccentrically loaded edge column connection, the software RFEM by the company Dlubal was used. 
The principal compression stresses act parallel to the so-called compressive stress trajectories, and principal tensile stresses act parallel to the tensile stress trajectories. Compressive stress trajectories (marked in red color) and tensile stress trajectories (blue color) are always orientated perpendicular to each other.
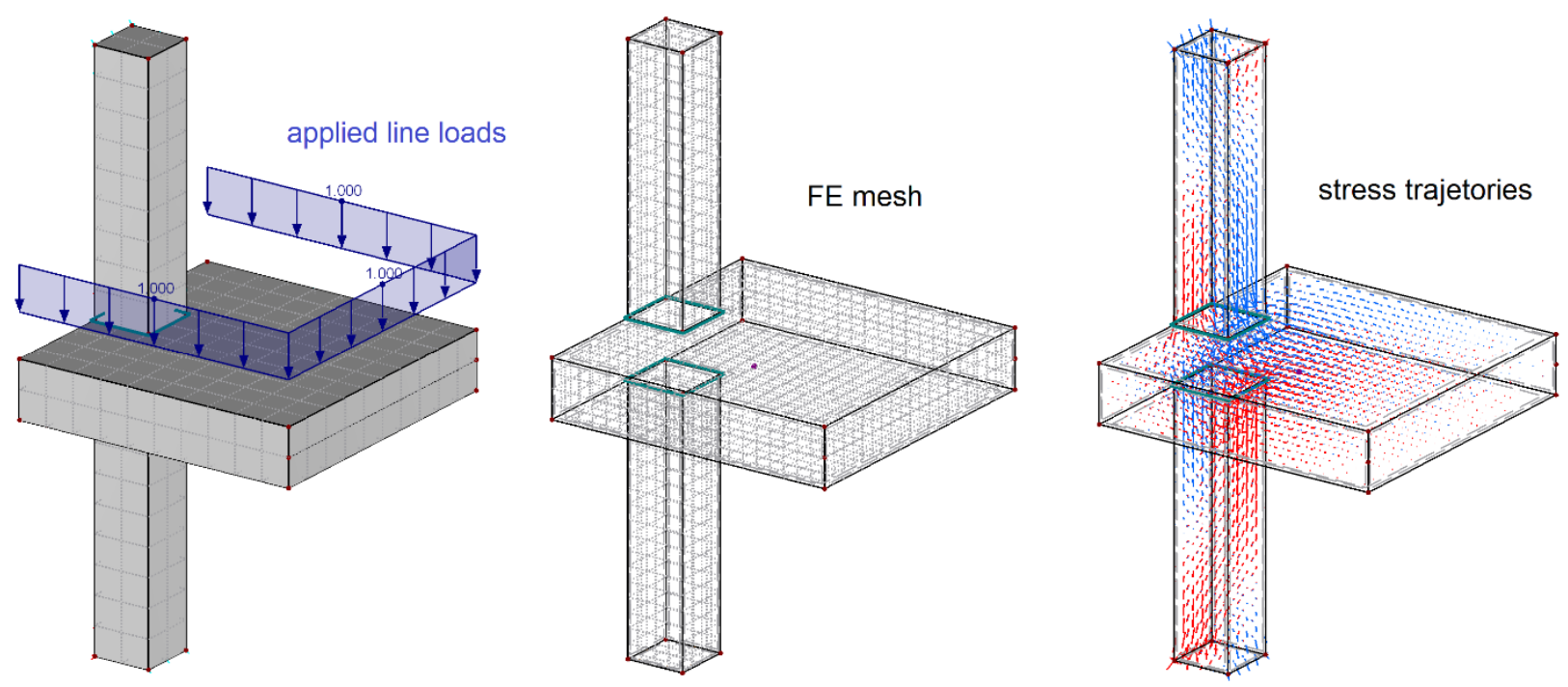

Figure 3-2 - Eccentrically loaded edge column, FE mesh, and stress trajectories
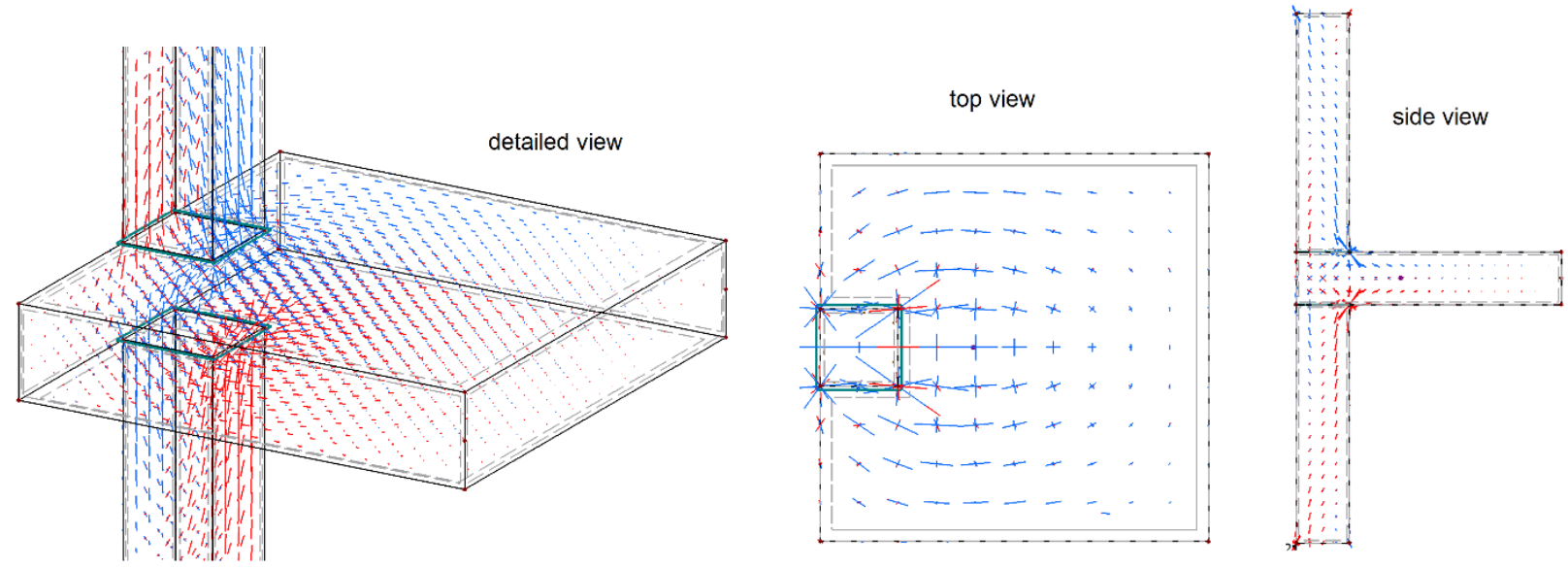

Figure 3-3 - Different views of the pathway of stress trajectories

When it comes to the development of strut-and-tie models, the compressive struts of the strutand-tie model should roughly follow the direction of the compressive stress trajectories (within \pm $15^{\circ}$ ) and the same applies to the tension ties and the tensile stress trajectories [13]. However, there is less restriction on the conformance of the latter because the tie consists of a finite arrangement of reinforcing bars. 


\subsubsection{Distribution and Calculation of Internal Forces}

The distribution of forces and moments in a slab-column connection do not exactly follow the linear theory. This leads us to the question of where to calculate the internal forces for design.
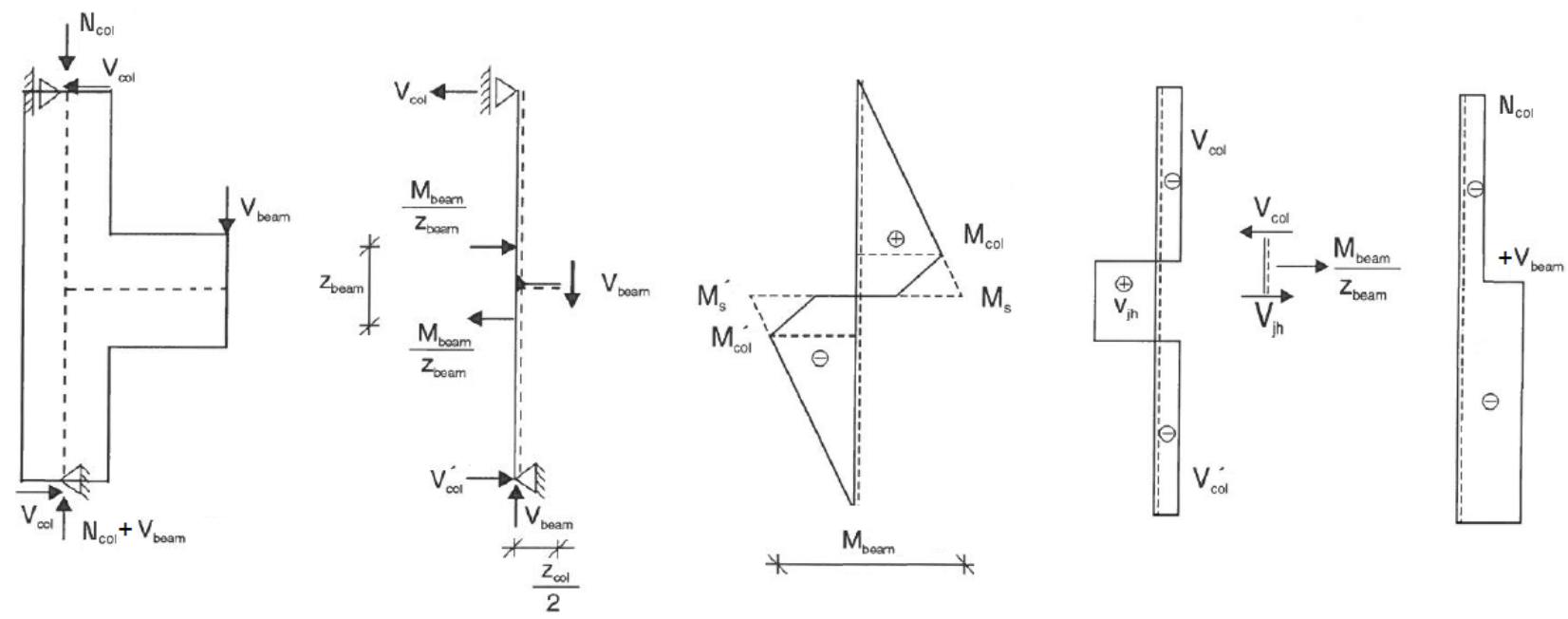

Figure 3-4 - Internal forces and resulting distribution of forces and moments [14]

The forces acting on the connection result from the distribution of forces of the adjacent elements. Thereby, the stiffness of the individual elements plays a significant role in how the forces are distributed. An equal distribution of moments and shear as shown in Figure 3-4 is only valid if the upper and lower column have the same stiffness.

Breaking down the slab-column connection to a simple framework whose axes refer to the centroidal axes of the columns respectively the slab, the distribution of internal forces can be easily determined by applying the linear theory. Hereinafter, making use of the differential correlation between shear and moment, it is possible to calculate the respective shares of shear and moment at the intersection of slab and column and according to [14].

The shear force $V_{j h}$ acting in the connection can be calculated from the following equation:

$$
V_{j h}=\frac{M_{\text {beam }}}{z_{\text {beam }}}-V_{c o l}
$$

The magnitude of the moment $\mathrm{M}_{\mathrm{col}}$ at the intersection of slab and column is given by:

$$
M^{\prime}{ }_{c o l}=M^{\prime}{ }_{S}-0,5 \times z_{\text {beam }} \times V^{\prime}{ }_{c o l}=V_{\text {beam }} \times \frac{z_{c o l}}{4}+V_{j h} \times \frac{z_{\text {beam }}}{2}
$$


The design for moment and shear of the slab and the column is carried out in accordance with the familiar methods proposed by the individual Codes. However, regarding the design of the connection itself, other solutions need to be found, as the Codes do not provide any specific rules on this topic. There exist different approaches on how to describe the load-bearing behavior.

In order to retrace the flow of internal forces within the connection, Kordina et. al [15] draw the correlation between a frame end node and a short beam charged with a single load (Figure 3-5). The magnitude of the applied load corresponds to the shear force $V_{\mathrm{jh}}$ that acts in the connection.
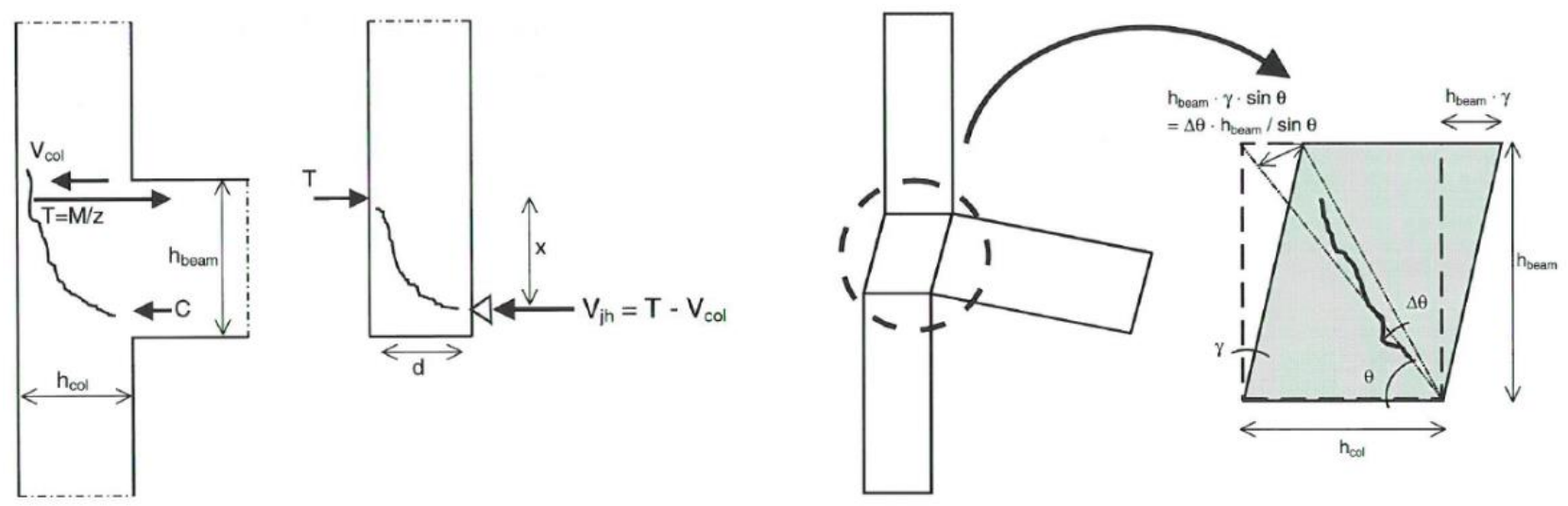

Figure 3-5 - Analogy to a short beam, deformation characteristic crack formation [14]

The basic mechanical behavior of the connection can be illustrated by using strut-and-tie models, which can be drawn back to the crack pattern of according test specimens. This topic, mainly forwarded by Schlaich et. al [16], will be treated in detail in the following chapters of this paper.

\subsection{ESTIMATION OF THE MAGNITUDE OF MOMENTS}

\subsubsection{Using Approaches from Literature $\left(\mathrm{C}_{\mathrm{o}}-\mathrm{C}_{\mathrm{u}}-\right.$ method)}

In one of its publications from 1988 [17], the German Committee of Reinforced Concrete (DAfStB - "Deutscher Ausschuss für Stahlbeton") presents a method, also known as the $\mathrm{C}_{0}-\mathrm{C}_{\mathrm{u}}$-method, for approximate calculation of the moments in edge and corner columns of flat slabs. It has to be taken into account that the method only allows the calculation of the moments due to the vertical loading of the slab. Moments due to horizontal loading must be calculated separately and may be overlaid with the moments of vertical loading. However, if we consider the building to be sufficiently horizontally braced we can neglect the influence of horizontal loading. 
The moments in edge and corner columns of flat slabs are calculated by assuming an equivalent frame in the required direction. The effective width $b_{m}$ of the slab representing the beam frame is calculated by the equation shown in Figure 3-6, whereby the coefficient $\lambda$ is dependent on the ratio of $\left(d_{s} / \min l_{2}\right)$ the may be read from the diagram.

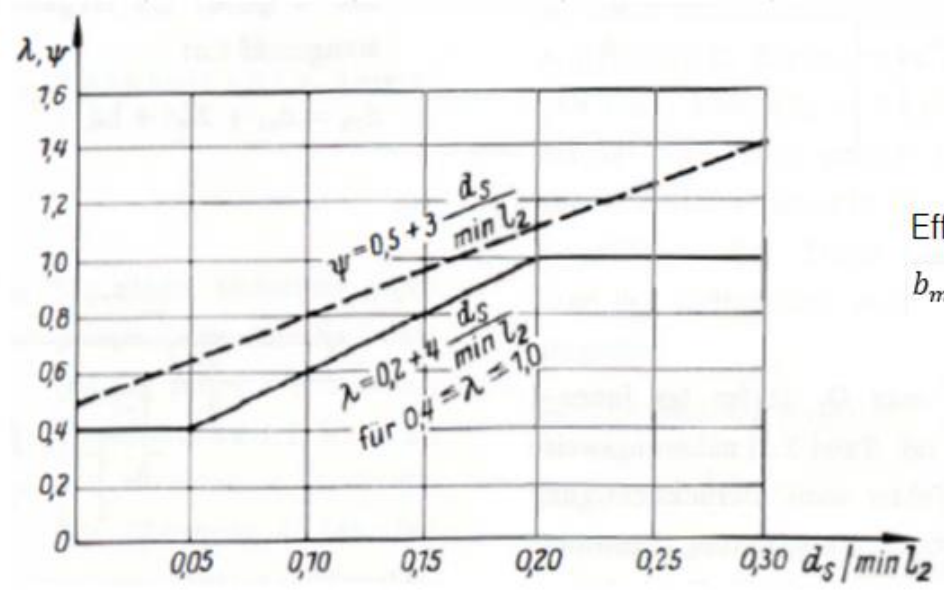

Effective width of equivalent beam frame: $b_{m}=\lambda \times \min l_{2}$

Figure 3-6 - $\lambda$ and $\psi$ and for calculating the effective width and clamping moment [17]

The distribution values $\mathrm{C}_{o}$ and $\mathrm{C}_{\mathrm{u}}$ include the stiffness of the elements and are used to calculate the actual moments of support in the upper $\left(\mathrm{M}_{\mathrm{so}}\right)$ and lower column $\left(\mathrm{M}_{\mathrm{su}}\right)$. The actual moment in the beam $M_{R}^{\prime}$ is equal to the sum of the value of these two moments.

The basic value is the clamping moment of a full restraint beam $M_{R}{ }^{(0)}$ which is calculated according to the equation given in Figure 3-7. The coefficient $\psi$ includes the increase of the support moments for broader columns.
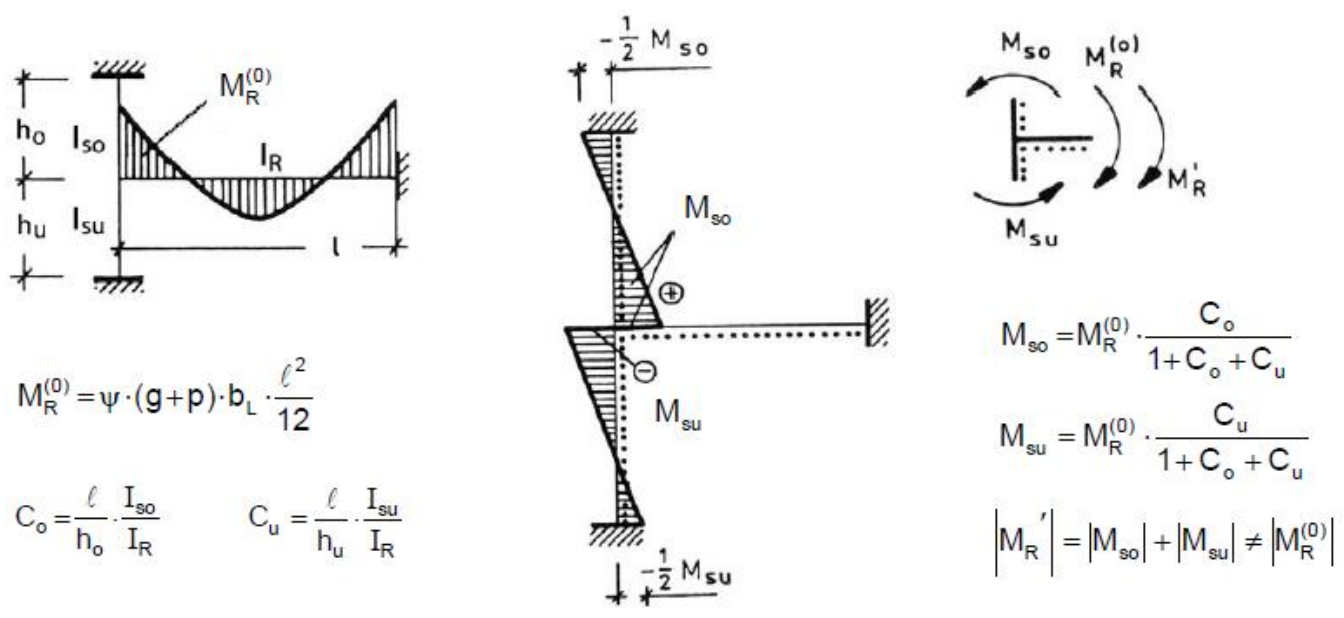

Figure 3-7 - Equations for calculation of moments in edge and corner columns [17] 
For simplicity, the calculation of the support moments of the example was carried out with an Excel sheet, which can be found in the Appendix. The results are compared with those of the FEM calculation in Chapter 3.3.

With regard to the relevant design locations and the "real" distribution of moments described in the previous chapter, the calculated moments should be reduced to the value of moment in the relevant design section. However, it is not clearly defined in [17] at which intersection the moments are calculated and therefore it would be a conservative approach to not reduce the values calculated by this method.

\subsubsection{Using Finite Element Analysis}

A precise and reliable estimation of the magnitude of the bending moments near point supports of slabs is one of the main problems in FE analysis. To keep a reasonable ratio between effort and accuracy Hartmann et al. [18] give the following recommendations (amongst others):

- always model the columns with their natural stiffness

- decrease the element size gradually towards the column center

- increase the thickness of the elements towards the center

- it is sufficient if the center node is supported, a multi-node model does not increase accuracy but may be suitable to simulate a rigid joint

For an exemplary finite element calculation of the moments, the software RFEM by the company Dlubal was used. The software offers three different default solutions on how to consider column supports of slabs (Figure 3-8). On the basis of the entered values of the column size and length, the software automatically calculates the stiffness of the replacement spring. Additionally, the size of the FE-mesh is automatically decreased towards the column center. The results directly above the column face area can be hidden, as singularities would impact the results in this area.
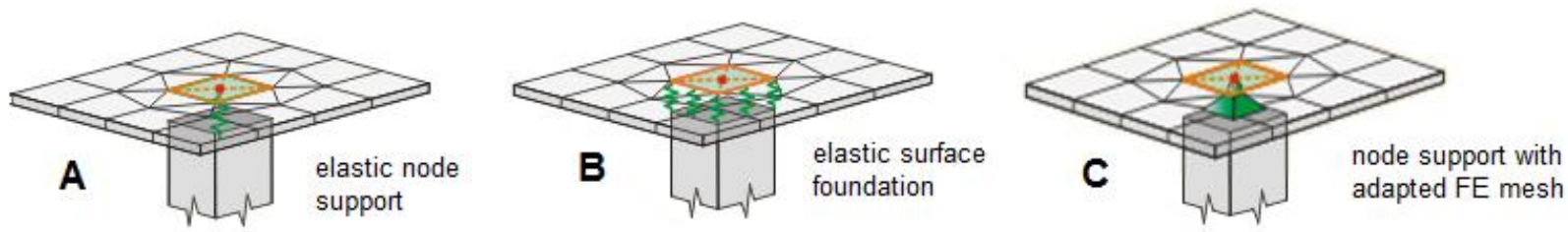

Figure 3-8 - Different default column support conditions offered by RFEM 
The values for the vertical and rotational stiffness of the single spring representing the elastic node support (A) are calculated in accordance with the following formulas. It is possible to represent either clamped or a hinged support conditions at the column head.

$$
k=C_{u, z}=\frac{E A}{h} \quad k_{\varphi}=C_{\varphi, \text { hinged }}=\frac{3 E I}{h} \quad C_{\varphi, \text { clamped }}=\frac{4 E I}{h}
$$

The representative values of the spring supports of the elastic surface foundation (B) are calculated in analogy to a beam as a function of the support condition at the column base. It is not possible to represent a hinged support at the column head.

Using a rigid node support $(C)$ does not represent the natural stiffness of the column and is therefore not recommended. In [19] they investigated an increase of the support moment of up to $40 \%$ while the field moment decreased about $21 \%$ when using a rigid node support in RFEM (compared to the calculations with support models $A$ and $B$ ).

\subsection{COMPARISON AND EVALUATION OF THE METHODS}

For the comparison between the two calculation methods, reference is made to the exemplary calculation in the Annex of this paper, respectively Chapter A.2 and Table A-1, where the calculated values are compared.

The values obtained by the $\mathrm{C}_{0}-\mathrm{C}_{\mathrm{u}}$-method only differ slightly from the values obtained by the calculation with RFEM. For the FE-calculation support models A and B were used, with the result that the differences in results are negligible.

As a result, both methods can be recommended for the determination of the magnitude of moments. However, when dealing with more complex and irregular floor layouts the $\mathrm{C}_{0^{-}}-\mathrm{C}_{u^{-}}$ method soon reaches its limits and a calculation by FEM becomes inevitable. 


\section{THE STRUT-AND-TIE METHOD}

As this paper aims to develop suitable strut-and-tie models that ensure moment transfer within slab-column connections it is necessary to look at the basic principles of the strut-and-tie method in the first place. Moreover, a short overview of existing suggestions for strut-and-tie models for corbels and frame corners is given, as these two structural elements are closely related to the slab-column connection and therefore may be helpful to develop a suitable strut-and-tie model for the latter in a next step.

\subsection{INTRODUCTORY AND GENERAL REMARKS}

Structural members may be divided into parts where the beam theory applies, the so-called Bernoulli or B-regions, and parts, adjacent to discontinuities or disturbances where the beam theory cannot be used. Such disturbed regions, also called discontinuity regions or D-regions, arise because of geometrical and/or loading or static discontinuities such as point loads, openings, corbels or frame corners.
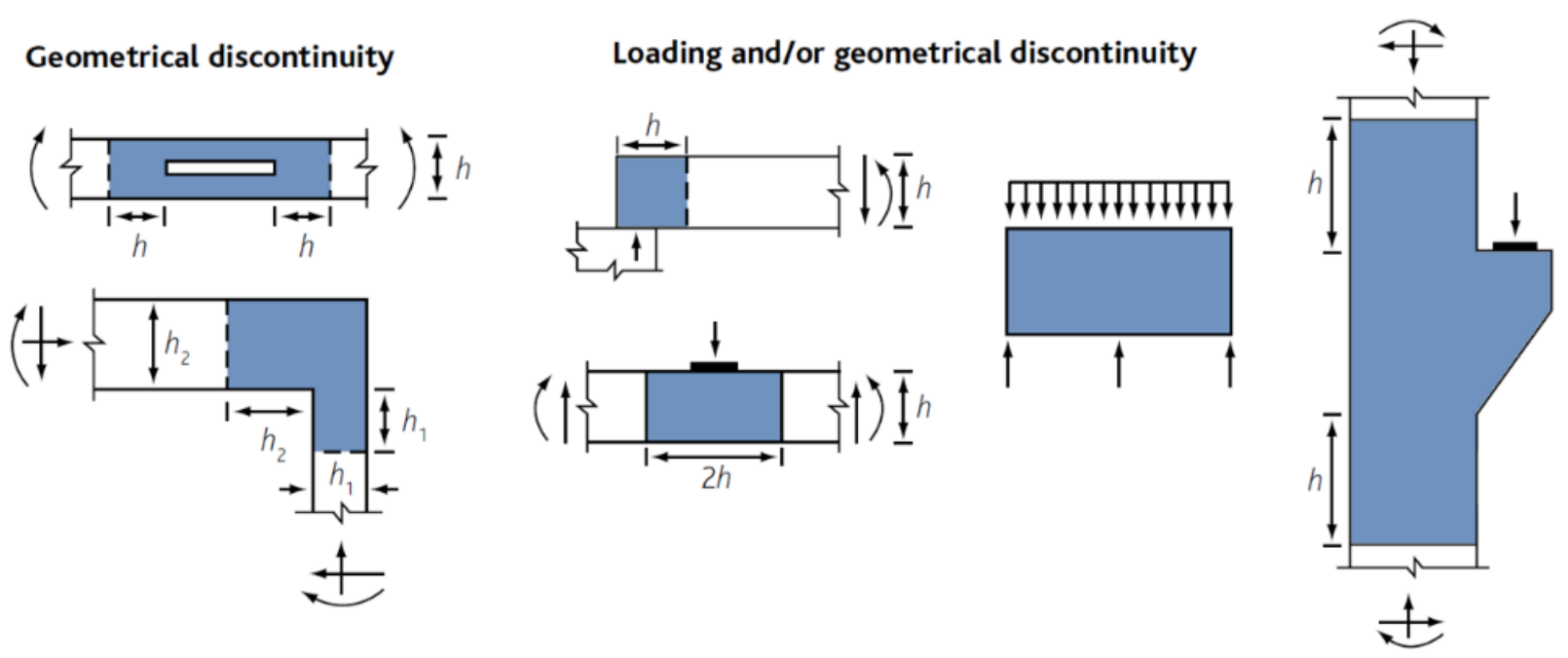

Figure 4-1 - Discontinuity regions in different structures [20]

The dividing sections between B- and D-regions can be assumed to lie approximately in a distance $\mathrm{h}$ from the geometrical discontinuity or the concentrated load. Thereby, the distance $\mathrm{h}$ is equal to the adjacent B-region, as can be seen in the figure above. 


\subsection{COMPONENTS OF STRUT-AND-TIE MODELS AND DESIGN RULES}

As shown in Figure 4-2, using the example of a simple beam structure, strut-and-tie models consist of three main elements: the concrete compressive struts, reinforcing bars as tension ties and joints or nodal zones. These components are discussed in the following.

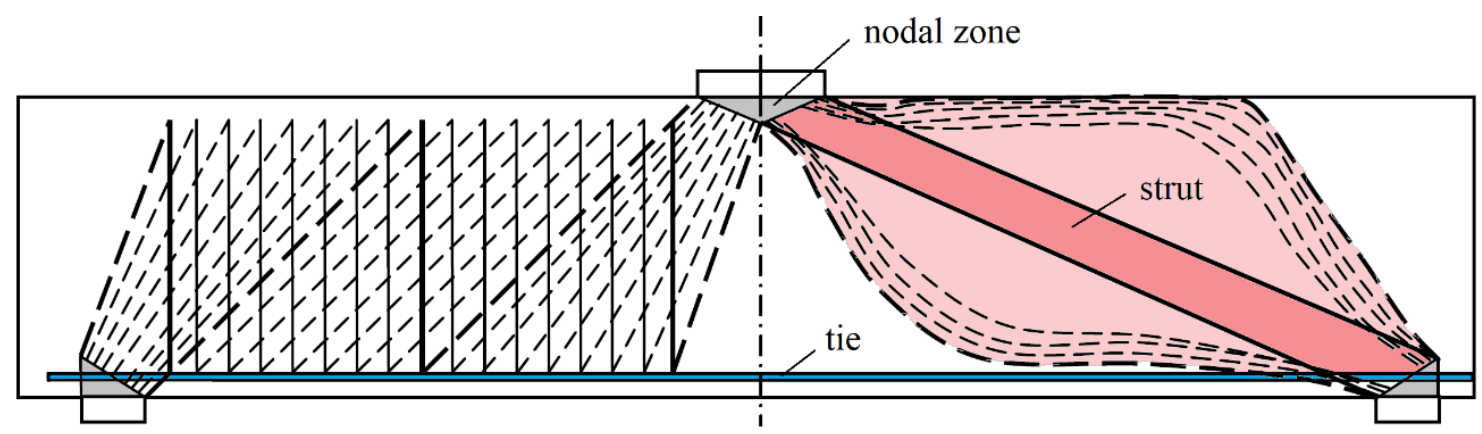

Figure 4-2 - Components of strut-and-tie models [21]

Normally it is sufficient to represent the struts and ties by lines along their center-lines. Thereby, the compression struts are usually represented by dashed lines along the axis of the struts, solid lines represent tension ties. However, in cases where the width of the struts must be considered, like for example in congested areas, it can be necessary and helpful to draw the strut-and-tie model to scale. Sometimes also different colors are used to distinguish between strut and ties to keep the consistency throughout this paper, struts will be marked in red and ties in blue color.

\subsubsection{Compression Struts}

The compression struts represent concrete compression stress fields. The way in which the compressive stress spreads from the idealized struts through the concrete can be defined in three different shapes: prismatic, fan-shaped, and bottle-shaped compressive stress fields (see Figure 4-3). Whereas the first one typically arises in B-regions, the two latter arise in D-regions and are due to dispersion of the stress paths radiating out from concentrated loads or reactions.

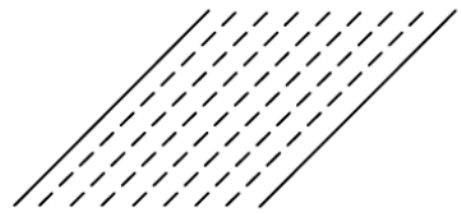

Prismatic strut

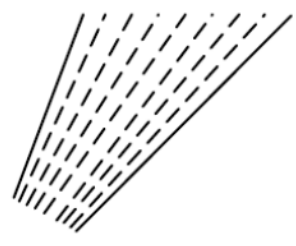

Fan-shape strut

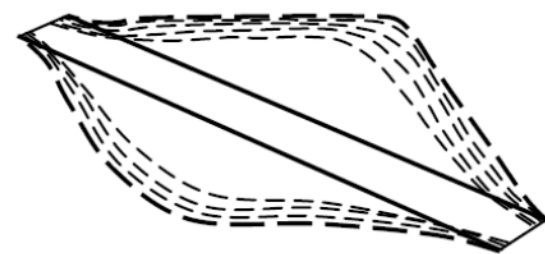

Bottle-shape strut

Figure 4-3 - Different types of struts in a strut-and-tie model [21] 
for partial discontinuity regions $\left(b \leq \frac{H}{2}\right)$

$$
T=\frac{1}{4} \frac{b-a}{b} F
$$

B Continuity region

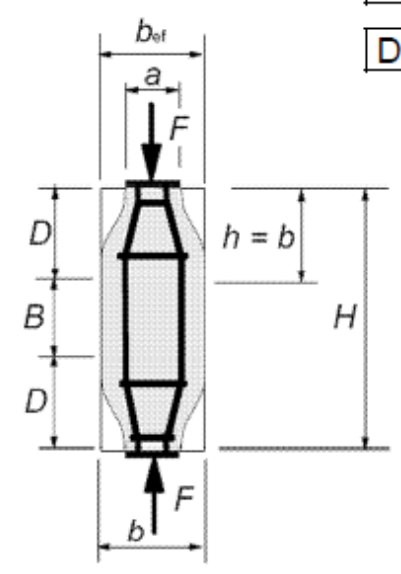

$b_{e t}=b$ for full discontinuity regions $\left(b>\frac{H}{2}\right)$

$$
T=\frac{1}{4}\left(1-0,7 \frac{a}{h}\right) F
$$

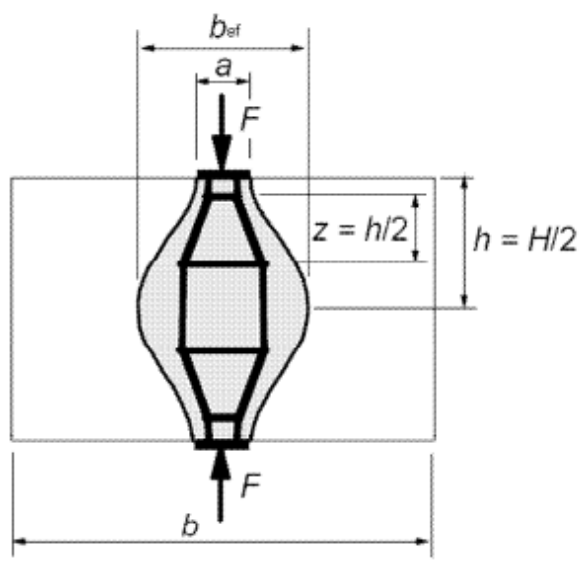

$b_{o f}=0,5 H+0,65 a ; a \leq h$

Figure 4-4 - Determination of transverse tensile forces in a compression field [6]

The spreading of the compression forces in bottle-shaped stress fields can lead to transverse tensions which may cause longitudinal cracks within the strut. The stress fields can be idealized using local truss models and can be calculated according to the equations given in Figure 4-4. To cover the transverse tensile forces stirrups may be necessary. The fan-shaped and the prismatic stress fields do not develop transverse stresses.

transverse compressive stress or no transverse stress

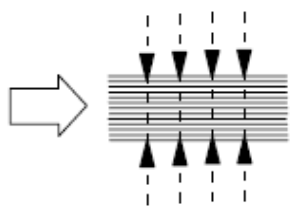

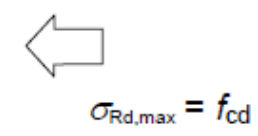

concrete struts with transverse tension
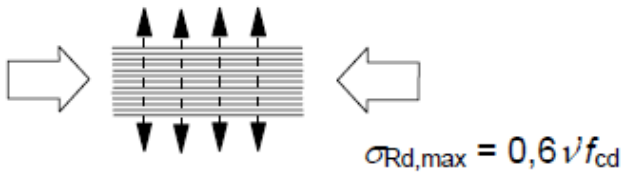

Figure 4-5 - Design strength of concrete struts with and without transverse tension [6]

The design strength for a concrete strut should be reduced in compression zones which develop cracks due to transverse tension according to Figure 4-5. However, it is appropriate to assume a higher design strength in regions where multi-axial compression state exists [6] which is the case for a slab-column connection. 


\subsubsection{Tension Ties}

The tensions ties normally represent one or several layers of tensile reinforcement steel in the same direction as the ties. The required steel cross section follows from the tie force in the ultimate limit state and the design yield strength of the steel.

$$
\text { req } A_{s}=\frac{F_{s d}}{f_{s d}} \quad f_{s d}=435 \mathrm{~N} / \mathrm{mm}^{2}
$$

In some cases, model ties can also stand for concrete tensile stress fields in places where no reinforcement is provided. Typical examples for this are slabs without stirrups.

To develop the design tensile forces the reinforcement should be adequately anchored at the nodes. If the reinforcement is provided in several layers it must be considered that the tie force is represented by the centerline of the reinforcement bars and therefore may change the position of the ties in the model. Furthermore, an adequate concrete cover must be taken into account.

\subsubsection{Nodal Zones}

The joints in strut-and-tie models, in other words, the regions where struts and ties change direction or intersect are known as nodal zones. The nodes are regions where forces deviate over a certain length and width. Nodal zones are assumed to fail by crushing, but also the anchorage of the tension tie is an important design consideration [13].

Nodes can be subdivided into smeared nodes and concentrated nodes. The most nodes in strutand-tie models are smeared (or continuous) nodes which occur in the body of a member and represent joints where the orientation of a wide stress field is diverted. As the concrete stresses in these kinds of nodes are insignificant, they are usually not checked in design.

Concentrated nodes occur at the intersection of concentrated ties and struts and therefore need to be carefully designed. Depending on the combination of struts $(C)$ and ties $(T)$ there exist essentially three types of concentrated nodes:

- $\mathbf{C}-\mathbf{C}-\mathbf{C}$ nodes are node regions bounded by compressive struts and bearing areas

- $\mathbf{C - C}-\mathbf{T}$ nodes are node regions where a tension tie is anchored in one direction

- C-T-T (or T-T-T) nodes where a tension tie is anchored in more than one direction 
The following design rules for the three different main types of concentrated nodes originate from the $\mathrm{EC}^{3}$. The value for $v^{\prime}$ which considers the reduction of the design strength in cracked compression zones due to transverse tension (see also Figure 4-5) is defined as 1,0 for the verification of nodes.
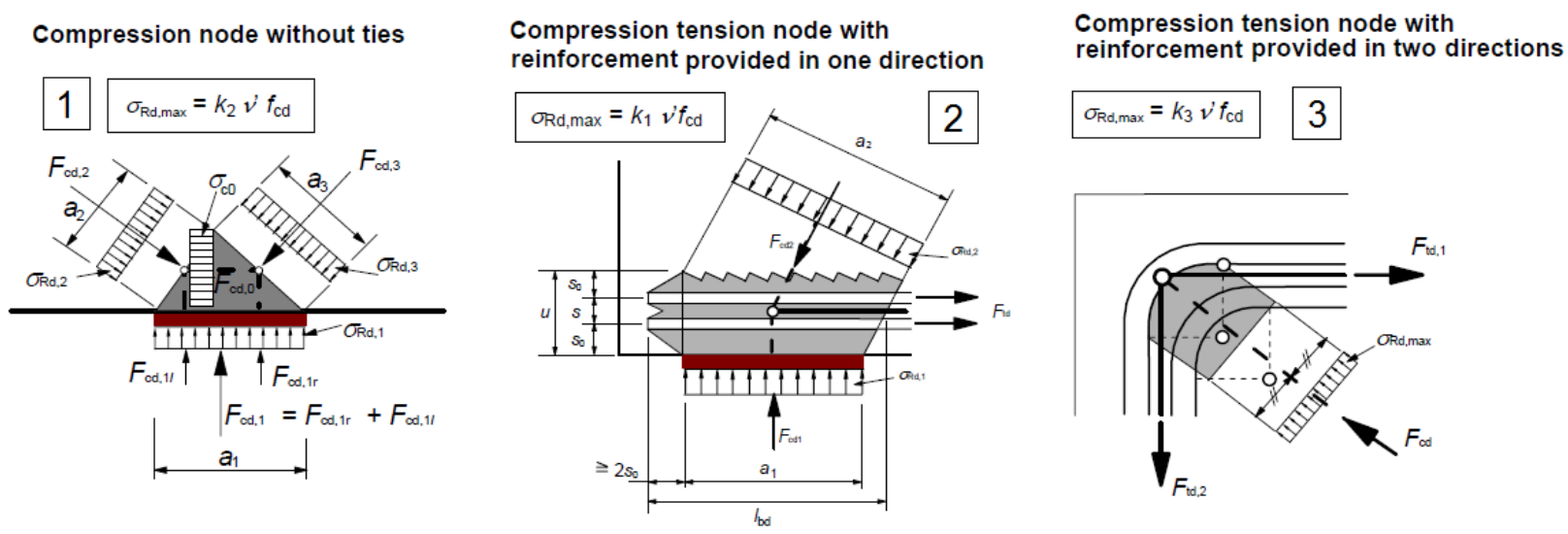

Figure 4-6 - Different types of nodes and design parameters according to the EC [6]

The values of the $k$ parameters are listed in Table 4-1. As for a more detailed verification and in areas where higher compressive strengths of the concrete due to the multiaxial stress state are expected, it is permitted to increase the strength up to $\sigma_{\mathrm{Rd}, \max } \leq 3,0 \mathrm{f}_{\mathrm{cd}}$.

Table 4-1 - Value of $k$ parameters according to EC2 including National Annex

\begin{tabular}{|l|l|}
\hline For compression nodes without ties & $\mathrm{k}_{1}=1,1$ \\
\hline For compression tension nodes & $\mathrm{k}_{2}=\mathrm{k}_{3}=0,75$ \\
\hline
\end{tabular}

The anchorage length of the reinforcement in compression-tension nodes (2) starts at the beginning of the node and should extend over the entire node length. The struts and ties of the node (3) do not need detailed verification if the requirements of minimum mandrel diameter according to EC are fulfilled (see Table 6-1).

With regard to the development of three-dimensional strut-and-tie models in the previous chapters, we will face much more complex nodes. In [16] design rules for more complex nodes are given, which are not presented in this paper for the sake of clarity. However, it is always possible to trace back complex nodes by overlapping the three main node types.

${ }^{3}$ DIN EN 1992-1-1 including German National Annex, 6.5 


\subsection{RELATED STRUT-AND-TIE MODELS}

In order to develop a valid strut-and-tie model for flat-column connections, it is useful to have a look at already existing models. Basically, the slab-column connection we are looking at is closely related to a frame end nodes such as shown in Figure 4-7.
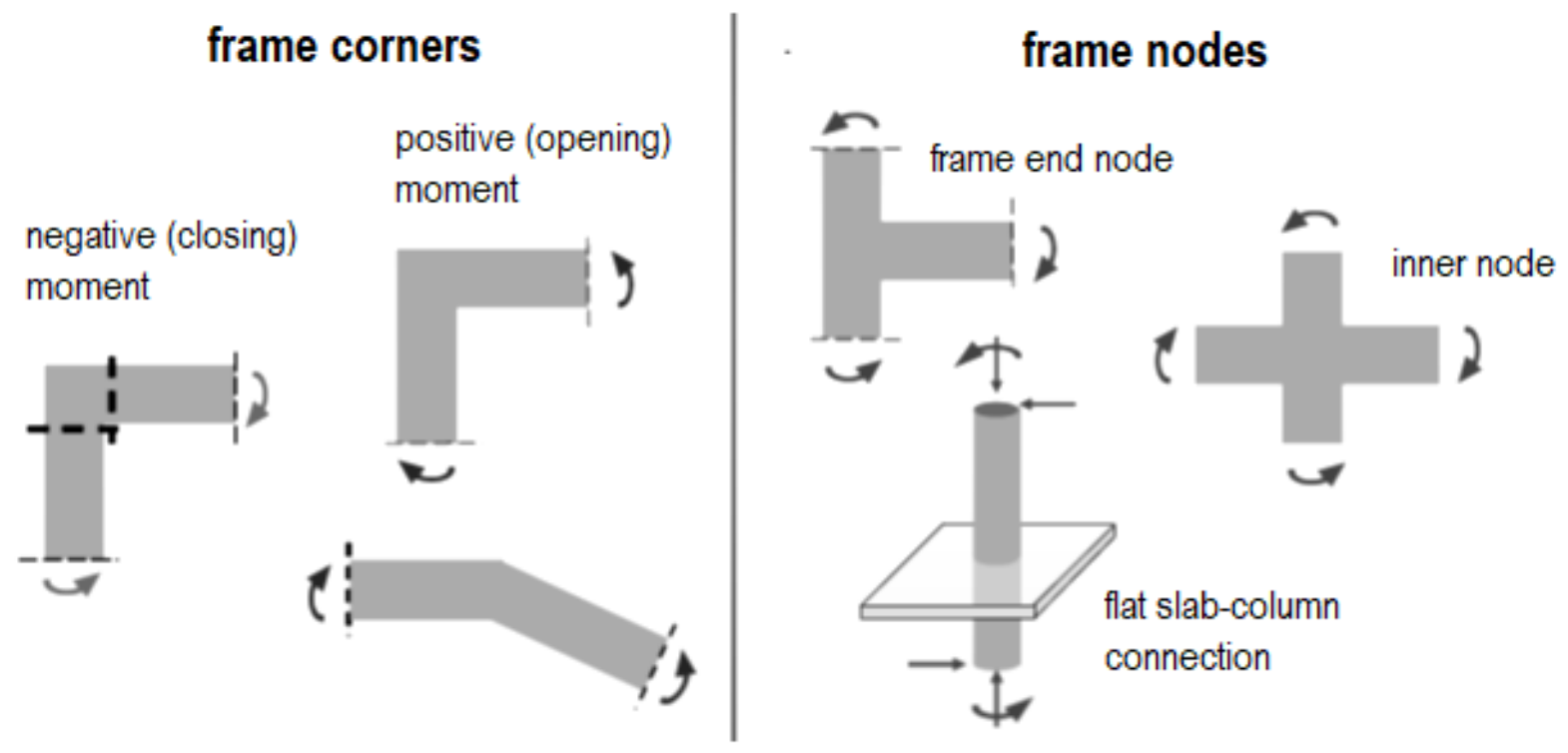

Figure 4-7 - Different examples of frame nodes [22]

As the bending moments within the columns act in the same direction and opposed to the moment within the beam we can easily reproduce the strut-and-tie model for a frame end node by overlaying the strut-and-tie models of an opening and a closing corner joint.

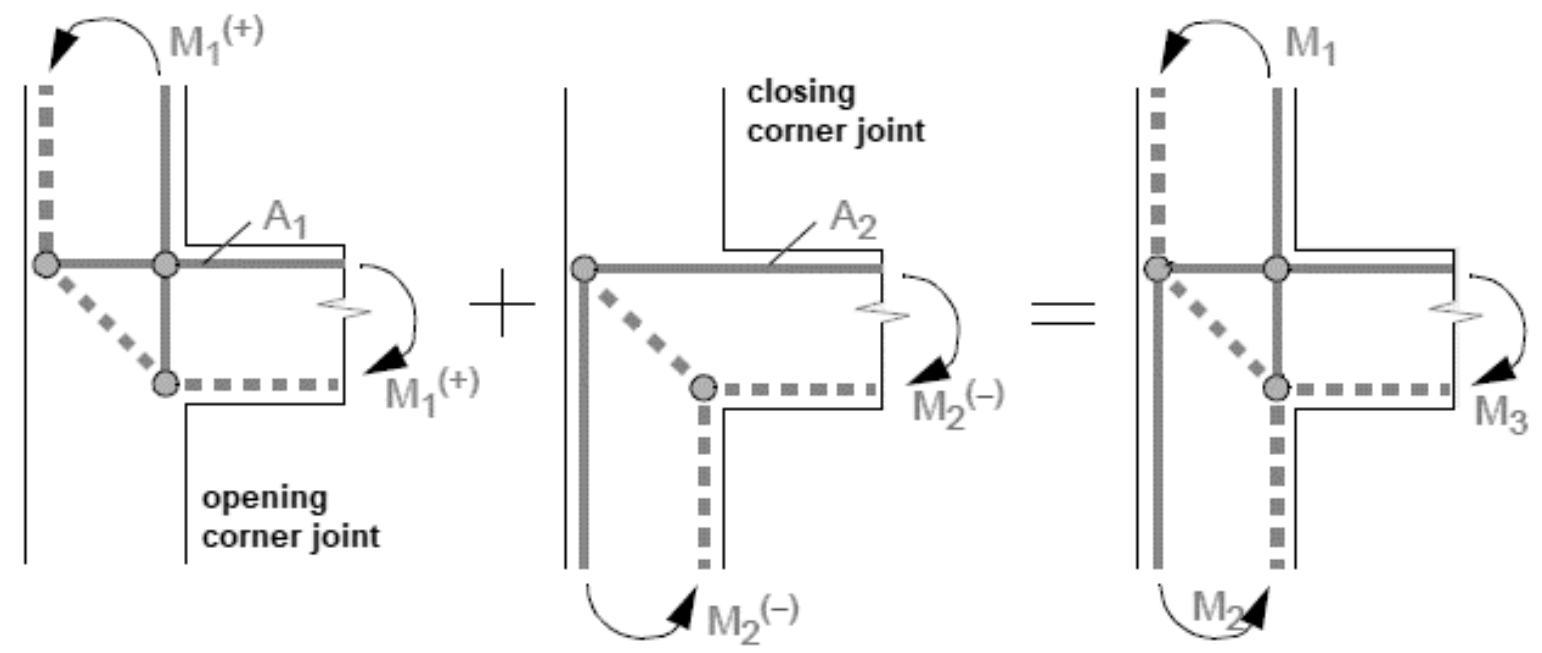

Figure 4-8 - Superposition of opening and closing corner joint [23] 
The strut-and-tie model above however is just a simplified model assuming only bending moments acting on the connection. As shown in Chapter 3.1 we also have to consider shear and normal forces acting within the columns and the beam. Figure 4-9 shows some exemplary strutand-tie models of a frame corner, a corbel and a frame end node where shear and normal forces were included. However, the flow of the individual forces is not clearly traceable, e.g. it cannot be traced back which struts and ties are responsible for leading the shear force from the slab into the lower column of the frame end node (right illustration).

This, however, may be remedied by breaking down the complete model into several models and by applying the different forces (bending moment, shear and normal force) individually. Later the original model can be retrieved by overlaying these individual models. In order to maintain clarity, this process will be carried out to develop valid strut and tie models in the previous chapter.
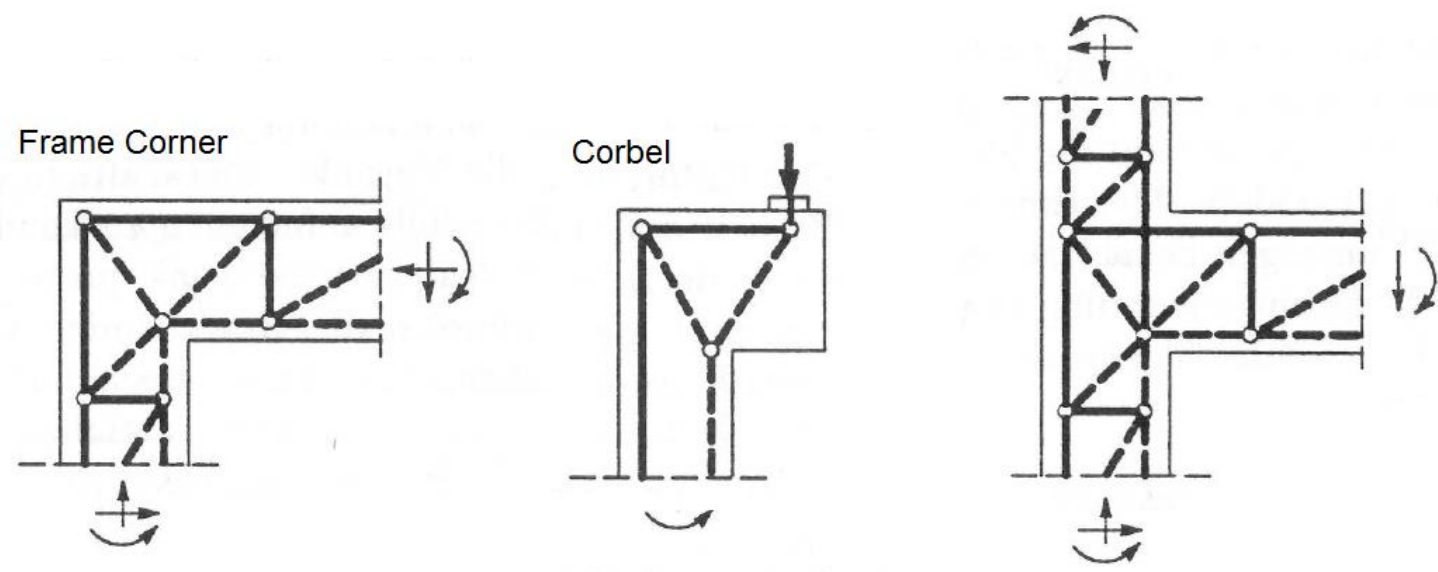

Figure 4-9 - Strut-and-tie models for a frame corner, corbel and a frame node [24]

One of the main differences between a frame end node and a slab-column connection is the fact that in a frame node there is only limited to no space for reinforcement bars covering transverse tension. Transverse tension may arise when reinforcement bars are anchored or when tension forces are redirected by adding bent bars (see red marking). Further explanations of the origin of these forces can be found in Chapter 6.1. In slab-column connections, however, it is a lot easier to provide the necessary reinforcement, as there is enough space available.

Another difference is that in a frame end node there is no surrounding concrete mass available that can provide confinement in case large vertical forces have to be transferred through the connection. This can be remedied by providing stirrups in the connection area. As explained in Chapter 2.2, confinement reinforcement may also be necessary for slab-column connections at edges and corners. 


\section{DEVELOPMENT OF STRUT-AND-TIE MODELS ADAPTED FOR RIGID SLAB-COLUMN CONNECTIONS}

The development of an adequate strut-and-tie model for slab-column connections will be carried out within several steps that build on one another. In order to preserve clarity, the models were created in two-dimensional space before transferring them into three-dimensional space.

First, a strut-and-tie model for the transmission of simple flexural loads (moment transfer) will be conducted. In a second step, additional vertical shear loading from the slab (punching shear) is included and overlaid with the first model. At last, shear forces within the columns are included.

The final three-dimensional models presented in the end are discussed in more detail in the following chapter, including the arrangement of reinforcement.

\section{General Remarks and Software Used for the Development of Models}

The software used for the development and representation of the following strut-and-tie models is RSTAB by the company Dlubal. All models were built up out of trusses which are only able to transfer normal forces. The supports applied at the ends of the trusses are restricted in their displacement and rotation by adding very soft springs as shown in Figure 5-1.

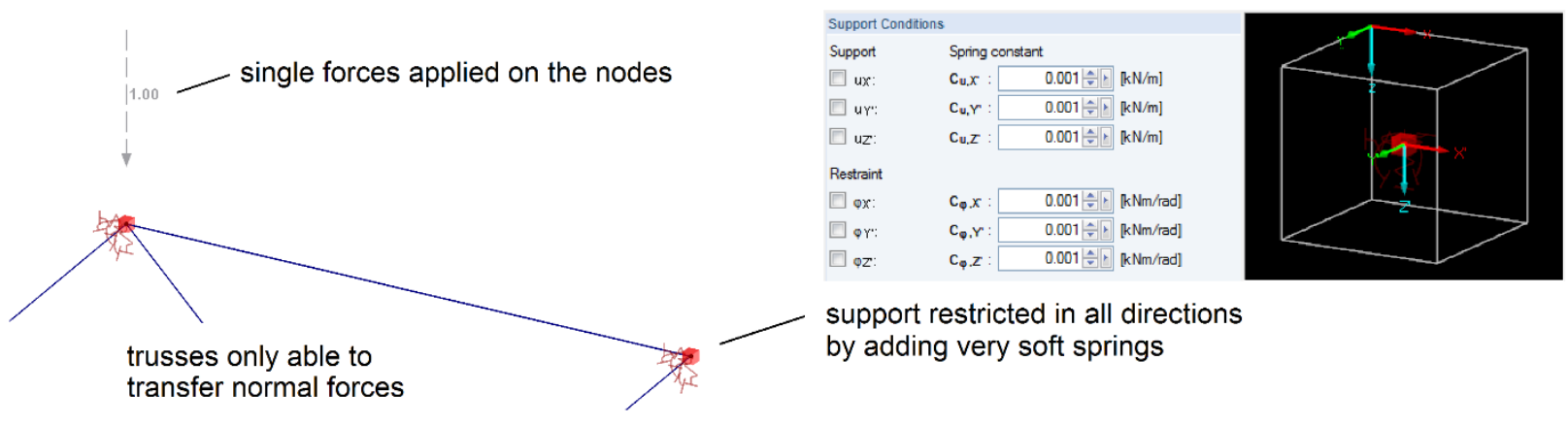

Figure 5-1 - Modelling of the strut-and-tie models with RSTAB

In order to control the distribution and the flow of forces, single forces were applied at the corresponding nodes, representing both the forces acting on the model and the forces resulting from the applied forces. Thereby, it was always necessary to ensure that all the applied forces are in equilibrium, both in their magnitude and their position. In case of an incorrect input of forces, additional support reactions would appear, indicating that the arrangement of forces is wrong, and the forces are not in balance. 


\subsection{SUBDIVISION INTO SECTIONS FOR DESIGN}

On the basis of the knowledge gained in Chapter 3.1, we can define the locations which are relevant for design. According to Jennewein et al [24] it is reasonable to cut the section at the location where the shear force becomes zero and therefore the moments just reach their maximum value. In other words, the design locations are shifted away from the internal corner by the value or area which is necessary to just cover the shear force of the adjoining part. The locations of the sections are shown in Figure 5-2 (marked in red and green color).
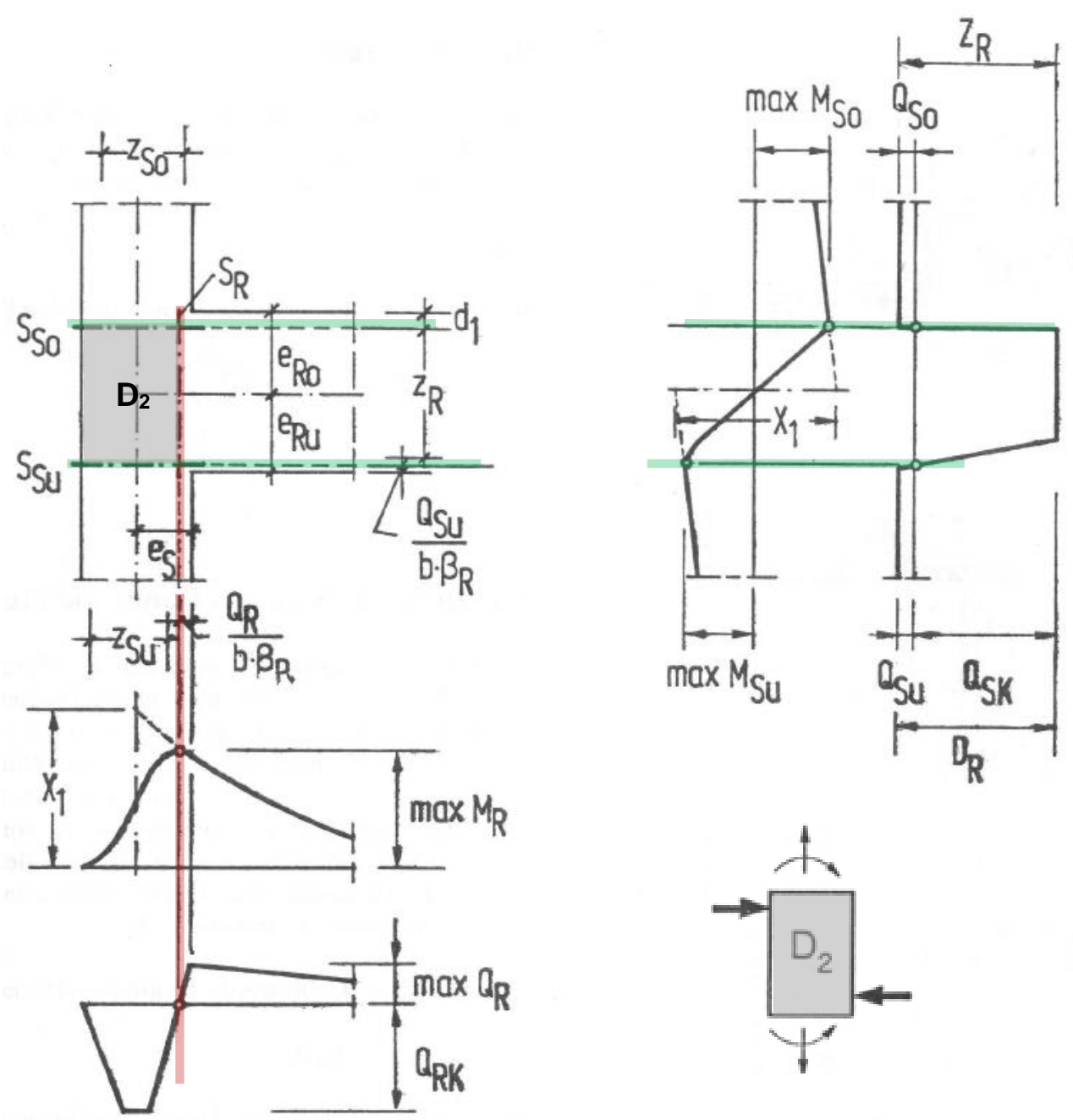

Figure 5-2 - Realistic flow of internal forces within frame end nodes [24]

In accordance with these just defined design locations, it is reasonable to subdivide the whole element into different B- and D-regions as shown in Figure 5-3. Moreover, it becomes clear that the inclusion of shear forces into the strut-and-tie model of the frame end node (respectively the 
slab-column joint) only plays a secondary role, as they do not appear within the $\mathrm{D}_{2}$-section. The shear forces are assumed to pass by the edges of the section and to be transferred directly into the adjacent $D_{1}$-sections; see also Chapter 5.2.2.
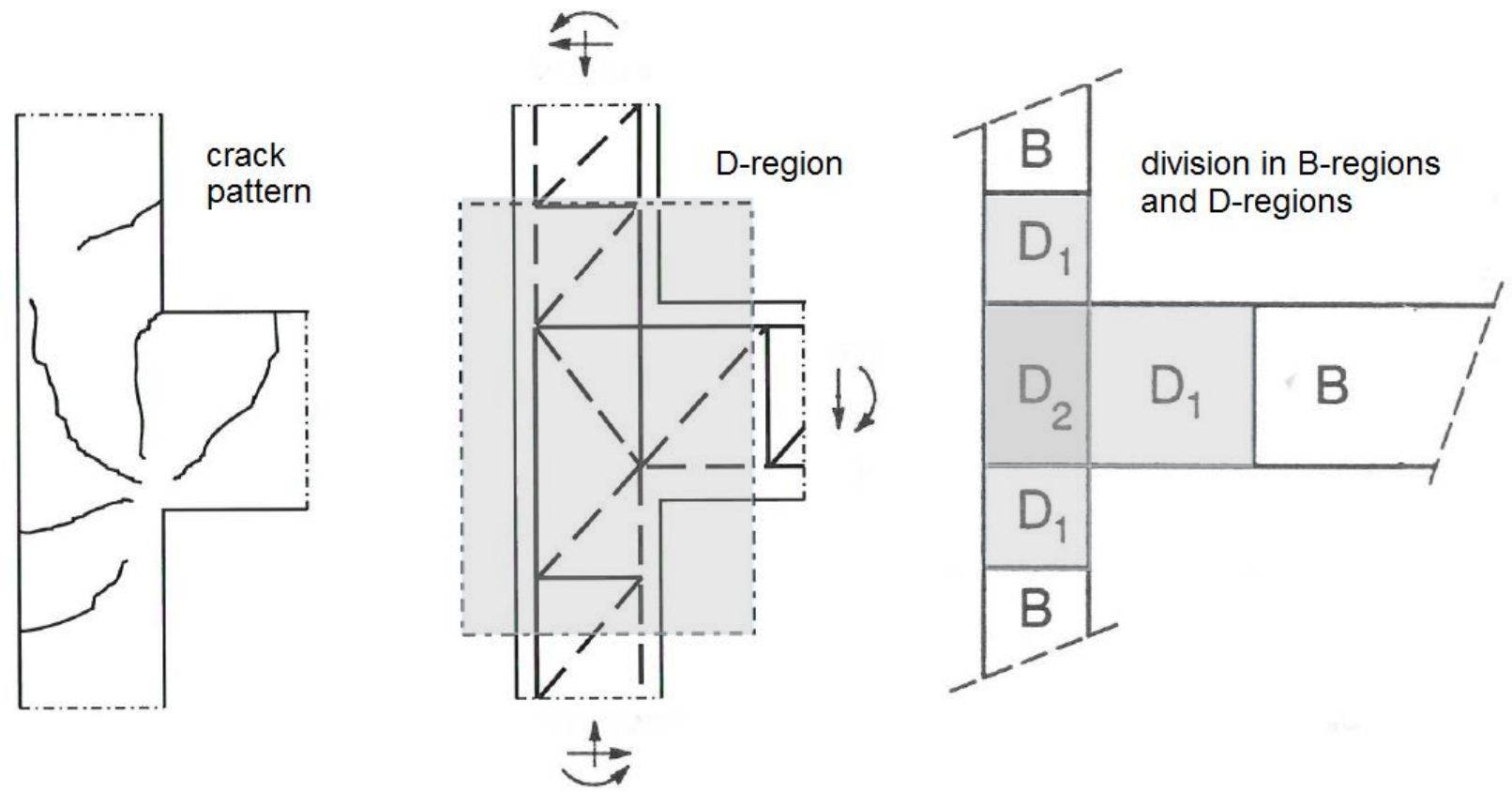

Figure 5-3 - Subdivision of the connection into different B- and D-regions [24]

The subdivision into different B- and D-regions helps us to understand the flow of forces and how to build up the strut-and-tie models. As can be seen in Figure 5-3, the whole discontinuity region (D-region) is further subdivided into one $D_{2}$-region and three $D_{1}$-regions adjoining the B-regions.
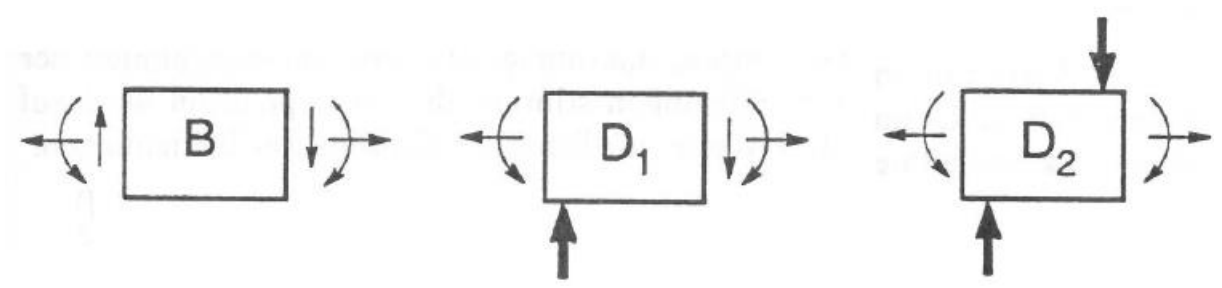

Figure 5-4 - Adjoining forces of B- and D-regions [24]

Both the $D_{1}$ and $D_{2}$-region represent regions of static discontinuities. While the $D_{1}$-region acts as a kind of transitional area between $D_{2}$ and B-region and basically pursues the same magnitude of shear forces as in the $B$ region, the solution for the $D_{2}$-region is more complex and diverse. 


\subsection{SUCCESSIVE DEVELOPMENT OF VALID STRUT-AND-TIE MODEL}

To begin, the models are developed in a two-dimensional space before transferring them into three-dimensional space in the following chapter. The models are built up step-by-step to keep clarity and to be able to understand the flow of the individual forces.

\subsubsection{Application of Flexural Forces}

In a first step, pairs of tensile and compression forces, which represent the moments acting in the slab and columns, were applied at the nodes of the truss.
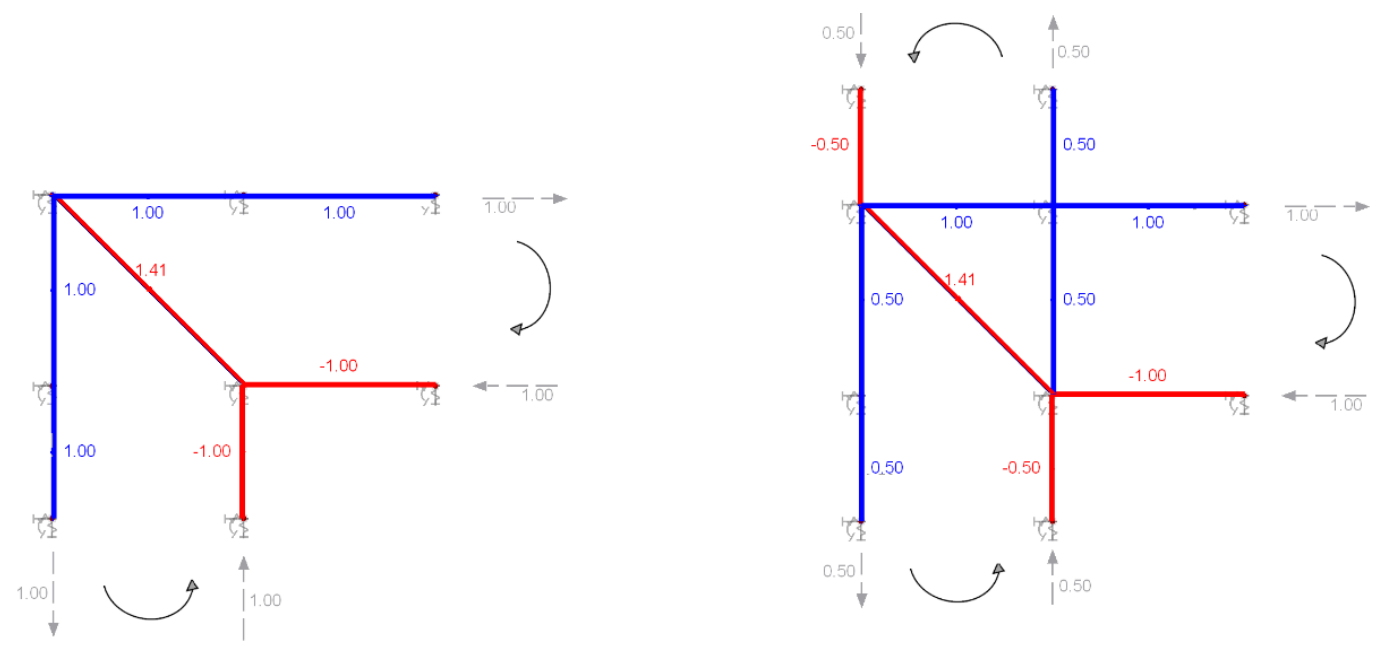

Figure 5-5 - Simple model with and without upper column charged with bending moment

The model on the left (without upper column support) indicates that the moment from the slab is fully transferred into the lower column. The model on the right shows that the initial moment from the slab is transferred into the upper and lower column, whereby each column absorbs half of the moment (assuming that both columns have equal stiffness).

\subsubsection{Inclusion of Shear Stresses within Slab}

Bending moments will always be accompanied by shear forces or in other words, the moments acting on the connection ultimately result from shear loads. Therefore, it is necessary to include the effects of shear in the model. This was achieved by adding a diagonal strut charged with a single vertical force at a distance of $h / 2$ away from the column face. The choice of this distance corresponds to the distance of the first row of punching reinforcement proposed by the $\mathrm{EC}^{4}$.

\footnotetext{
${ }^{4}$ DIN EN 1992-1-1 including German National Annex, 6.4 .5 (1) and 9.4 .3 (4)
} 


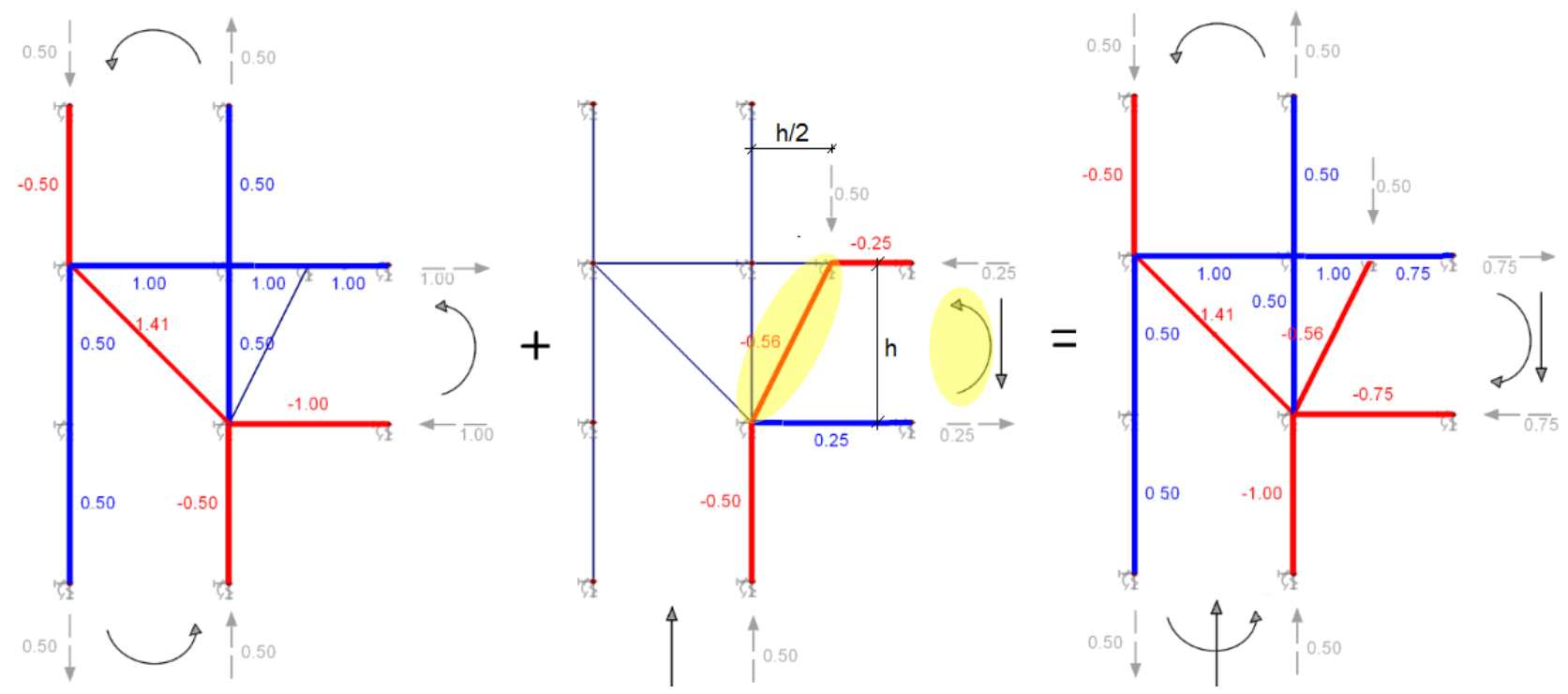

Figure 5-6 - Strut-and-tie model with shear forces

In accordance with the subdivision into different sections presented in the previous chapter, the shear force is assumed to be directly transferred into the lower column (Figure 5-6) following the flow of forces within the $D_{1}$ section. Due to the eccentricity of the shear force, an additional moment occurs resulting in an additional pair of forces within the slab. This 'compensating' moment (marked in yellow color) is acting in the opposite direction leading to a reduction of the total slab moment when overlapping the two models.
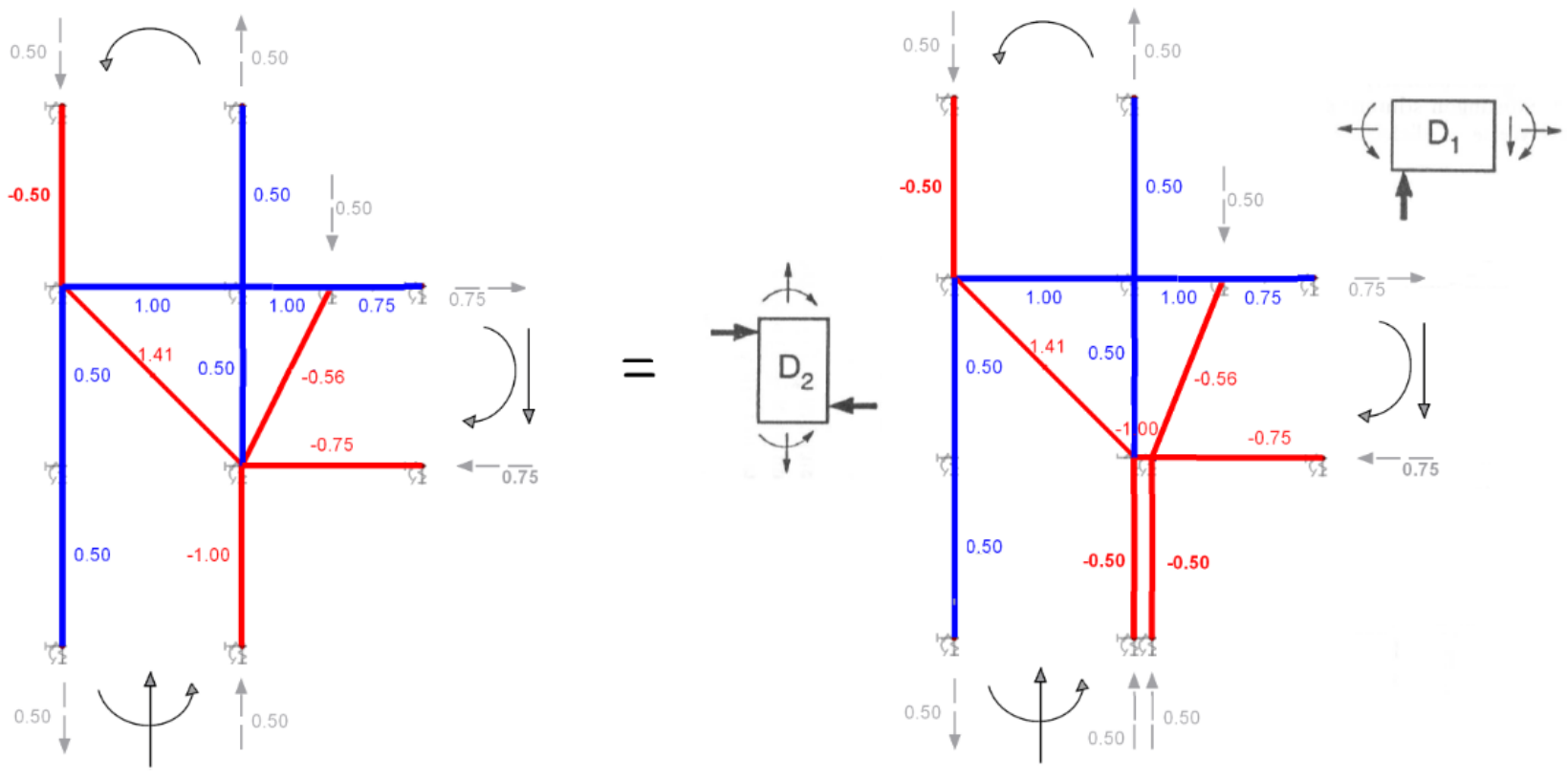

Figure 5-7 - Splitting of trusses to point out different D-sections 
A subdivision of the vertical strut into two separate parts (Figure 5-7) helps to understand the distinction between the $D_{1}$ and $D_{2}$ section. It also demonstrates that the $D_{2}$ section is not affected by the additional shear force and therefore remains a section charged with 'pure' bending.

\subsubsection{Inclusion of Shear Stresses within Columns}

In a third and last step shear acting at the interface of the columns is included in the model.

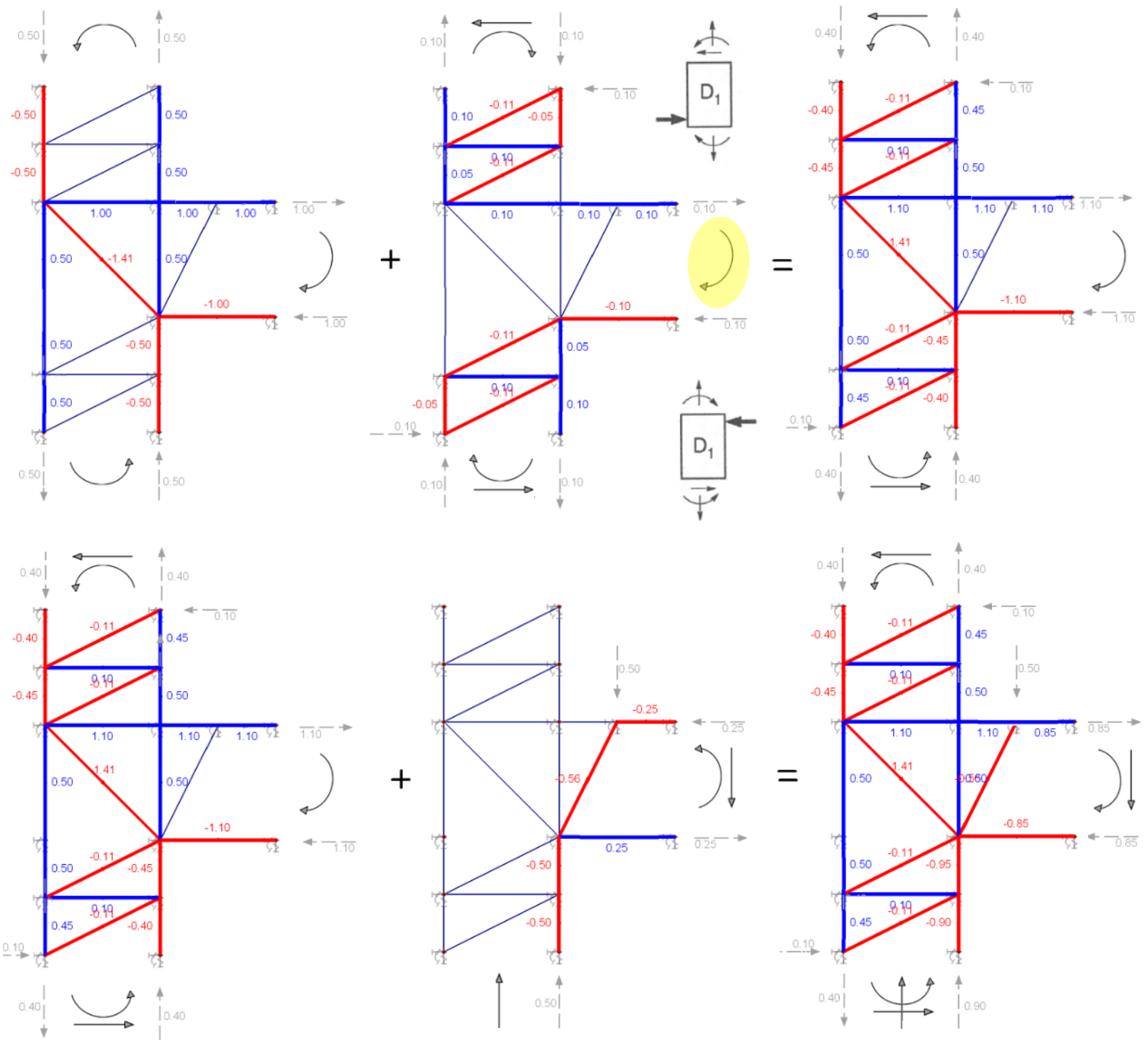

Figure 5-8 - Including shear stresses at the interface of the columns

The inclusion of shear stresses acting at the interface of the columns is carried out in a similar way as for the shear stresses acting within the slab. Once again, the flow of forces is related to the according D-sections. 
As can be seen in Figure 5-8 (marked in yellow color) the horizontal forces representing the shear in the columns have a share of the total moment acting in the slab. This should not be interpreted as an increase of the slab moment resulting from the inclusion of shear, but more as an image of the interplay between all internal forces acting within the connection.

The magnitude of the shear force acting in the columns in mainly a result of the distribution of stiffness of upper and bottom column. For the strut-and-tie models shown in Figure 5-8, the stiffness of both columns is assumed to be equal. In this case, the distribution of shear within the columns is consistent over the connection point and does not have an influence on the balance of forces within the slab (cf. Figure 3-4). However, if the stiffness of upper and lower column is not equal, an additional normal force has to be considered within the slab, matching the leap of the distribution of shear.

For the following three-dimensional strut-and-tie models the shear force within the columns was not included as it does not have an influence on the actual behavior and design of the connection.

\subsection{DEVELOPMENT OF THREE-DIMENSIONAL MODELS}

In the following, the just developed two-dimensional models are transferred into threedimensional space. When comparing the resulting strut-and-tie models with the pathway of the stress trajectories elaborated in Chapter 3.1.1, it can be noted that the struts and ties of the model fit roughly to the pattern of the principal compressive and tensile stresses.
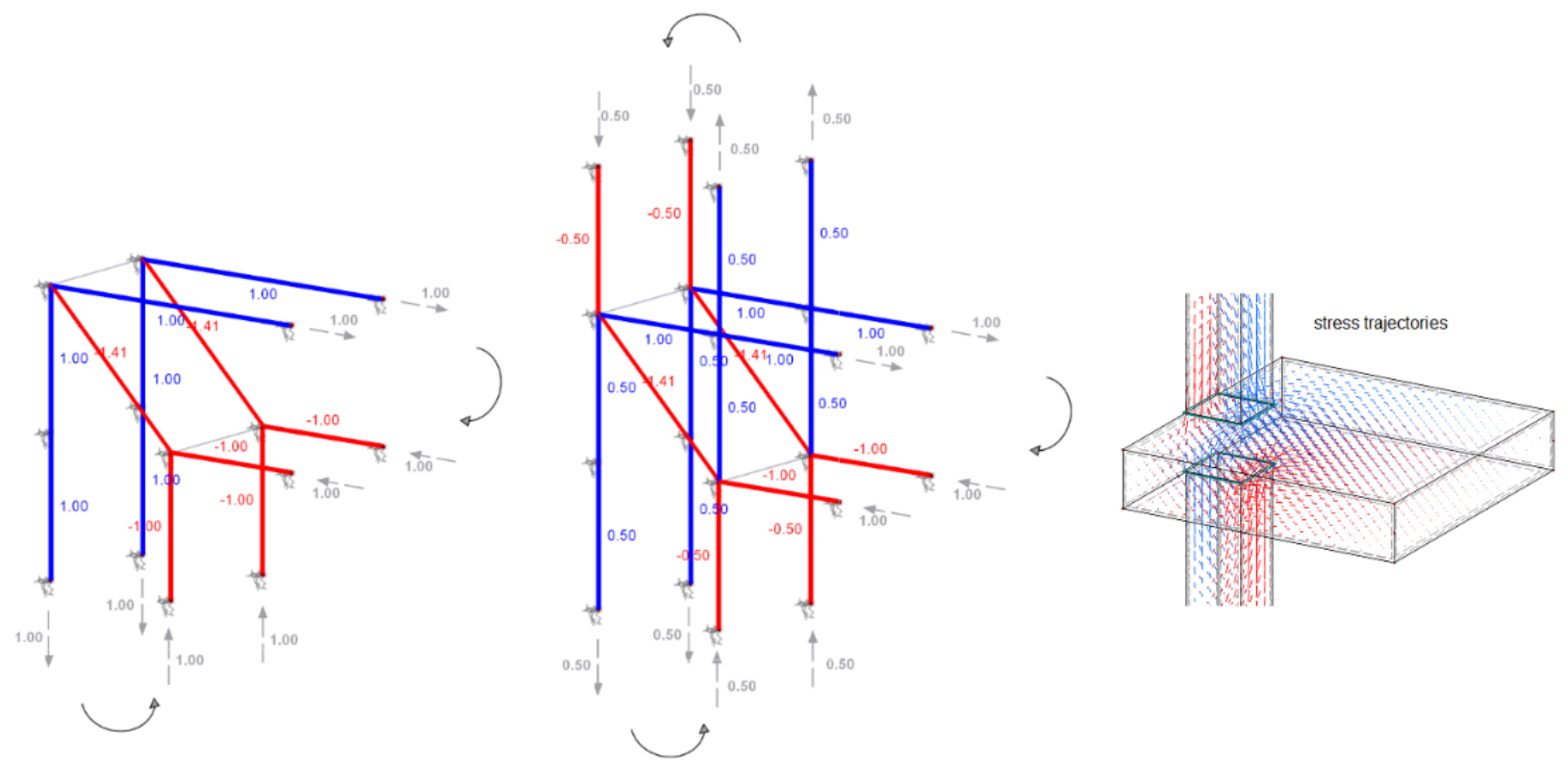

Figure 5-9 - Simple 3D-strut-and-tie model charged with pure bending 
Working in three-dimensional space, advantage can be taken in guiding the forces in both vertical and horizontal planes. This brings up new possibilities, especially in re-arranging the tension ties which represent the location of the reinforcement bars.

In the scope of this paper three three-dimensional strut-and-tie models, as shown in Figure 5-10, were developed. All of them are charged with a slab bending moment and shear.
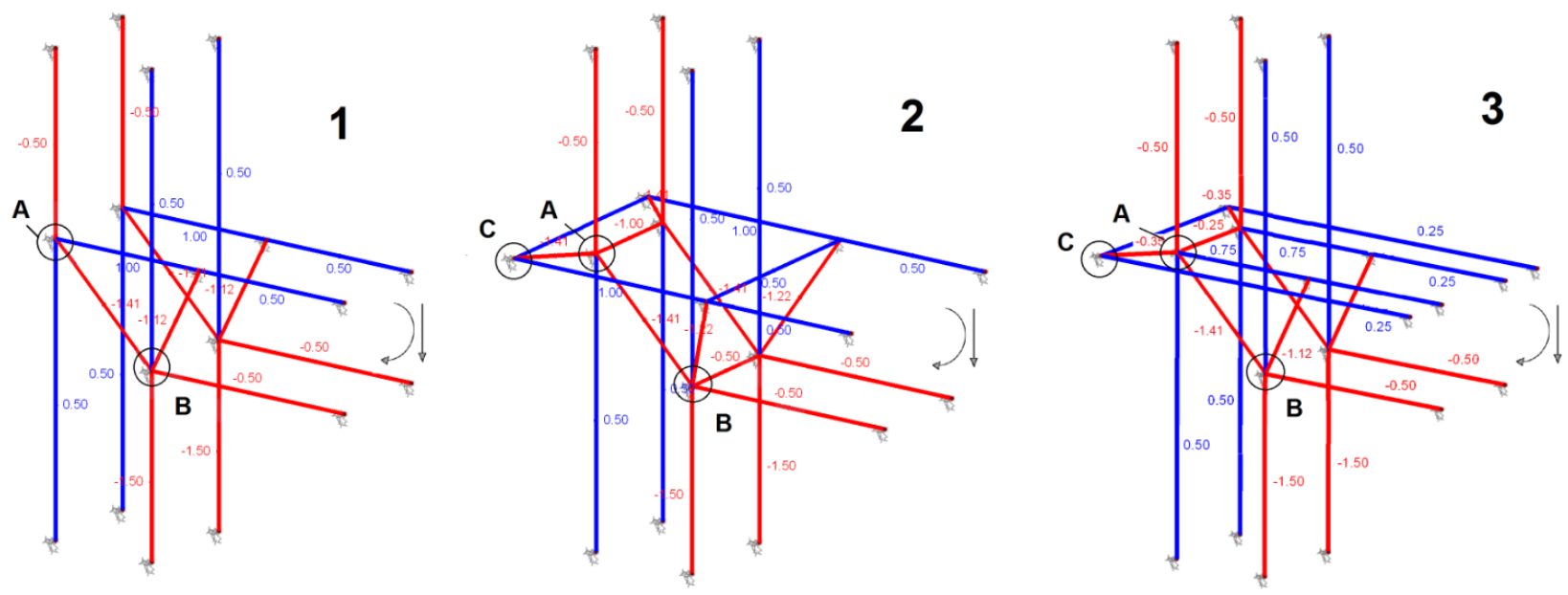

Figure 5-10 - Different strut-and-tie models in three-dimensional space

The first model (1), in the following also referred to as the "simple" model, is composed of two duplicates of the two-dimensional model which were arranged one behind the other. Basically, the two parts act independently from each other and do not contain any connecting struts or ties.

In the second model (2) the two upper ties are moved outwards the original position within the horizontal plane. The two short horizontal struts are needed to transfer the tensile forces from node $\mathrm{C}$ into node $\mathrm{A}$. Due to the equilibrium of forces in node $\mathrm{C}$ an additional tension tie in the transverse direction is necessary, connecting the two C-nodes. The resulting loop-like pathway of the tensile forces that encloses the vertical members, is the reason why the model will be called "horizontal reinforcement loop"-model in the following.

As the single force representing the shear has to be placed eccentrically to node $B$ in the horizontal direction, an additional tension tie connection the two D-nodes is necessary to keep the equilibrium of internal forces. As this single force is only a simplification of the actual distribution of shear acting on the connection, this tie is not relevant for the final reinforcement design. 
The last model (3), is basically a combination between the first two models, also referred to as the model which represents the case of "outsourcing of reinforcement". Combining the two models has the advantage that the magnitude of the individual tensile forces decreases.

The three models presented in Figure 5-10 will be further discussed and examined when it comes to their reinforcement design in Chapter 6.2. An exemplary calculation and verification of the crucial struts, ties, and nodes (according to Chapter 4.2) will be carried out in the calculation example which can be found in the Appendix of this paper. 


\section{POSSIBLE REINFORCEMENT DESIGN SOLUTIONS}

This chapter aims to develop reinforcement design solutions based on the previously developed strut-and-tie models. As already mentioned slab-column joints are closely related to corbels and frame corners and therefore is their reinforcement design.

\subsection{GENERAL RULES FOR REINFORCEMENT DESIGN}

In the following, a short overview of some general reinforcement rules is given which is necessary to understand the following design of reinforcement. All the design rules will be based on the regulations in EC2 and compared to the regulations in $\mathrm{ACl}$ where applicable,

\subsubsection{Distribution of Reinforcement}

The $\mathrm{EC}^{5}$ recommends distributing the calculated bending moment which results from the rigid connection between slab and columns over a length equivalent to three times the column width (for inner and edge columns). As for corner columns, the effective width refers to the diagonal direction, as shown in Figure 6-1.
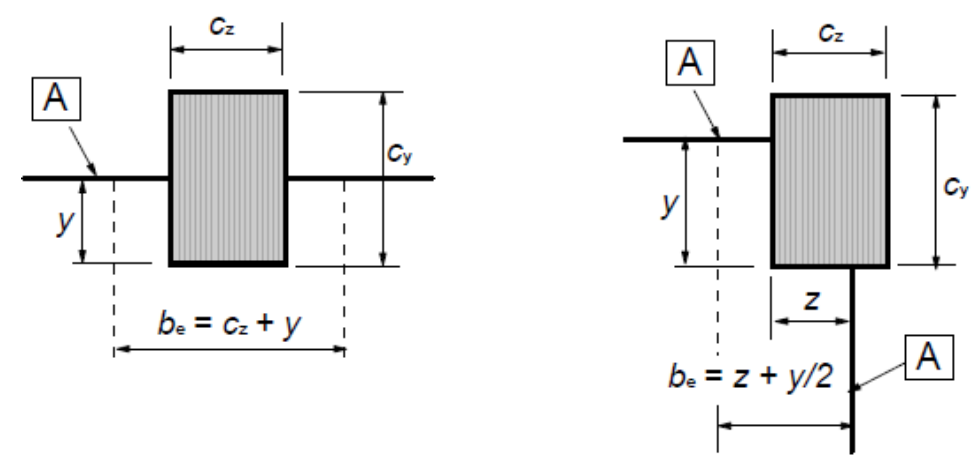

A Slab edge

Figure 6-1 - Distribution of reinforcement according to EC [6]

In an $\mathrm{ACl}$ recommendation for the design of slab-column connections [2] it is recommended to place the required reinforcement for moment transfer within a width $2 c_{1}+c_{2}$ centered on the column for edge connections and respectively $c_{1}+c_{2}$ for corner connections, as illustrated in Figure 6-2. For inner columns and moment transfer parallel to the edge of edge connections the required reinforcement should be placed within lines $1.5 h$ either side of the column, whereby $h$ represents the slab thickness.

${ }^{5}$ DIN EN 1992-1-1 including German National Annex, 9.4.2 (Figure 9.9) 


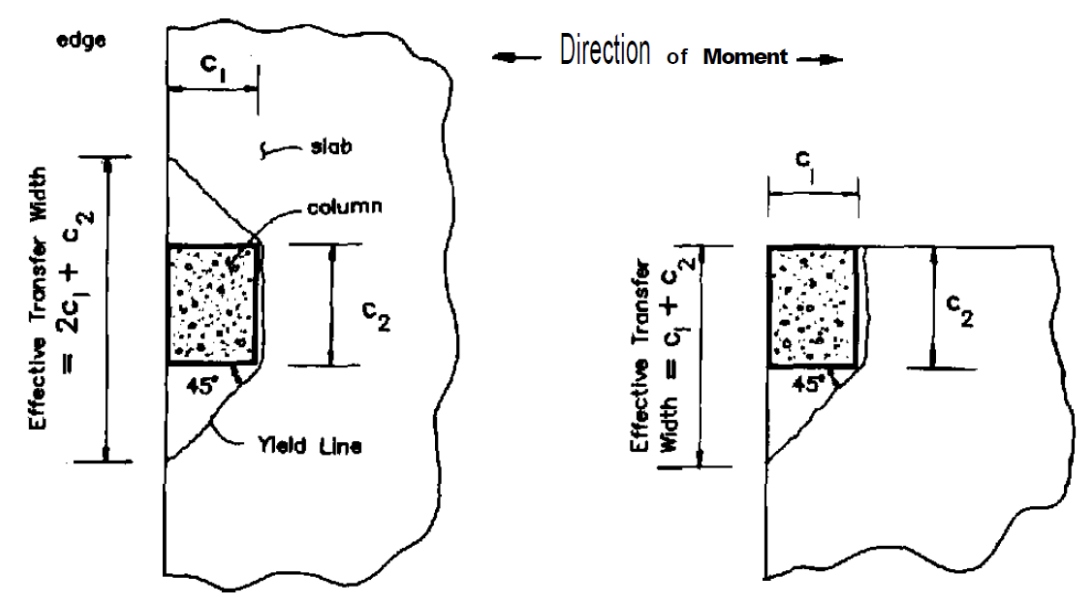

Figure 6-2 - Distribution of reinforcement according to ACl [2]

\subsubsection{Minimum Mandrel Diameter to Avoid Damage to Reinforcement}

According to the EC2, the minimum diameter to which a bar is bent shall be such as to avoid bending cracks in the bar, and to avoid failure of the concrete inside the bend of the bar. Therefore, the following minimum mandrel diameters $\left(D_{\min }\right)^{6}$ are defined in dependence on their diameter and the existing concrete cover perpendicular to the plane of bending.

Table 6-1 - Minimum mandrel diameter for diagonal and other bent bars

\begin{tabular}{|l|c|c|c|}
\hline \multirow{2}{*}{$\begin{array}{l}\text { Din for diagonal bars } \\
\text { and other bent bars }\end{array}$} & \multicolumn{3}{|c|}{ concrete cover perpendicular to the plane of bending } \\
\cline { 2 - 4 } & $>100 \mathrm{~mm}$ and $>7 \varnothing$ & $>50 \mathrm{~mm}$ and $>3 \varnothing$ & $\leq 50 \mathrm{~mm}$ and $\leq 3 \varnothing$ \\
\cline { 2 - 4 } & $10 \varnothing$ & $15 \varnothing$ & $20 \varnothing$ \\
\hline
\end{tabular}

Table 6-2 - Minimum mandrel diameter for hooks, loops, and stirrups

\begin{tabular}{|l|c|c|}
\hline \multirow{2}{*}{$\begin{array}{l}\text { Din } \\
\text { and stirrups }\end{array}$} & \multicolumn{2}{|c|}{ diameter of reinforcement bar } \\
\cline { 2 - 3 } & $\varnothing<20 \mathrm{~mm}$ & $\varnothing \geq 20 \mathrm{~mm}$ \\
\cline { 2 - 3 } & $4 \varnothing$ & $7 \varnothing$ \\
\hline
\end{tabular}

With regard to the reinforcement arrangements presented in Chapter 6.2, all bars that are anchored by adding a bend, hook or loop should meet the minimum mandrel diameter presented in Table 6-2. For bar diameters greater or equal to $20 \mathrm{~mm}$, as it will likely be the case with regard to the large forces that are transmitted, a minimum mandrel diameter of $7 \varnothing$ should be chosen.

For the regular $90^{\circ}$ bent bar (e.g. Figure 6-10) a mandrel diameter equal or greater than $10 \varnothing$ is sufficient, as the concrete cover perpendicular to the plane of bending is infinitely large. However,

${ }^{6}$ DIN EN 1992-1-1 including German National Annex, 8.3 (Table 8.1DE) 
when it comes to the horizontal loop (e.g. Figure 6-14 and Figure 6-16) the present concrete cover gets decisive for the choice of the minimum mandrel diameter. Although the horizontal loop is placed underneath the upper slab reinforcement layer, it is likely to end up with a concrete cover less than $50 \mathrm{~mm}$ and therefore a diameter that needs to be greater or equal to $20 \varnothing$. The reason why providing sufficient concrete cover perpendicular to the plane of bending is further explained in Chapter 6.1.5.

\subsubsection{Confinement by Surrounding Concrete or by Reinforcement}

Confinement may be provided by the surrounding concrete itself (given that there is enough concrete mass around a relatively small compression field) or by transverse reinforcement (e.g. provision of stirrups in the joint region of the column).
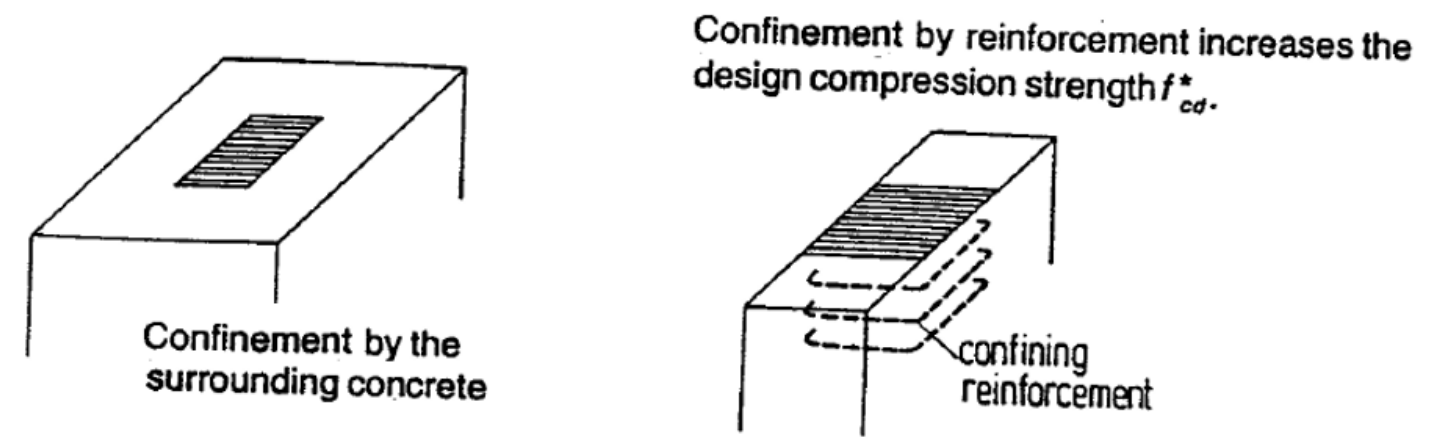

Figure 6-3 - Confinement by concrete or by reinforcement [25]

It has already been discussed in Chapter 2.2 that providing sufficient confinement in the area of the connection is crucial with regard to its load-bearing capacity.

Obviously, inner slab-column connections are less crucial, as they are surrounded by concrete all-round. In the case of transmission of large loads through the connection, in combination with the use of higher concrete strengths for the columns as for the slab, additional confinement by e.g. stirrups may still be necessary. As for edge and corner columns, there will always be at least one side that is not supported by the surrounding concrete mass. Therefore, measures have to be taken and either a slab overhang (see also Chapter 7.1.5) or additional confining reinforcement should be provided. 


\subsubsection{Anchorage of Reinforcing Bars}

According to the $\mathrm{EC}^{7}$, reinforcing bars shall be anchored in a way that the bond forces are safely transmitted to the concrete avoiding longitudinal cracking or spalling. The anchorage length of a reinforcement bar is dependent on the bond conditions which in turn depend on the height of the slab, as illustrated in Figure 6-4. The minimum height for slabs containing shear reinforcement is set to $200 \mathrm{~mm}$ by the EC. In this case, 'good' bond conditions count for both upper and lower reinforcement of the slab. However, if the slab thickness exceeds $300 \mathrm{~mm}$ the upper reinforcement is assumed to be located within the zone of 'poor' bond conditions.
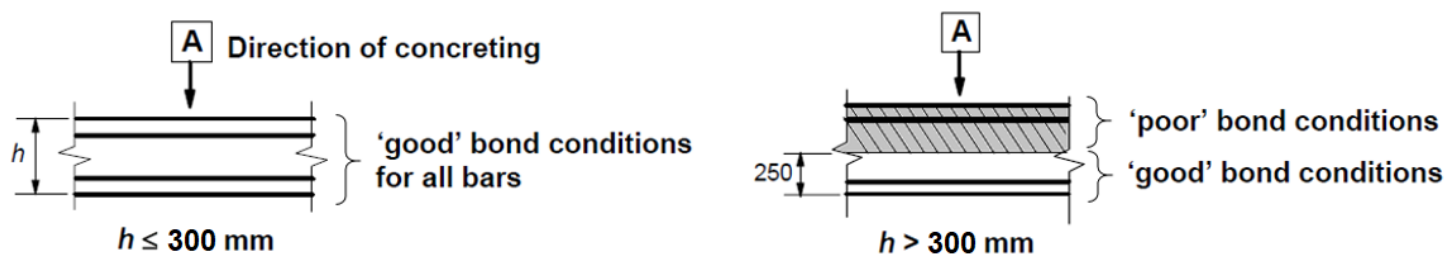

Figure 6-4 - Definitions of areas of 'good' and 'poor' bond conditions [6]

Sufficient anchorage length may be provided by simple straight bars, although the resulting length of the bar likely exceeds the available space. The anchorage length may be reduced according to EC by adding a bend or hook at the end of the bar or by using a loop (Figure 6-5). Further reduction can be achieved by adding transverse bars or by considering transverse compression (see also Chapter A.3).
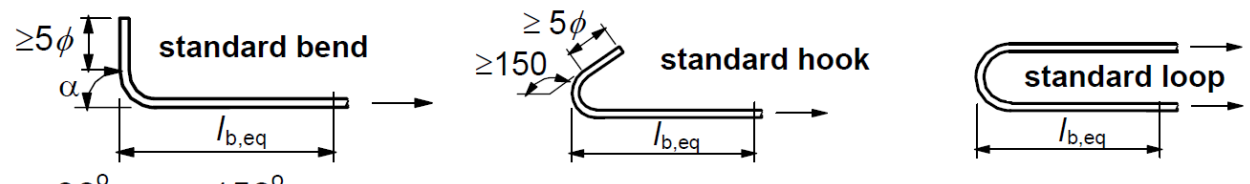

$90^{\circ} \leq \alpha<150^{\circ}$

\section{Figure 6-5 - Methods of anchorage other than by a straight bar [6]}

If there is only limited or too less space to prove anchorage by bond (neither by using straight reinforcement bars nor for hooks or bends) is it possible to use anchorage elements which are similar to those used for the anchorage of tendons. These anchorage elements are kind of small steel plates that are installed at the end of the reinforcement bar that needs to be anchored. The anchor plate can either be attached by a simple screw thread or by an adequate weld on the external side of the plate, as shown in Figure 6-6.

\footnotetext{
${ }^{7}$ DIN EN 1992-1-1 including German National Annex, 8.4 (Figure 8.1 and 8.2)
} 

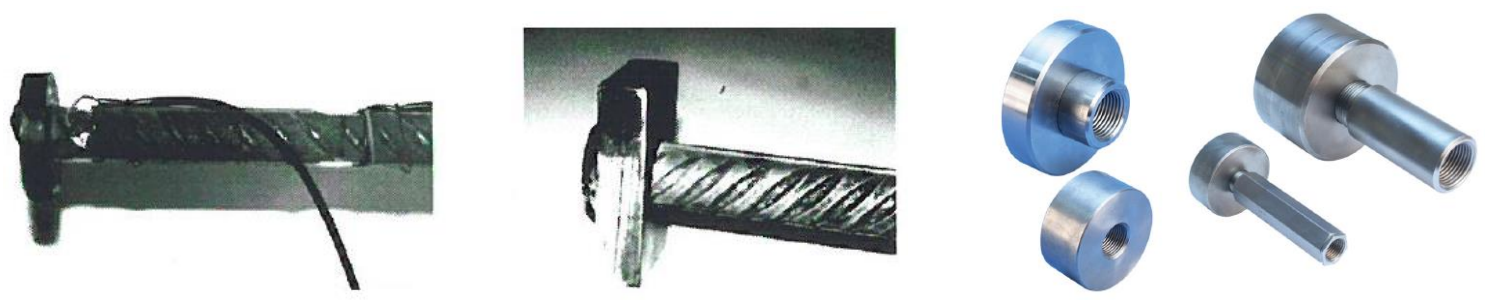

Figure 6-6 - Welded anchor heads [14] and anchor heads as a screw connection [26]

By using anchor plates it is generally possible to reduce the anchorage length up to $100 \%$. However, it has to be kept in mind that the concentrated load introduction results in transverse tension which may need to be covered by adding additional (e.g. helical formed) reinforcement. At the same time, it can be argued that transverse tension does not cause problems at this point as the surrounding concrete is subjected to a multiaxial loading state (cf. Chapter 2.2).

In a study by J. Hegger et al. [14] results of "pull-out" tests conducted on frame end nodes using different types of anchorage elements were collected and compared qualitatively. In Figure 6-6 the different anchor types are listed in the order of their ultimate load-bearing capacity which increases from the left to the right.

It was observed that the load-bearing capacity of a straight bar, anchored by nothing than bond forces, was insufficient at the chosen length. The ultimate load achieved by using a $180^{\circ}$ bent bar was $10-20 \%$ lower than that of a $90^{\circ}$ bent bar. The use of an anchor plate was found to be the most effective anchor type, as the load-bearing capacity was $15-60 \%$ higher than that of bent bars [14]. However, all of the different anchor types have in common that adding stirrups or transverse bars, as well as enlarging the concrete cover, increases the load-bearing capacity.

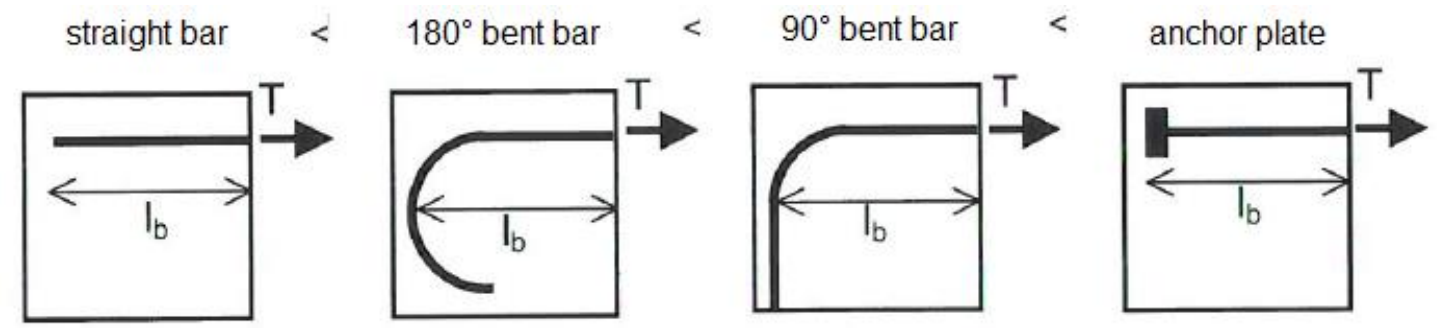

Figure 6-7 - Ultimate load T in dependence on the anchor types [14]

Reducing the anchorage length by adding an anchor plate or by adding welded transverse bars is not object of this study, however, consideration might be given to these types of anchorage with regard to slab-column connections. For more information on the solution using anchor plates, reference is made to a dissertation by M. Bruckner [27]. 


\subsubsection{Transverse Tension Resulting from Reinforcement Arrangement}

Transverse tension may arise when reinforcement bars are anchored or when tension forces are redirected by adding bent bars (Figure 6-8). Normally, the arising tensile forces do not get crucial for design if the anchorage length or bending diameters are chosen in accordance with the specifications made in the Codes. However, in case of limited space conditions or in case that the anchorage length needs to be reduced, adding transverse reinforcement bars (perpendicular to the direction of anchorage respectively the bent) that cover the tensile forces is advisable.

In case that the transverse tension occurs perpendicular and close to the edges of an element, sufficient concrete cover has to be provided in order to avoid spalling of the concrete in that area, especially when dealing with large forces.
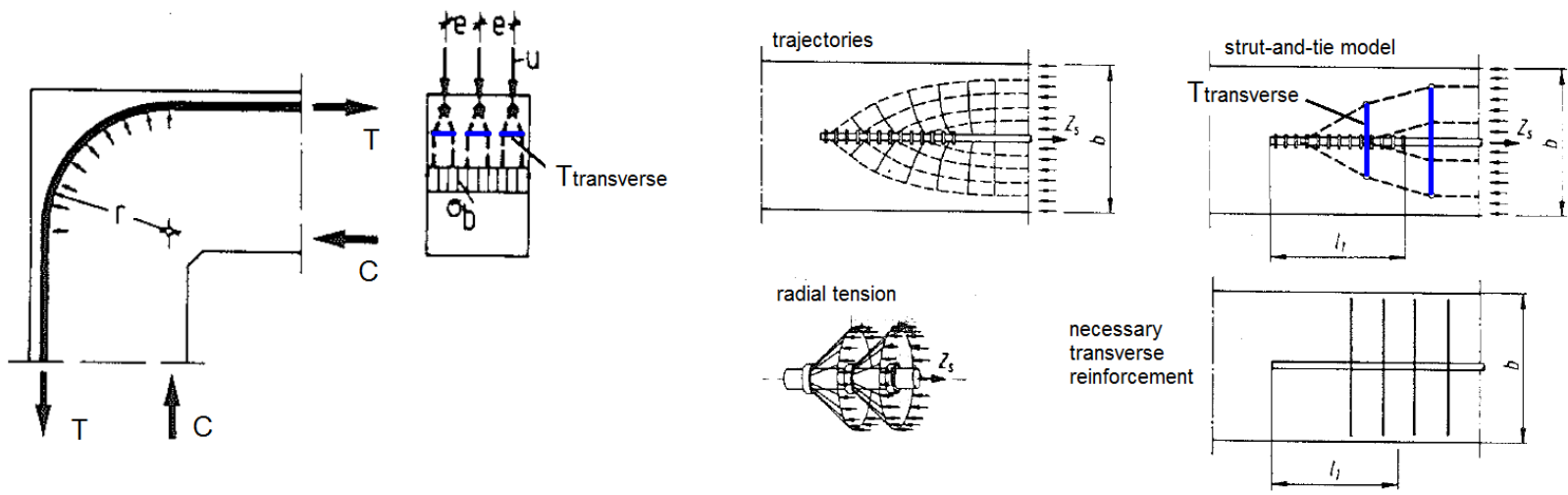

Figure 6-8 - Transverse tensile forces resulting from redirecting or anchoring forces [16]

For the investigations in the scope of this paper, transverse tension does not get crucial in case of the $90^{\circ}$ bent bar or the standard bends used for anchorage (e.g. Figure 6-10 and Figure 6-11). The arising transverse tensile forces can be assumed to be covered by the already present lattice girders in the slab. Moreover, the present "mass" of the concrete slab in the horizontal direction prevents the concrete from cracking in the area of the connection.

Though, care should be taken when it comes to the design of the horizontal loop reinforcement (e.g. Figure 6-14). In this case, the tensile forces act in an axis perpendicular to the slab surface and require closer consideration to avoid spalling of the concrete. 


\subsection{REINFORCEMENT DESIGN SOLUTIONS}

In the following, the three different strut-and-tie models presented at the end of Chapter 5.3 will be further discussed. Furthermore, different reinforcement design solutions will be presented for each model, followed by an illustrative three-dimensional reinforcement model.

\subsubsection{Design Solutions for a Simple Model Charged with Moment and Shear}

The first model presented in Figure 6-9 is referred to as "simple model". Unlike the following two models, it does not make use of three-dimensional space respectively the flow of internal forces is independent of each "side". This strut-and-tie model is similar to that of a frame end node.
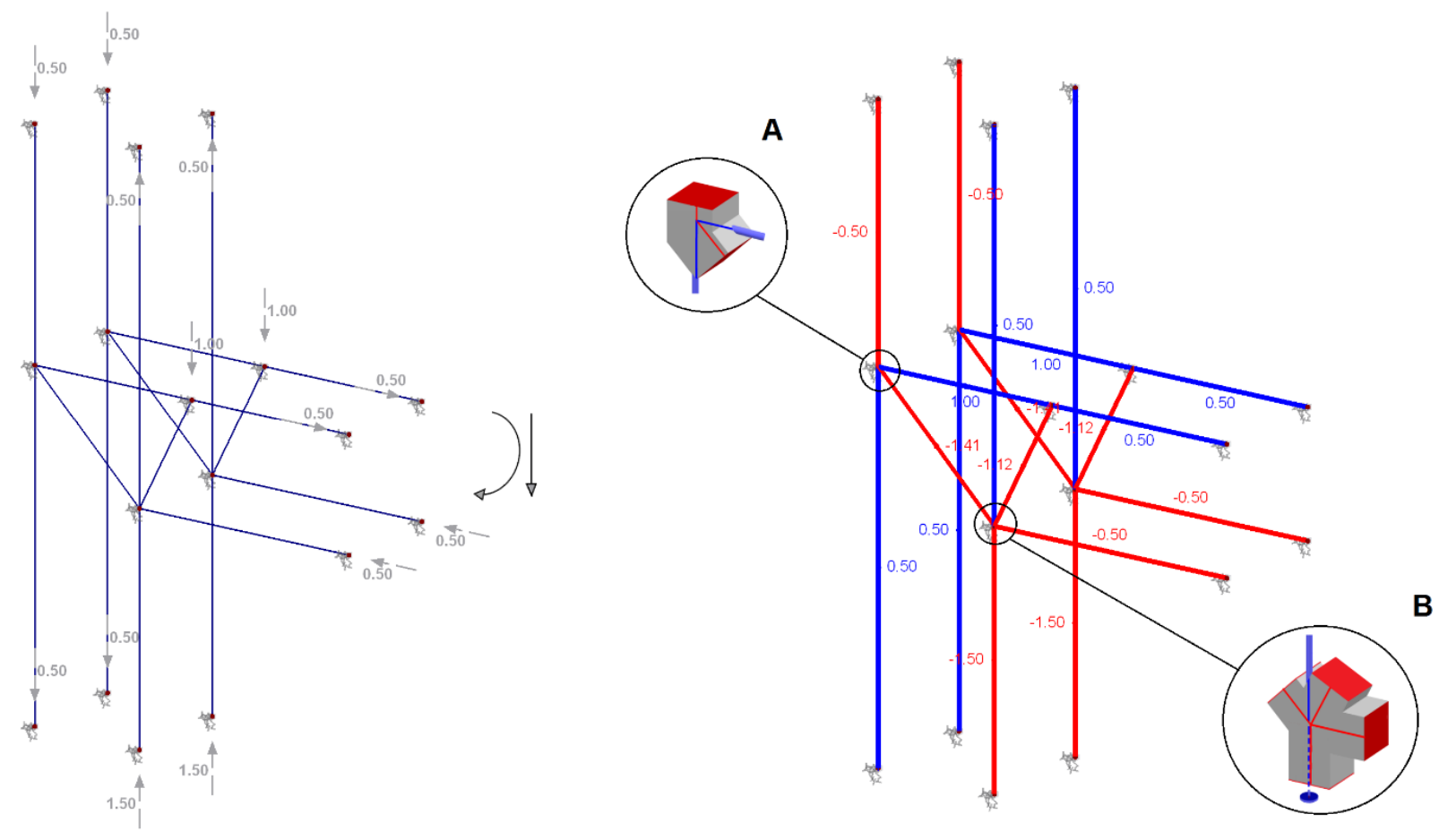

Figure 6-9 - Simple model charged with bending moment and shear

Basically, there exist two reinforcement solutions which are dependent on whether a slab overhang is available or not. Probably the most simple and economical way is to use $90^{\circ}$ bent bars as shown in the left illustration in Figure 6-10. This solution, however, may be difficult to reconcile with the sequence of construction as column and slab are usually concreted separately. In order to simplify the installation of reinforcement with regard to the existing construction joints it is worth considering to realise the required bending by overlapping two looped bars, as shown in the right illustration in Figure 6-10. To ensure the transmission of forces in that overlapping 
part, the requirements for the minimum lap length need to be fulfilled. However, regarding the large forces that are dealt with, the minimum lap length can likely not be met, or space problems will occur in the upper left corner due to the allowable rebar spacing and twice as many bars. Therefore, arranging them one below each other may provide a remedy. Due to transverse forces, resulting from the transmission of forces from one bar to the other, also spalling of the concrete on the surface could be a problem.
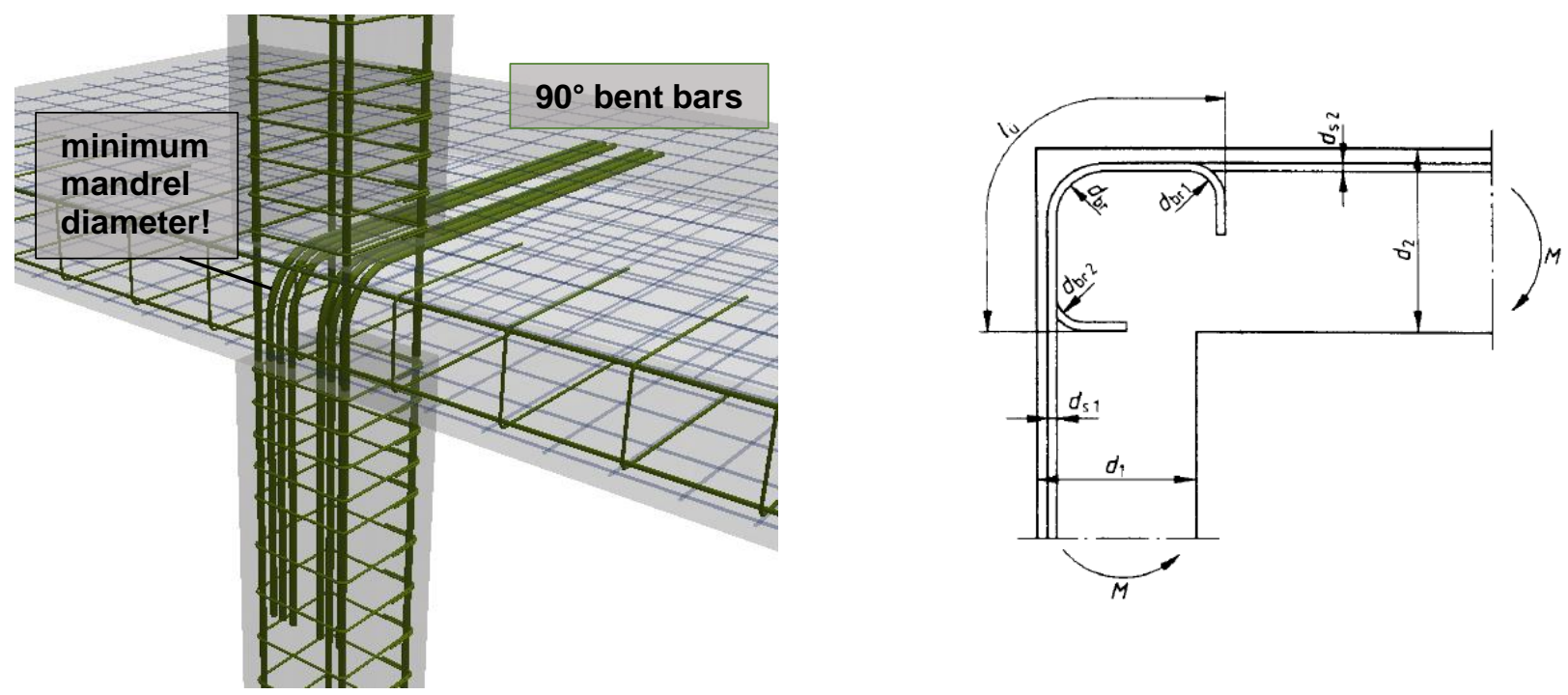

Figure 6-10 - Reinforcement design solution for simple model (90 bent bars) [27]

In case that a slab overhang is available the horizontal ties may be anchored directly in the horizontal plane, using either straight, hooked or looped bars. Again, regarding the magnitude of forces, it is likely to end up with great anchorage lengths and thus wide overhangs.

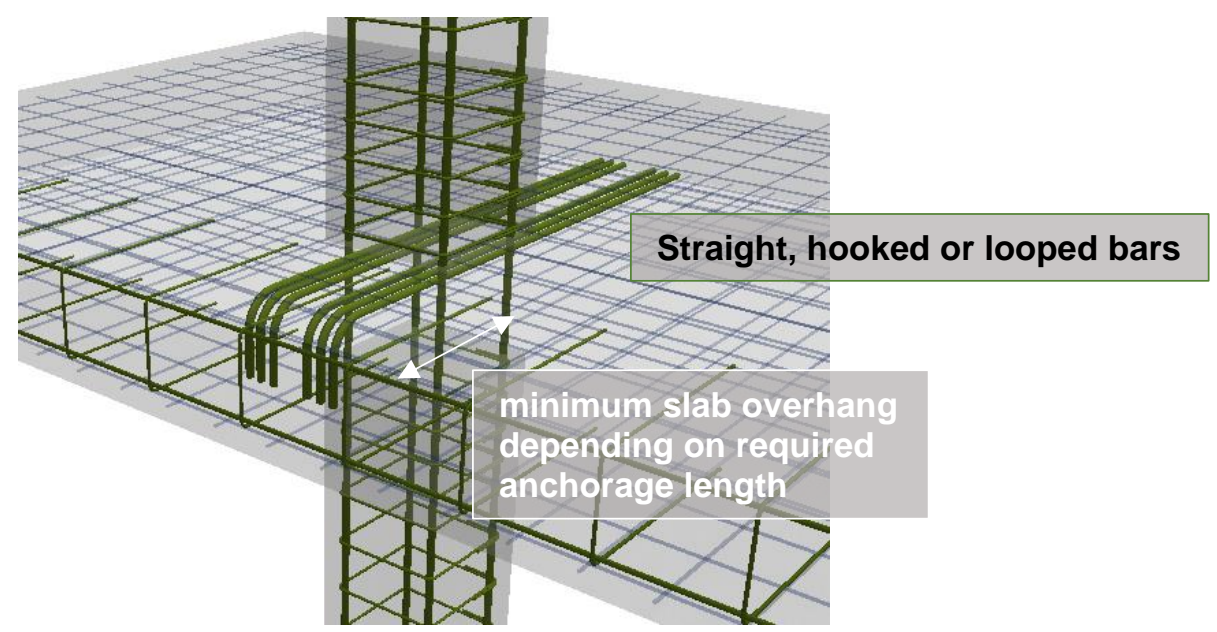

Figure 6-11 - Reinforcement design solution for simple model (anchorage of bars) 


\subsubsection{Design Solution with Horizontal Reinforcement Loop}

The key feature of the following strut-and-tie model is the complete outsourcing of the upper tension ties in the horizontal direction and away from the original plane.

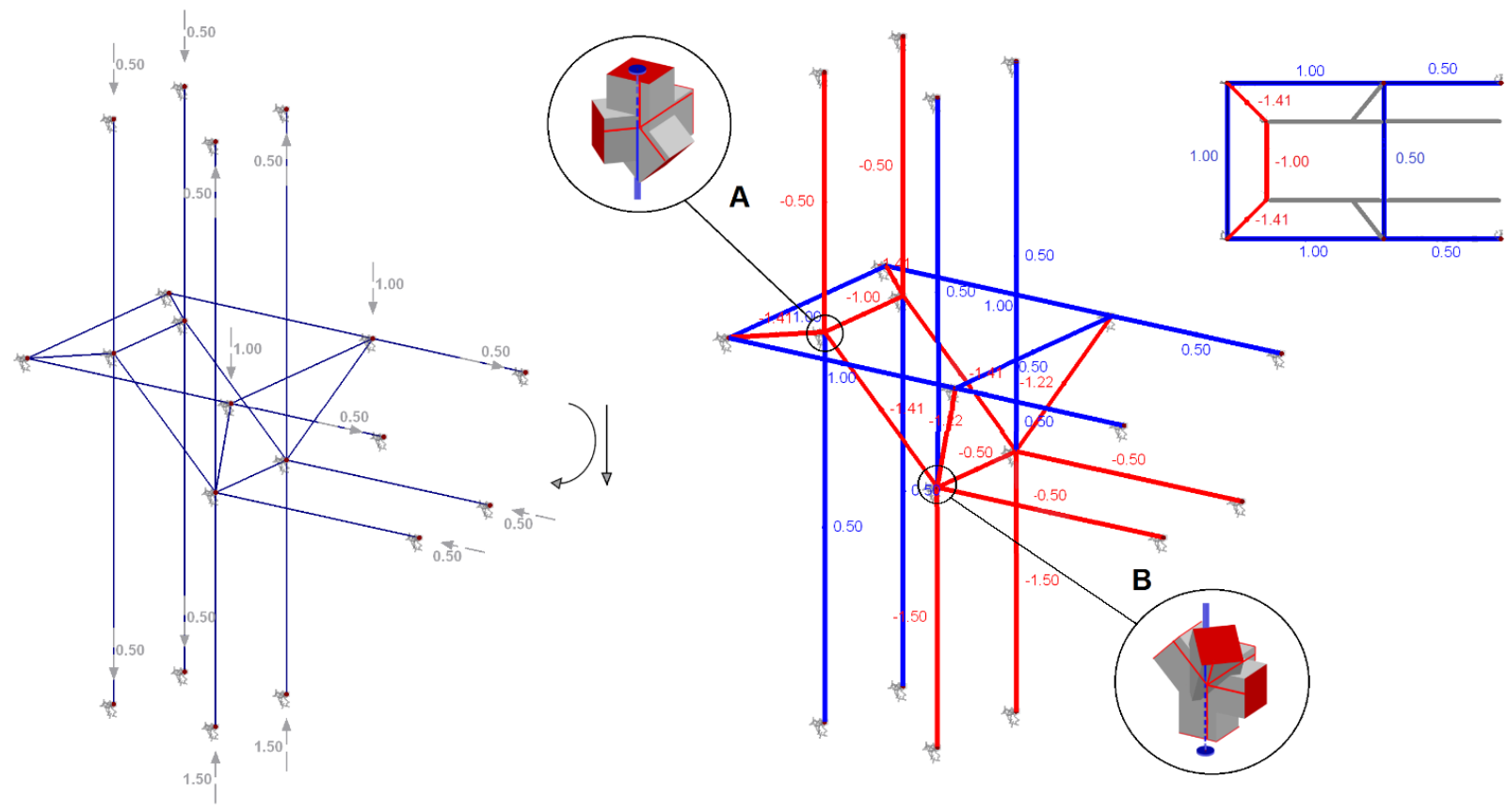

Figure 6-12 - Strut-and-tie model with horizontal reinforcement loop

The idea for this strut-and-tie model was prompted by Held et al. [28]. In their publication, they examined the design of a rigid connection between a flat slab and an edge composite column. Similar as for precast concrete columns and due to limited space conditions, it was not possible to realize the rigid connection by conventional reinforcement arrangement. Their solution was to add a horizontal reinforcement loop on the upper side of the slab that encloses the steel core of the composite column (Figure 6-13).
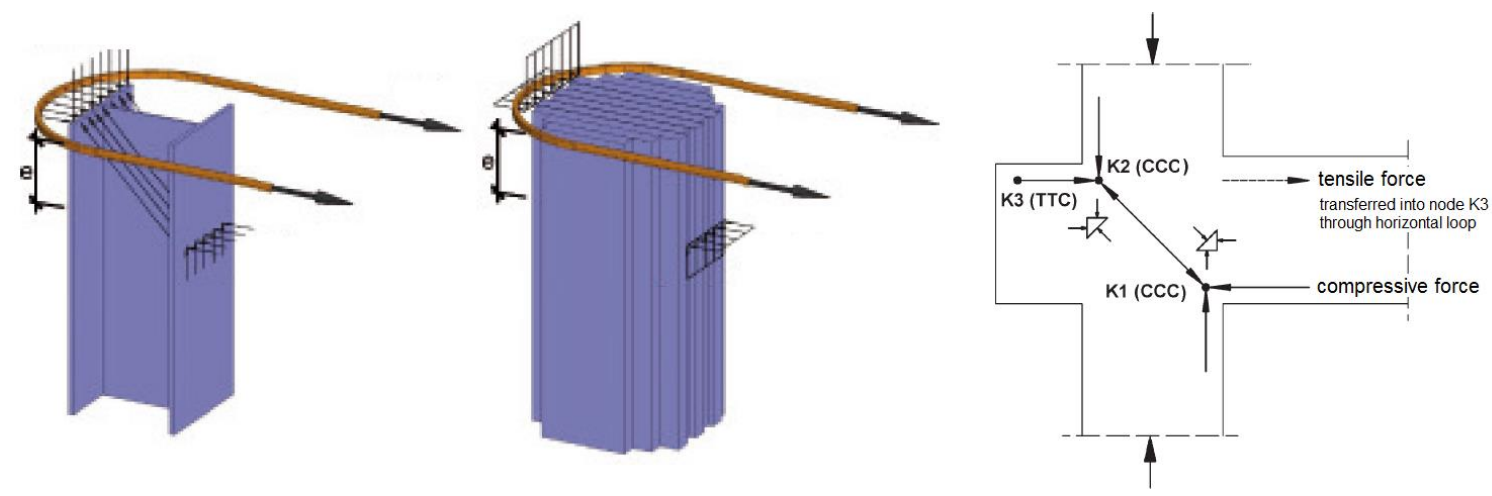

Figure 6-13 - Model for the distribution of forces and strut-and-tie model [28] 
This idea was taken up and transferred to a reinforced concrete slab-column connection (without a steel core) resulting in the strut-and-tie model presented in Figure 6-12. The corresponding reinforcement design is as simple as for the composite column connection and consists of a horizontal reinforcement loop enclosing the column, as illustrated in Figure 6-14. The clear advantage of this design is the simple installation of the reinforcement loop at the time when the column is already concreted and the slab is reinforced. The loop does not affect or rather touches any construction joints and at the same time requires a smaller overhang than the previous solution where the overhang width was dependent on the anchorage length. The width of the loop itself is restricted by the maximum width of reinforcement distribution (Chapter 6.1.1).

The compression nodes A and B should not become crucial for design, as they are located in an area of multiaxial compressive stress state. The transverse tensile force (marked in blue color) resulting from the deflection of the shear force is assumed to be absorbed by the already existing slab reinforcement.

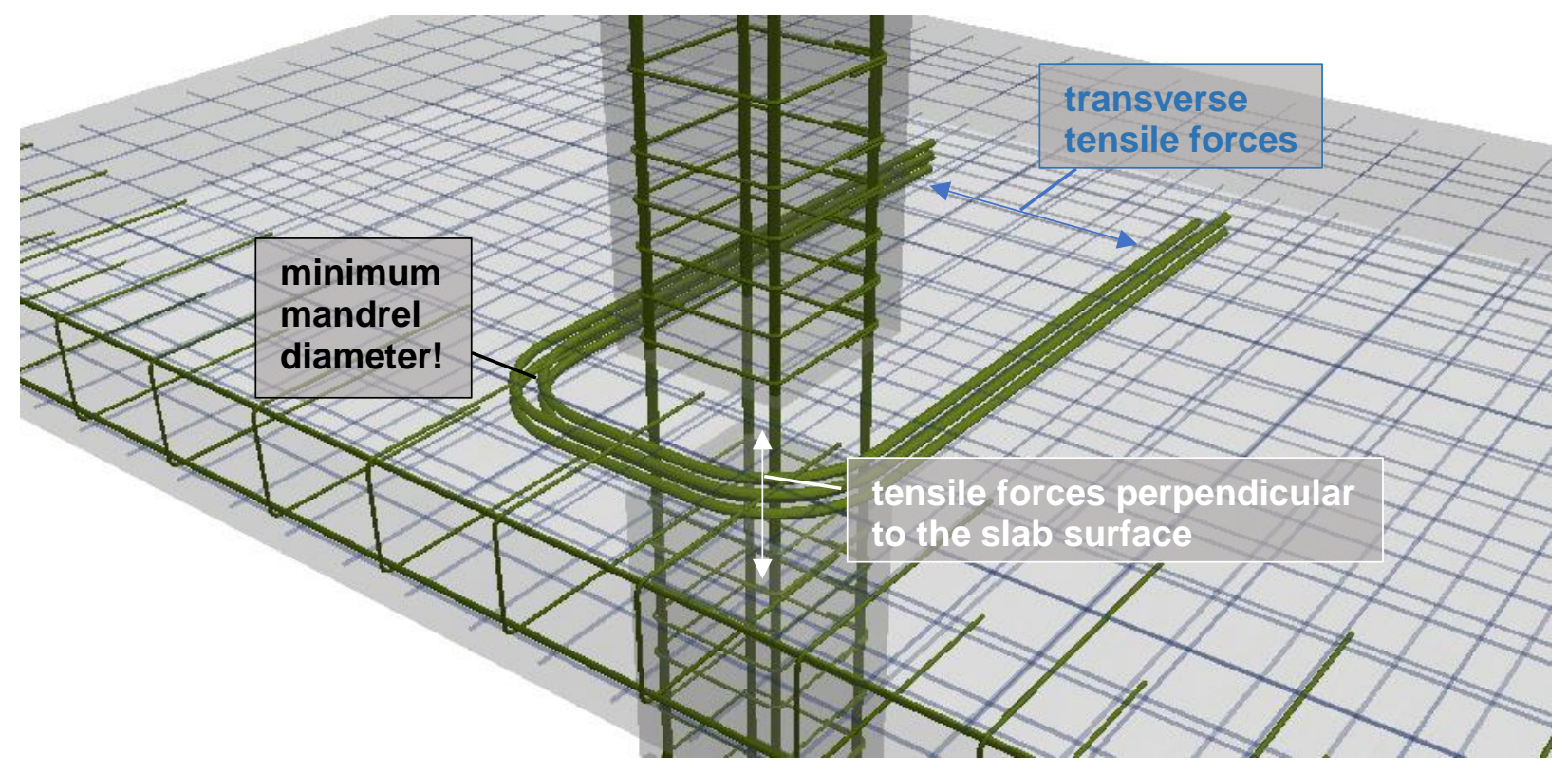

Figure 6-14 - Reinforcement design solution with horizontal reinforcement loop

An important and critical point in this design are the transverse tensile forces resulting from the bending of the horizontal bars (cf. Chapter 6.1.5). The tensile forces perpendicular to the slab surface may lead to the spalling of the concrete in that area. To prevent this, it is necessarily recommended to meet the minimum mandrel diameters presented in Chapter 6.1.2 and to provide sufficient concrete cover. Another possibility to prevent concrete spalling would be to add supplementary vertical reinforcement, similar to ordinary slab shear reinforcement. 


\subsubsection{Outsourcing of Reinforcement}

Another idea for reinforcement design would be to outsource the upper reinforcement partially and therefore split the tensile force into smaller parts. Basically, this model is a combination between the two previously presented models reducing the respective share of the magnitude of the tensile force, whereby the magnitude of the diagonal compressive force stays the same.

The clear benefit of this design is that in consequence of the lower tensile forces within the individual ties the anchorage length of the upper reinforcement bars is reduced. Like for the previous model the major disadvantage of the design is that a slab overhang must be provided.

Necessary bending diameter and strut angles are to be chosen as for the previously presented models. The maximum width to which the bars can be distributed was discussed in Chapter 6.1.1.
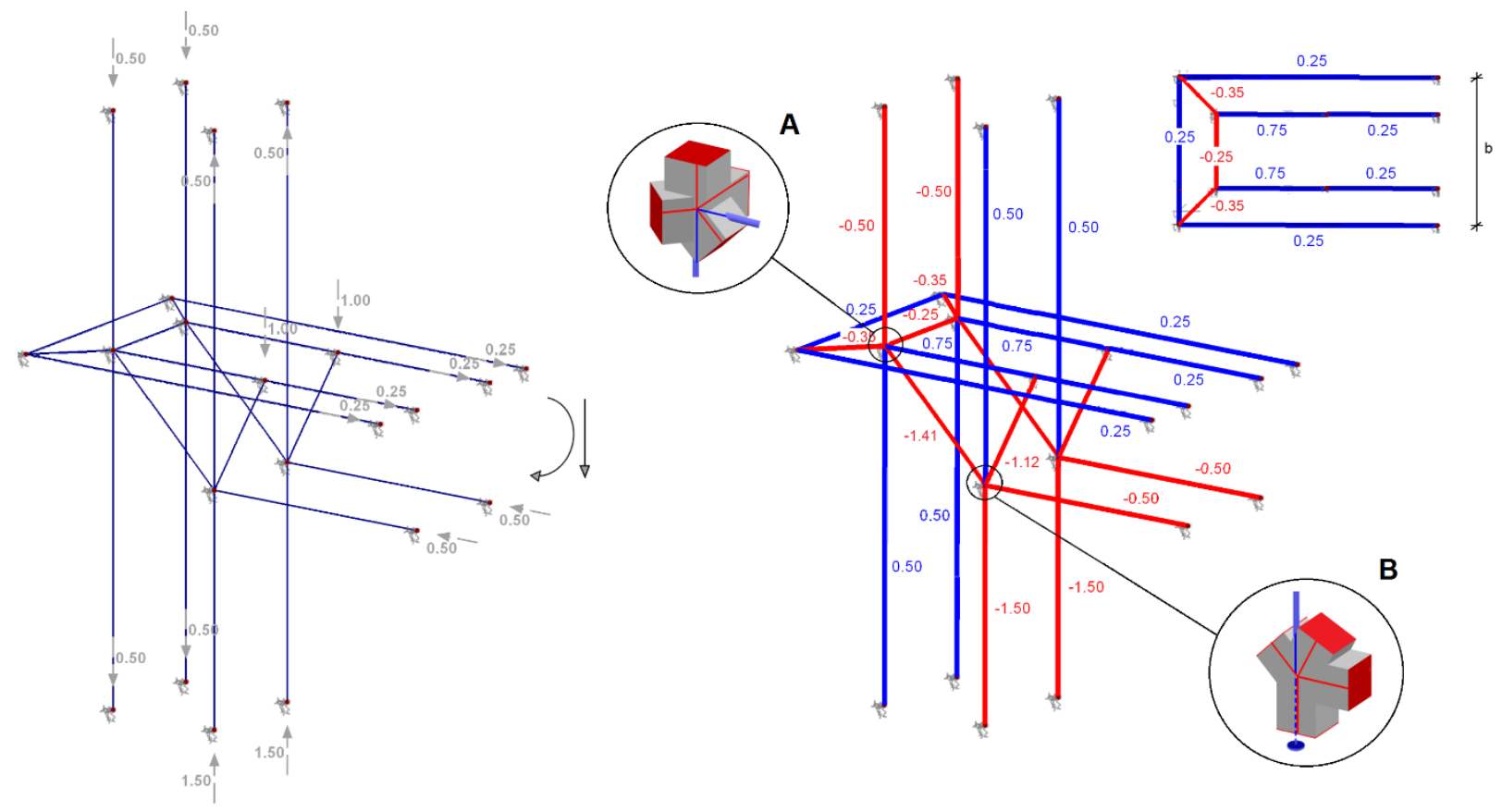

Figure 6-15 - Outsourcing of reinforcement

Two different reinforcement design solutions matching the strut-and-tie models are presented in Figure 6-16. Depending on the available space and length of the overhang either a combination of a horizontal loop and straight bars with a standard bend (left picture) or an arrangement of simply anchored bars (right picture) are possible options.

As this model represents a combination of the two previous ones, it is referred to the two previous chapters for more detailed information about the reinforcement arrangement and potentially crucial points of design. 

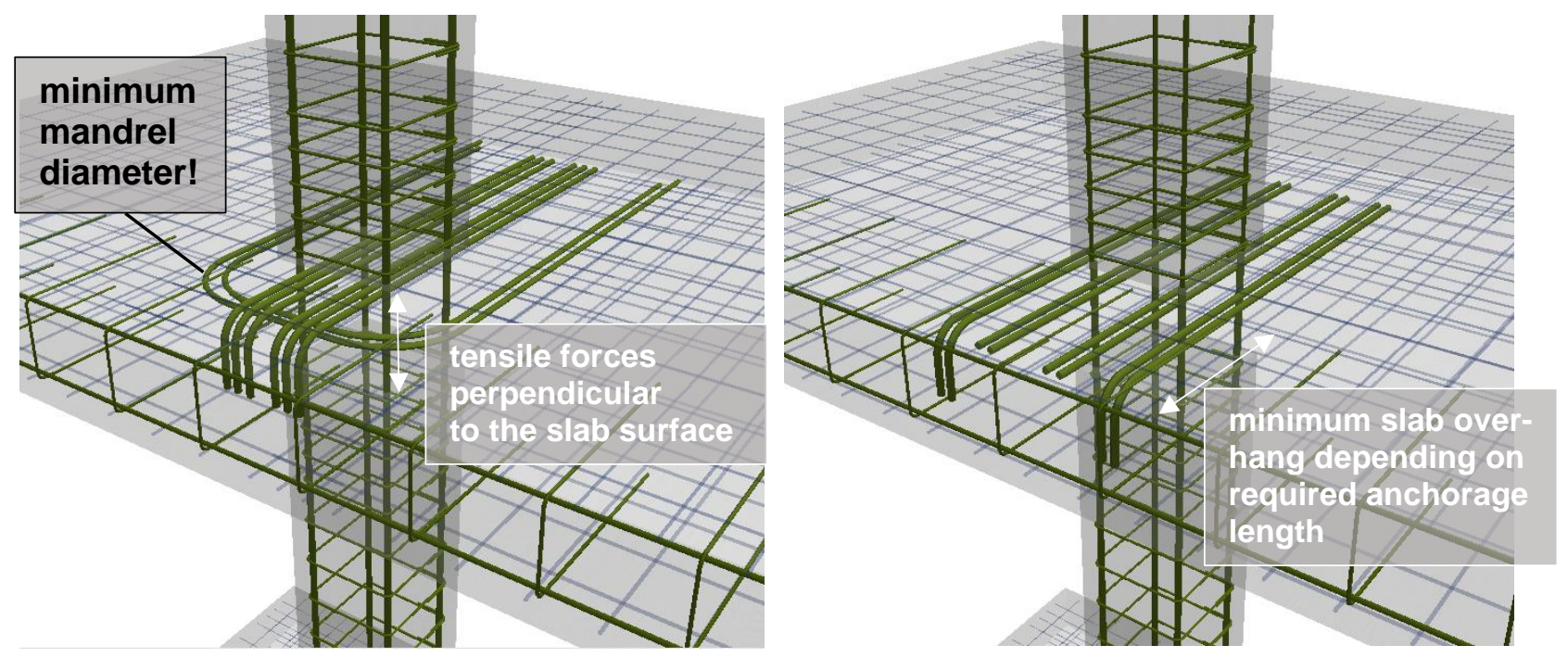

Figure 6-16 - Reinforcement design solutions with the outsourcing of reinforcement bars

\subsection{TRANSMISSION OF LARGE FORCES}

For the case of normal strength concrete slabs sandwiched between high strength concrete columns, mostly accompanied by the transmission of large column loads through the connection area, reference is made to Chapter 2.2.

As shown in Figure 2-5, lacking confinement reinforcement may lead to an increase of the stresses within the previously verified struts and ties.

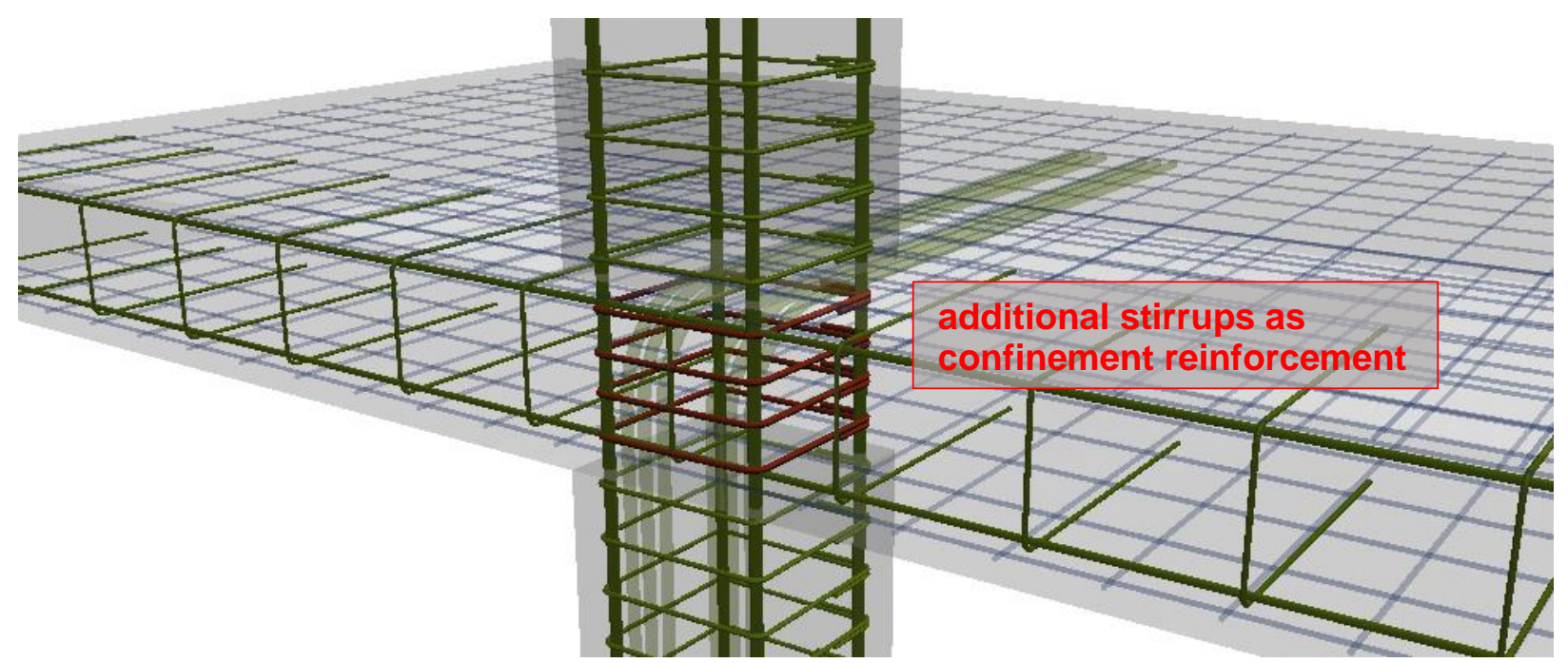

Figure 6-17 - Additional stirrups to ensure confinement 


\section{PARAMETRIC STUDY AND RECOMMENDATIONS}

\subsection{PARAMETRIC STUDY}

The following parameters and their influence on the reinforcement design are examined:

- dimensions of the column and depth of the slab

- stiffness of the connection, slenderness of the column

- existence and length of a slab overhang beyond the column edge

- existence and magnitude of a surcharge of upper floors

- magnitude of the moment

- strength of the concrete used for the connection

It should be mentioned that many of these parameters are directly related to or influence each other. All the parameters are going to be described and elaborated in more detail in the following chapters resulting in a flow chart and final recommendations for the reinforcement design of slabcolumn connections.

\subsubsection{Stiffness of the Connection}

The stiffness of the connection depends on the following parameters:

- dimensions/slenderness of the columns above and below the connection

- $\quad$ size of the load that is transferred from the levels above (surcharge)

- strength of the concrete used for the connection

With regard to the calculation of the magnitude of the transfer moments in Chapter 3.2, it is obvious that the stiffer the connection is the more load it attracts and therefore the larger is the moment that has to be transferred through the connection.

That means that for example a high concrete strength (as it is common for spun-concrete columns as mentioned in Chapter 1.3) is favorable for the transmission of forces within the connection and the design of the concrete struts but is at the same time responsible for the connection to be charged with even higher forces.

\subsubsection{Dimensions of the Column and Slab Thickness}

As for the depth of the slab, it is obvious that the thicker the slab is the more it weighs and the greater is the moment that results from the slab load itself and which has to be transferred into 
the column. At the same time, the larger the dimensions of the column or in other words the larger the area of support the more load the connection will attract and therefore the moment that has to be transferred will again be greater.

\section{Angle of Diagonal Compression Strut}

According to Schlaich et al. [16] angles between struts and ties in a strut-and-tie model should be aimed to be greater than $45^{\circ}$. Angles below $30^{\circ}$ are unrealistic or linked with large deformations of the structural element. As for our model, the angle of the main diagonal compression strut depends on the dimensions of slab and column respectively on the ratio between slab depth (h) and column width (c).
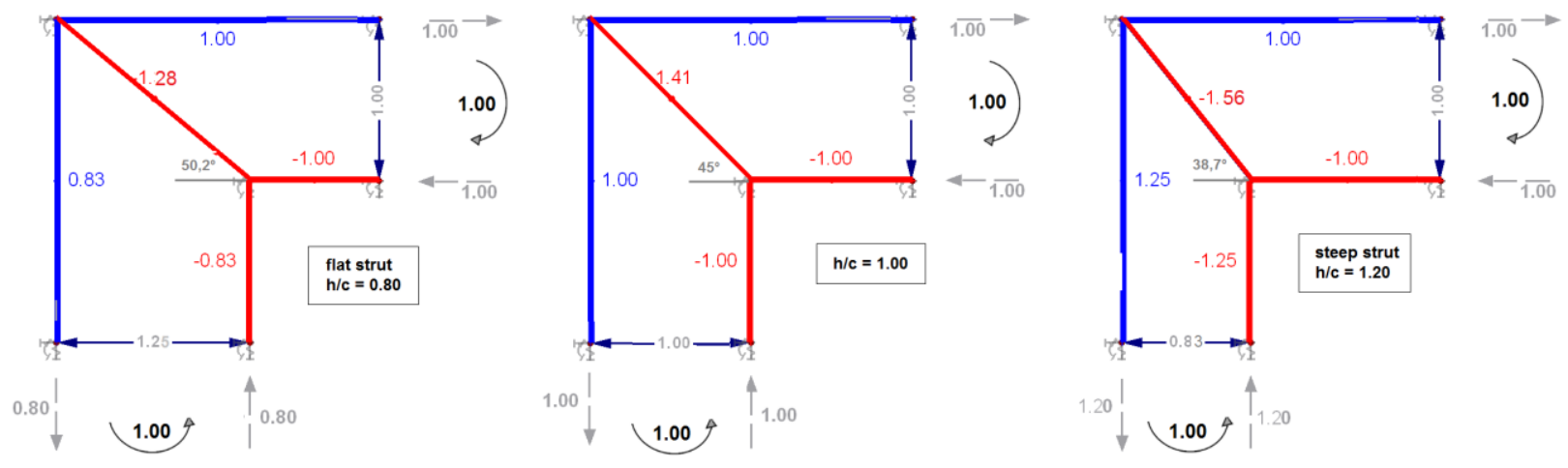

Figure 7-1 - Influence of angle of compression strut on internal force distribution

In real practice, especially when e.g. spun-concrete columns are used, it is likely, that the height of the slab exceeds the width of the column. However, with regard to the magnitude of forces, a flat compression strut would be preferable, as the compression force within the diagonal strut as well as the tensile force in the vertical tie drop the flatter the strut is. In order not to fall below an angle of $30^{\circ}$ between the strut and the tie at the upper right corner of the model, the ratio between the depth of the slab and the width of the column should not be less than 0,6. Taking into account the additional concrete cover and the fact that the struts and ties do not represent the real edges of the structure does not have considerable effects on the ratio and the angle of the strut itself.

Table 7-1 - Values of compression and tensile forces for different strut angles

\begin{tabular}{|l|c|c|c|c|c|c|}
\hline Ratio depth slab / width column & $\mathbf{0 , 6}$ & $\mathbf{0 , 8}$ & $\mathbf{1 , 0}$ & $\mathbf{1 , 2}$ & $\mathbf{1 , 4}$ & $\mathbf{1 , 6}^{\mathbf{1}, \mathbf{0}}$ \\
\hline Angle of compression strut & $\mathbf{3 1}^{\circ}$ & $\mathbf{3 8 , 7 ^ { \circ }}$ & $\mathbf{4 5}^{\circ}$ & $\mathbf{5 0 , 2 ^ { \circ }}$ & $\mathbf{5 4 , 5 ^ { \circ }}$ & $\mathbf{5 8}^{\circ}$ \\
\hline Diagonal compression force $[\mathrm{kN}]$ & 1,17 & 1,28 & 1,41 & 1,56 & 1,72 & 1,89 \\
\hline Tensile force in column $[\mathrm{kN}]$ & 0,6 & 0,8 & 1,0 & 1,2 & 1,4 & 1,6 \\
\hline
\end{tabular}


Table 7-1 shows the value of the diagonal compression force as well as the tensile force transferred into the column for different ratios respectively strut angles. The slab moment was set to the value " 1 ".

\subsubsection{Existence and Magnitude of a Surcharge}

Figure 7-2 shows the influence of a surcharge whereby the magnitude of the surcharge was increased from the left to the right model. It can be seen that the additional surcharge has a positive effect with regard to the vertical tensile force within the column which is reduced or completely eliminated by the existence of additional vertical pressure.
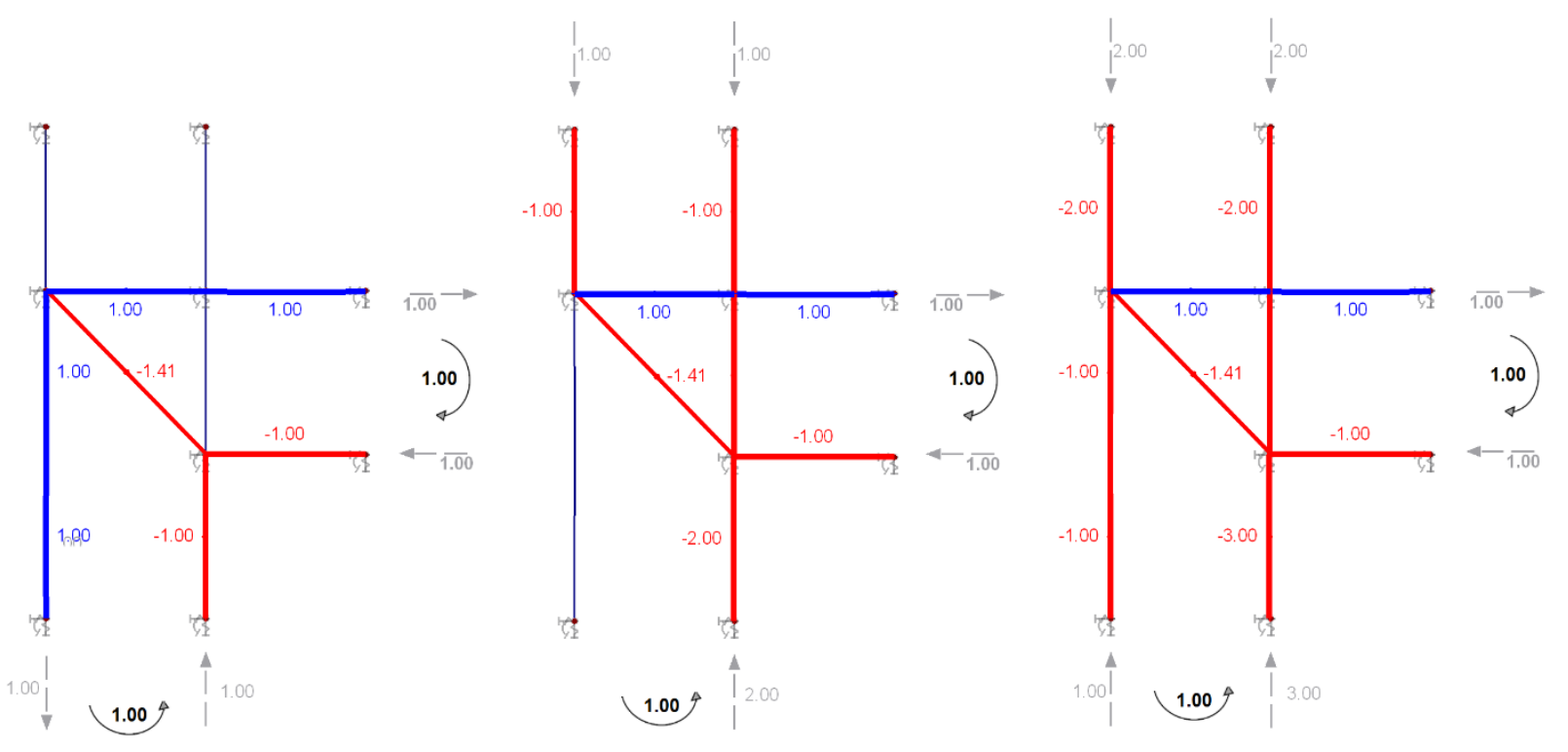

Figure 7-2 - Influence of magnitude of a surcharge

With regard to Chapter 2.2, the existence of a surcharge that puts the concrete in a state of multiaxial compression may be favorable in terms of increased concrete strength in that area. At the same time, if a transfer of the bending moments in the connection is not intended in the first place and a hinged connection is assumed for design, an additional surcharge may result in an unintended restraint between slab and column.

\subsubsection{Concrete Strength}

It is obvious that increasing the concrete strength increases the strength of the entirety of the joint. An increase in compressive strength is not only advantageous for the bearing capacity of the concrete struts but also for the transfer of large column loads through the connection. 
As already mentioned in Chapter 7.1.1, it has to be taken into account the increasing the strength of the concrete of the slab in the column area also increases the stiffness and therefore attracts load. This, in turn, results in larger support loads and bending moments acting on the joint.

\subsubsection{Existence and Length of a Slab Overhang}

Although a slab overhang beyond the column edge may not be desired because of architectural or optical reasons it provides significant advantages in terms of the load and stress distribution within the joint as well as for the design of reinforcement.

With regard to the transmission of large loads from high strength concrete columns through normal concrete slabs, it has been investigated in [1] that providing only a small slab overhang increases the actual strength of the joint significantly. The existence of the overhang provides confinement and therefore prevents spalling of the concrete in the area of the slab as can be seen in Figure 7-3. Also worth mentioning is the increase in punching shear resistance resulting from the lengthening of the control perimeter. For these reasons, it is recommended in [1] to design the slab-column connection in a way that the overhang is at least equal to the slab thickness.
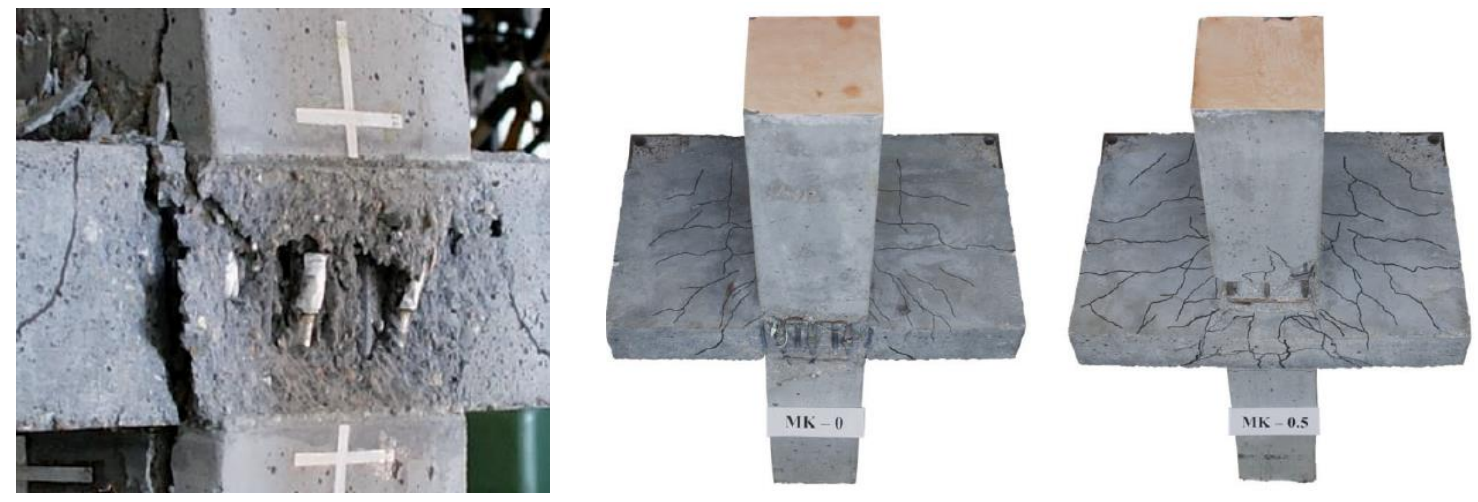

Figure 7-3 - Spalling of the concrete as a result of the non-existent overhang [1]

With regard to the reinforcement design solutions presented in Chapter 6.2, it can be seen that providing a slab overhang offers new and probably more economical possibilities in arranging the reinforcement for a rigid slab-column connection, avoiding the necessity of a $90^{\circ}$ bent downwards into the column. 


\subsection{FLOWCHARTS AND RECOMMENDATIONS}

The following flowcharts shall give an overview and recommendations for the design of rigid slabcolumn connections. At the same time, they shall serve as a summary of the results of this work. Based on the first three chapters, Figure 7-4 gives a general overview on whether moment transfer between flat slab and column has to be considered in the design and, if this is the case, on how to estimate the magnitude of the corresponding moments.

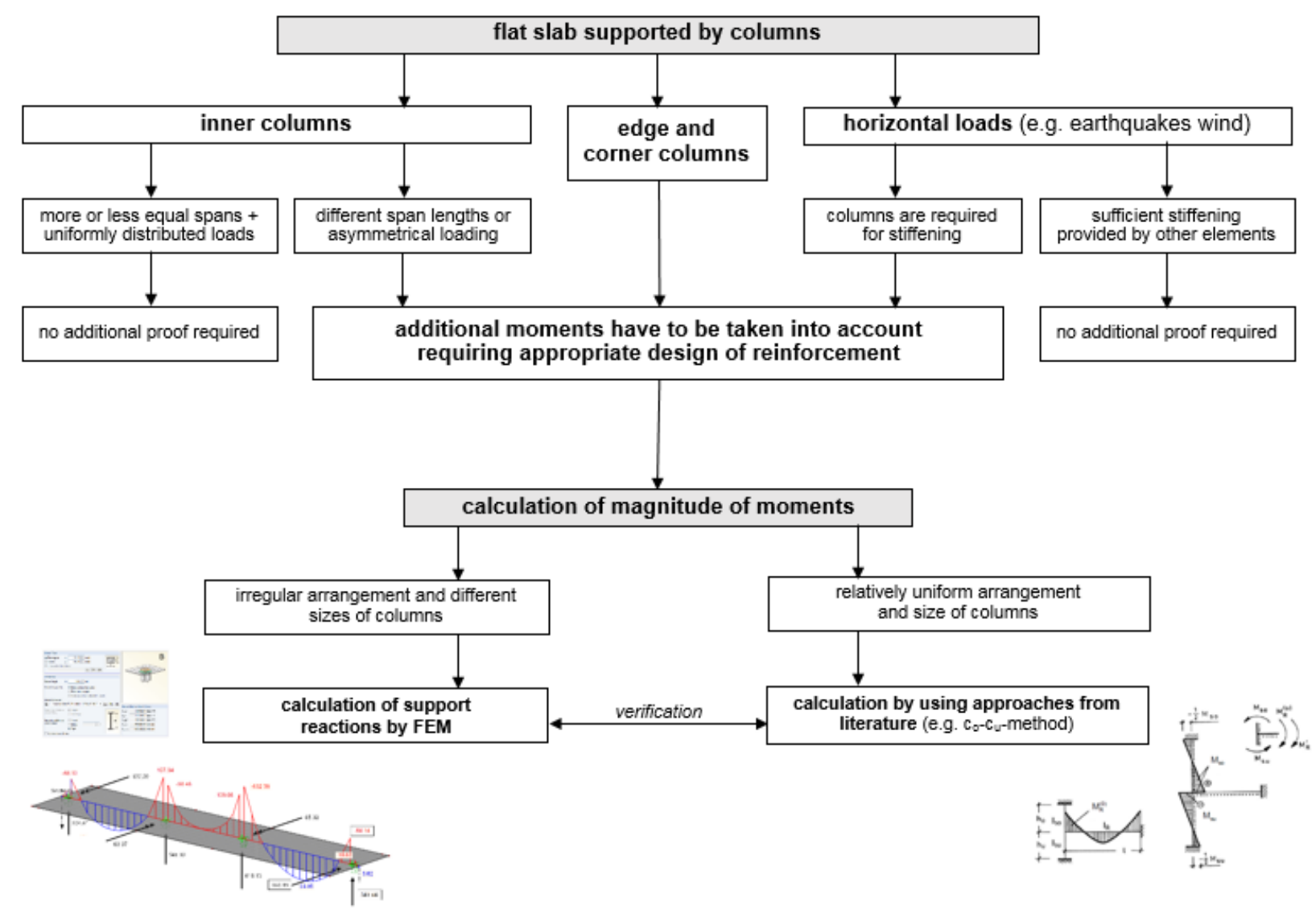

Figure 7-4 - Necessity of considering moments and calculation methods

Particular attention should be paid to the fact that edge and corner columns will always be subjected to an additional moment. Even if a flexible joint is assumed for design, as it is common practice, accidental restraint may still enable moment transfer. 
The flowchart presented in Figure 7-5 shall give recommendations on how to choose the most suitable reinforcement arrangement depending on a given situation. It must be noted, that the following recommendations are just a rough guideline. As the individual parameters are strongly dependent on the specific situation (e.g. dimensions, stiffness, magnitude of moments) and on each other, verification on a case-by-case basis is strictly necessary.

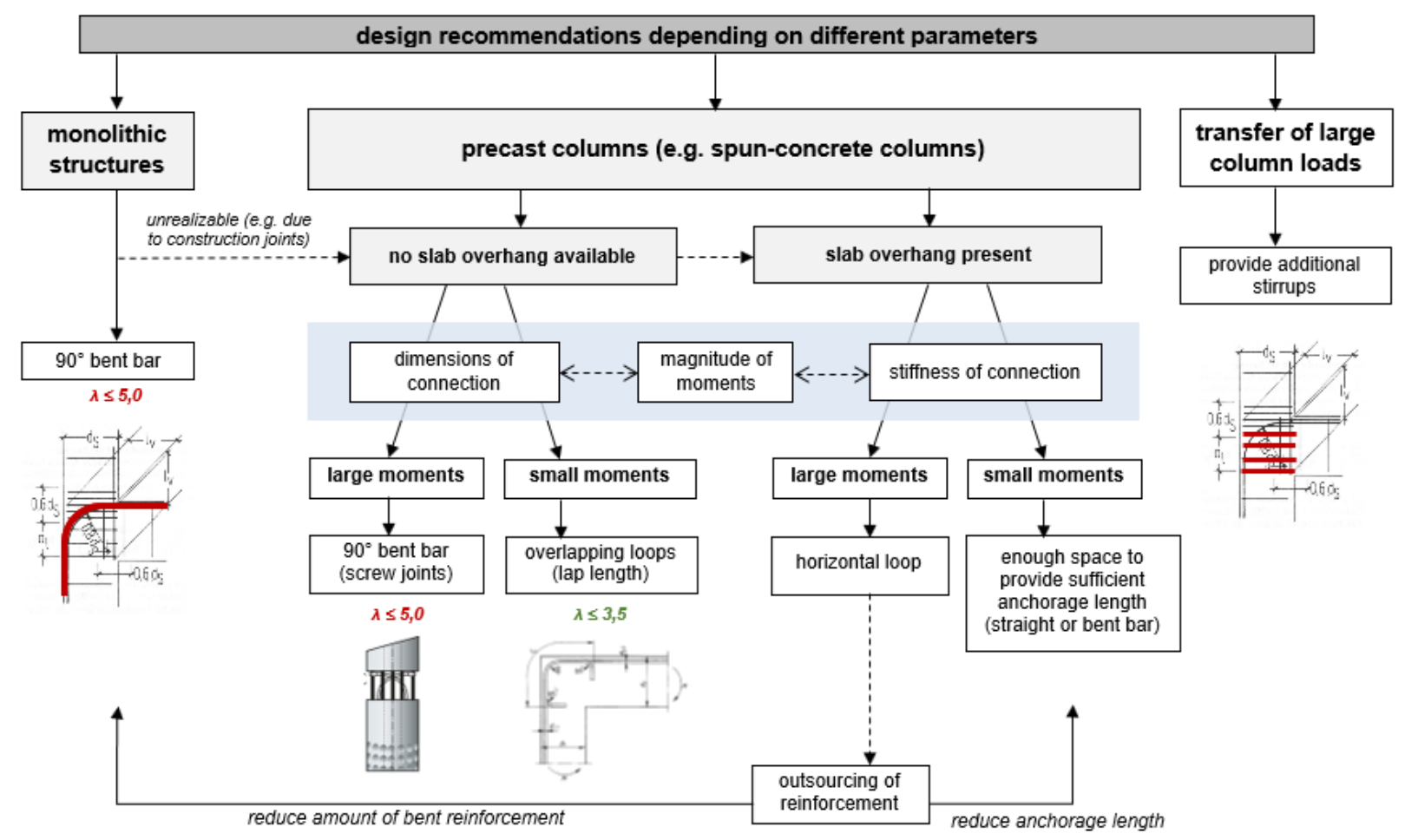

Figure 7-5 - Reinforcement design solution depending on different parameters

The values of the shear slenderness $\lambda$, which are calculated in the Appendix, shall serve as a rough reference value to evaluate the magnitude of the moment.

Basically, the solution using a simple vertical $90^{\circ}$ bent bar to redirect the tensile force from the horizontal into the vertical plane (based on the "simple" strut-and-tie model) can be seen as the simplest and maybe also the most economical solution. However, the installation of this bent bar may be difficult to reconcile with the sequence of construction, especially when it comes to the use of precast elements (cf. Chapter 6.2.1)

If precast columns are used or if the just discussed solution using the bent bar is not executable, we can move forward in the middle part of the flowchart. Dependent on whether a slab overhang 
is present or not, we have the choice between four solutions which, in turn, are dependent on the magnitude of the transfer moment. The magnitude of the moment can be seen as the result of an interplay between several parameters. These parameters include but are not limited to the dimensions of the connection itself as well as its stiffness, the span length etc. and were discussed in more detail in the previous chapters.

If there is no slab overhang planned, but the installation of a continuous $90^{\circ}$ bent bar as described above is not possible, it can be referred to several alternative options. One solution, provided that the present moments are not too large, could be to install two overlapping loops and verify sufficient lap length. In order to meet the required clear space between the bars, it is very likely that arranging the loops side by side will not be possible. Therefore, arranging them one below each other may provide a remedy. However, if the magnitude of the moments is too large, it is likely that the lap length cannot be met. In this case, it should be considered to realize the $90^{\circ}$ bent by either using screw connections (cf. Chapter 1.3) or anchor heads (cf. Chapter 6.1.4).

Providing a slab overhang means that it is possible to anchor the upper tensile force behind the actual connection. This can be realized by either using simple straight or bent bars meeting the required anchorage length (cf. Chapter 6.2.1). If there is not enough space to meet the required lengths respectively if the magnitude of moments is too large, the solution using a horizontal loop could be a good and economic alternative (cf. Chapter 6.2.2).

Basically, it is always possible to "exonerate" the specific reinforcement arrangement by "outsourcing" of reinforcement (cf. 6.2.3). As a result, it is possible to reduce the required bar diameters respectively the required anchorage length. The outsourcing of reinforcement, however, is only effective if a slab overhang is present and the anchoring of the outsourced bars is happening in the area behind the connection. Otherwise, the outsourced bars will discharge the main reinforcement.

Notwithstanding the above, it has to be verified whether sufficient confinement in the area of the connection is given (cf. Chapter 2.2 and 6.1.3). The situation becomes particularly critical if large loads are transmitted from the column above and if no slab overhang is provided. But even if a slab overhang is present, additional stirrups in the area of the connection may be necessary to provide sufficient confinement. 


\section{CONCLUSION}

This paper has shown, that the common practice, which is to assume that the connections between flat slabs and columns are hinged, is often not justified. Especially when it comes to the design of edge and corner columns, solutions on how to achieve a rigid design, respectively on how to transfer the moments from the slab into the column, need to be found. At the same time, most of the current codes do not give precise information on how to verify these types of connections, let alone on how to design the reinforcement.

The strut-and-tie models which were developed in the scope of this paper, can not only help to understand the flow of forces but also verify the arrangement of the reinforcement bars in a way that is approved by the current codes. Each of the three developed models, including their specific reinforcement arrangement, has its advantages and disadvantages and should be chosen in accordance with the given conditions.

While there exist numerous experimental results on inner nodes respectively inner slab-column connections the amount of research in the field of moment transfer within edge and corner columns of flat slabs is quite small, especially when it comes to experimental proof of the theoretical findings. As this paper likewise represents only a theoretical approach on how to design rigid slab-column connections it is inevitable to verify the developed concepts experimentally before putting them into practice.

To conclude, it is important to understand that this paper only provides rough reference values when it comes to the choice of an adequate reinforcement design for a rigid slab-column connection. This is less due to the simplifications that were made in the beginning but more to the fact, that the whole design is dependent on many different parameters and therefore may vary strongly in the individual case. 


\section{A APPENDIX - EXEMPLARY CALCULATION}

\section{A.1 DESCRIPTION OF THE PROJECT}

In order to get a feeling for the magnitudes of the moments in slab-column connections and to give the (theoretically) developed strut-and-tie models a trial when charged with 'real' loads, the following project shall serve as an example for an exemplary calculation.

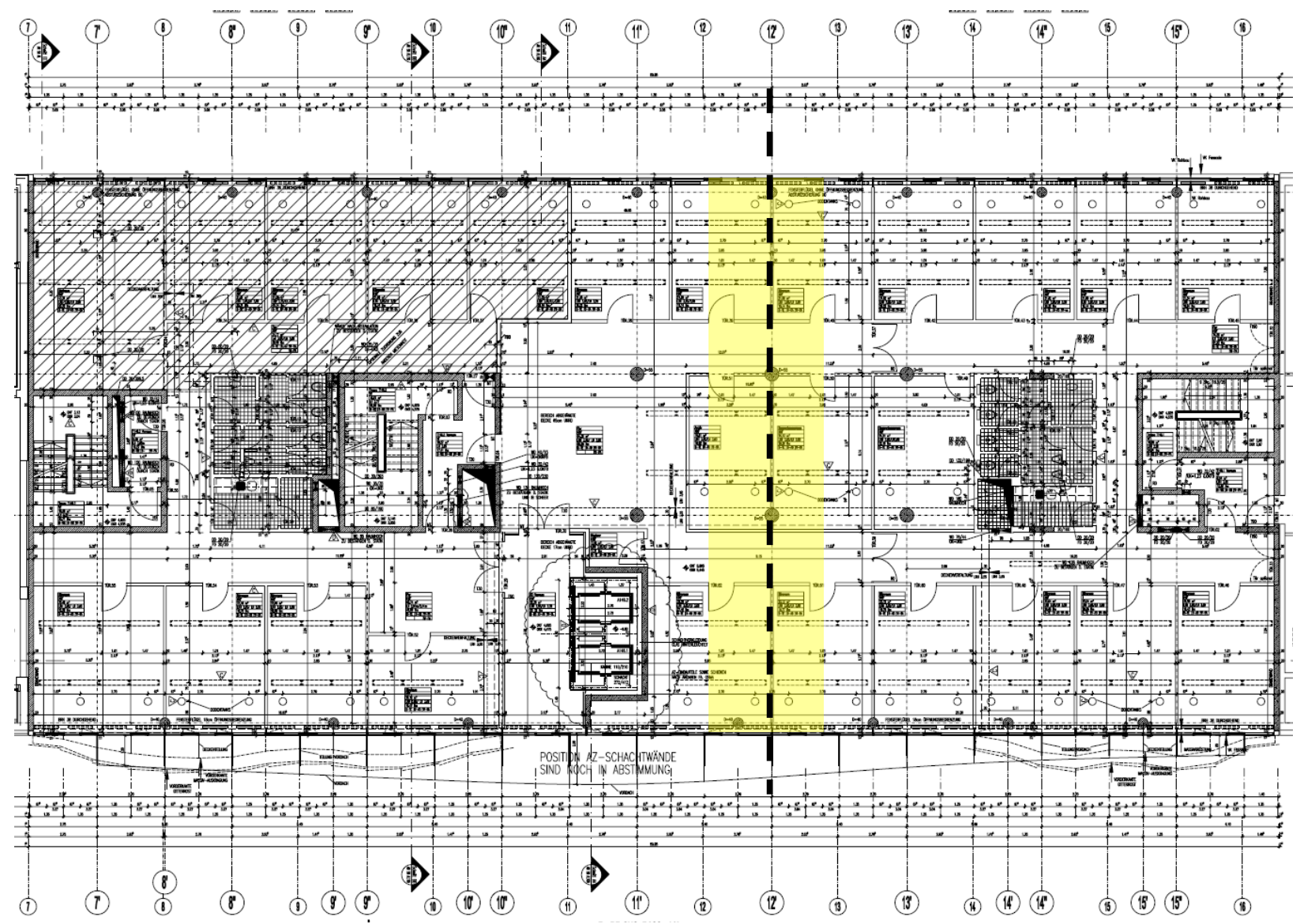

Figure A-1 - Plan view of the first floor of an institutional building

For the calculations, we regard a stripe of the slab of a width of $5,4 \mathrm{~m}$ and a length of $22,3 \mathrm{~m}$ in total (including the slab overhang) as marked in yellow color in Figure A-1. To simplify the following calculations, we assume that all the four columns are located on the same axis. The two edge columns $(\varnothing=40 \mathrm{~cm})$ are slightly smaller than the inner columns $(\varnothing=55 \mathrm{~cm})$.

The spans between the columns are quite large and are $7,30 \mathrm{~m}, 5,70 \mathrm{~m}$, and $8,30 \mathrm{~m}$ long, as illustrated in Figure A-2. The calculations will concentrate on the edge column next to the largest span, as this column represents the most unfavorable case. 


\section{Dimensions of Slap Stripe}

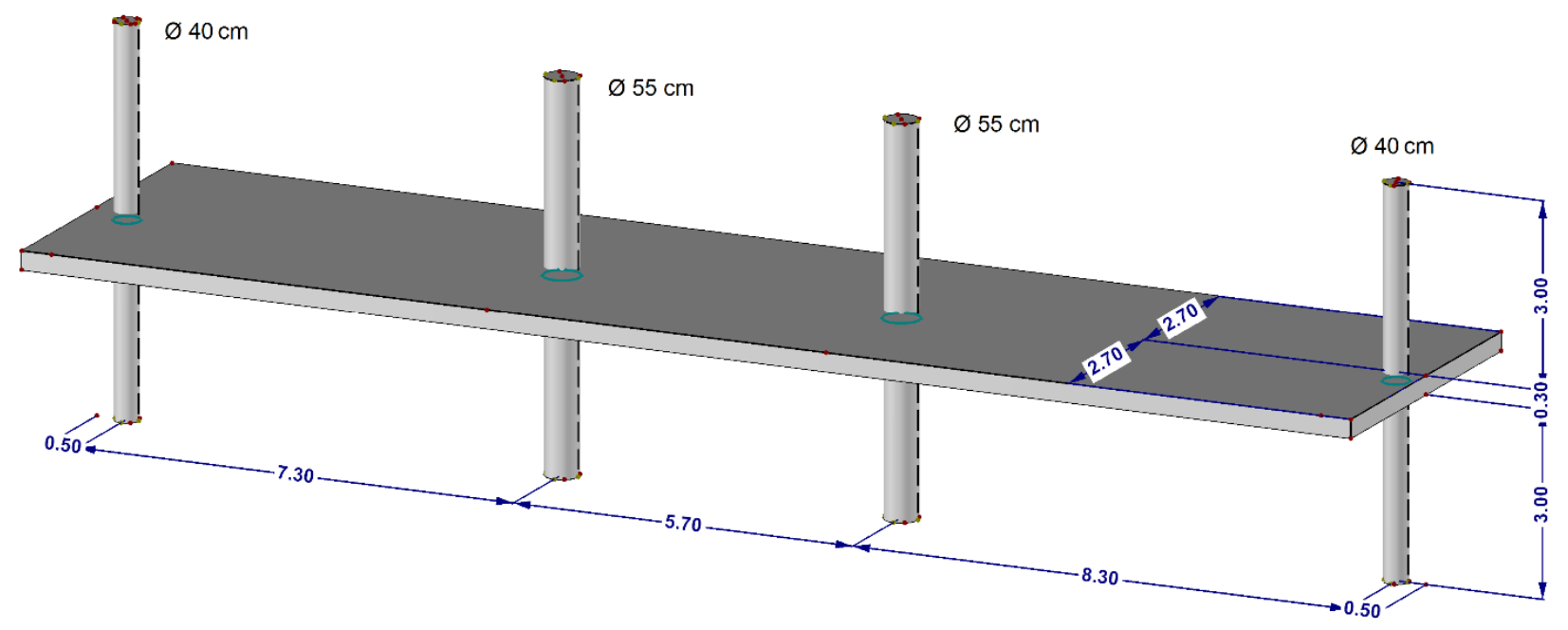

Figure A-2 - Dimensions of the regarded exemplary slap stripe

Thickness of the slab:

$\mathrm{h}=30 \mathrm{~cm}$

Concrete cover (assumption): $\quad \mathrm{c}_{\text {slab }}=\mathrm{C}_{\text {column }}=3 \mathrm{~cm}$

Diameter of round columns: $\quad d_{\text {edge }}=40 \mathrm{~cm} \quad d_{\text {interior }}=55 \mathrm{~cm}$

Height of the columns: $\quad h_{o}=h_{u}=3,0 m$

\section{Loads}

The following (uniformly distributed) loads where applied onto the slab:

Self-weight of the reinforced concrete slab:

$\mathrm{g}_{\mathrm{slab}}=25 \mathrm{kN} / \mathrm{m}^{3} \times 0,3 \mathrm{~m}=7,5 \mathrm{kN} / \mathrm{m}^{2}$

Additional permanent load (floor construction etc.): $\quad g_{\text {perm }}=2,5 \mathrm{kN} / \mathrm{m}^{2}$

Service loads:

$\mathrm{q}_{\mathrm{ser}}=5,0 \mathrm{kN} / \mathrm{m}^{2}$

For design the characteristic loads are multiplied by safety factors according to EC.

$p_{\text {d,total }}=1,35 \times\left(7,5 \mathrm{kN} / \mathrm{m}^{2}+2,5 \mathrm{kN} / \mathrm{m}^{2}\right)+1,5 \times 5,0 \mathrm{kN} / \mathrm{m}^{2}=\underline{\underline{21 \mathrm{kN} / \mathrm{m}^{2}}}$ 


\section{A.2 ESTIMATION OF THE MAGNITUDE OF MOMENTS}

As the $\mathrm{C}_{\mathrm{o}}-\mathrm{C}_{\mathrm{u}}$-method can only be applied on rectangular columns an equivalent column size of $35 \times 35 \mathbf{~ c m}$ was chosen for both edge and inner columns. To be able to compare the results in the end, this simplification was also used for the FEM-calculations.

$I_{\mathrm{O}}=\frac{\pi \times d^{4}}{64}=\frac{\pi \times 40^{4}}{64}=125664 \mathrm{~cm}^{4}=I_{\square} \quad b_{\square}=\sqrt[4]{125664 \times 12}=35 \mathrm{~cm}$

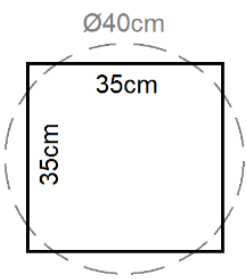

\section{Using Approaches from Literature}

The following calculation of the moments by the $\mathrm{C}_{0}-\mathrm{C}_{4}$-method was carried out with Microsoft Excel. A copy of the calculation sheet can be found in Figure A-4. The yellow fields within the sheet represent the input values.

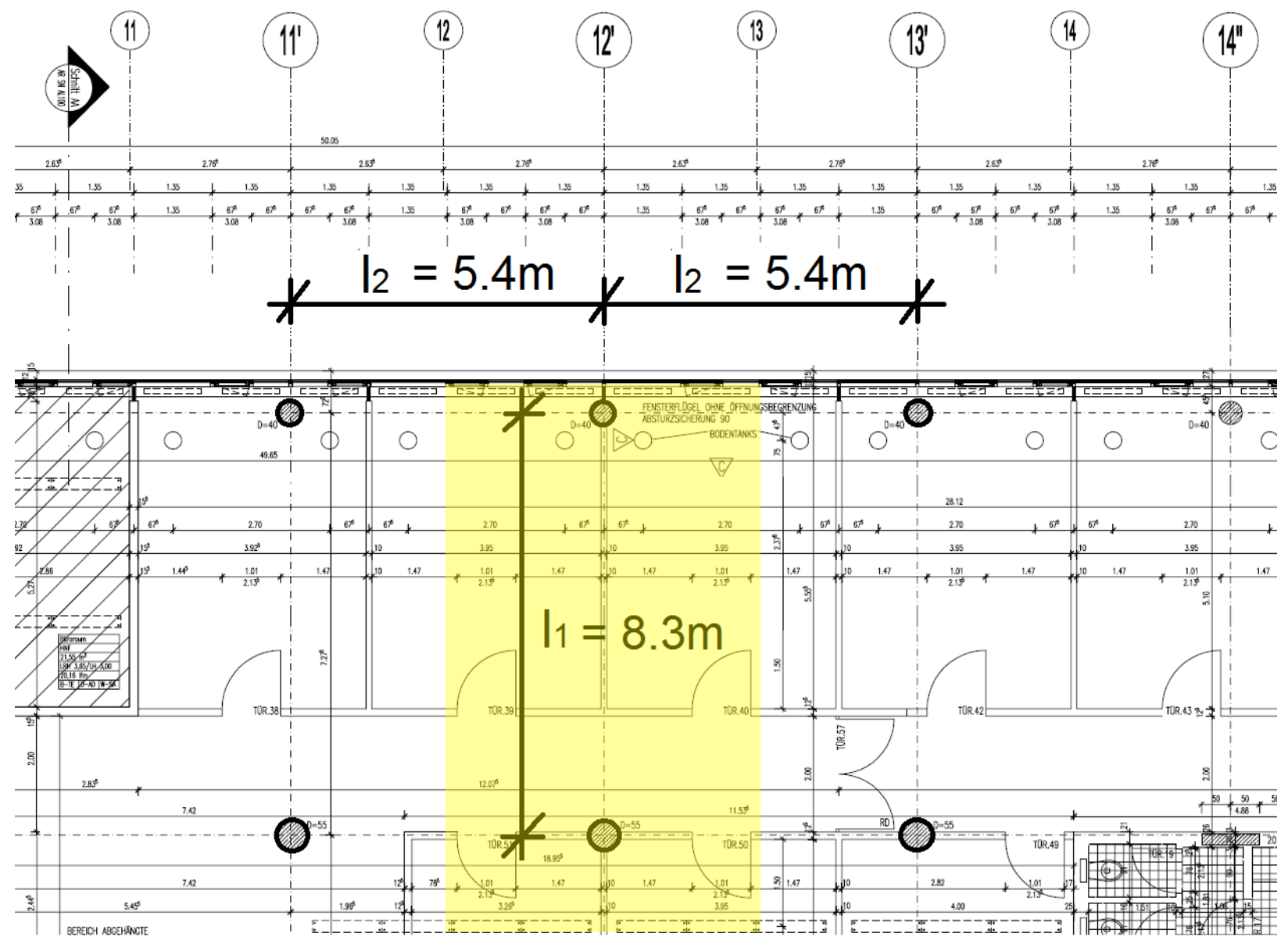

Figure A-3 - Definition of lengths $I_{1}$ and $I_{2}$ according to "Heft 240" 


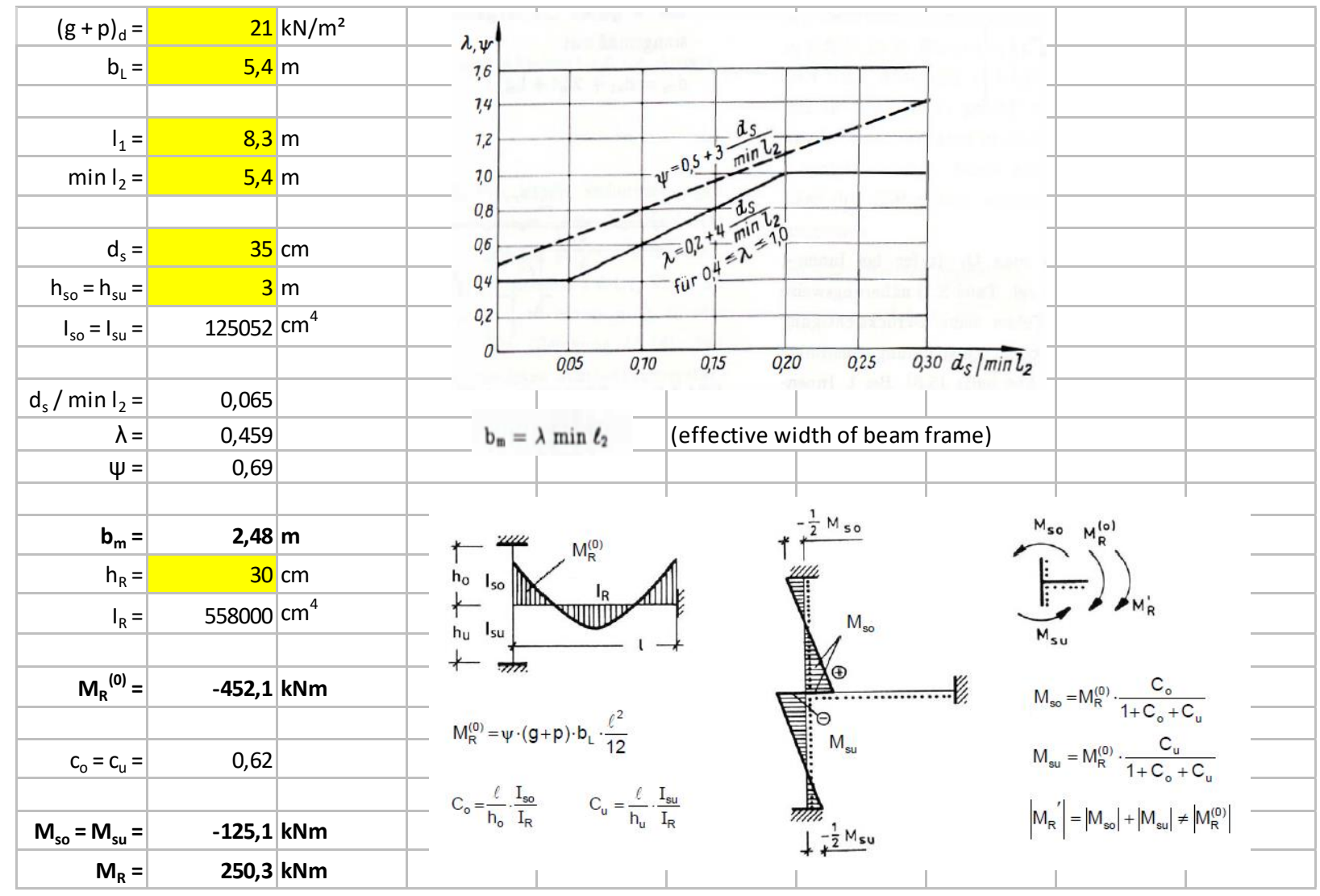

Figure A-4 - Calculation of moments by the Co-Cu-method

\section{Using Finite Element Analysis}

For an exemplary finite element calculation of the moments, the software RFEM by the company Dlubal was used. The program offers different default solutions on how to consider column supports of slabs. For this exemplary calculation two different models of support were tried out in order to compare the differences in value in the end. The two different models and settings are presented in the screenshots in Figure A-5.

As the program only allows the input of a single column, the height of this replacement column was chosen as $1,5 \mathrm{~m}$, so that the automatically calculated stiffness of the replacement spring is equal to that of two columns of a length of $3,0 \mathrm{~m}$. 

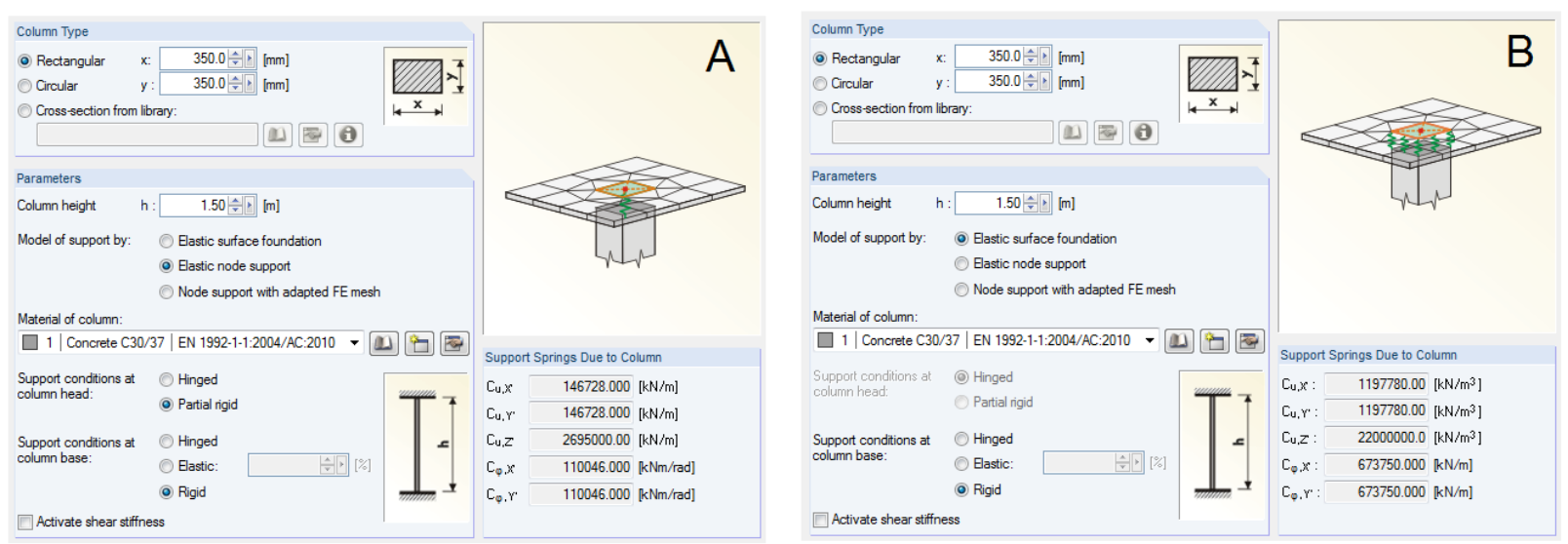

Figure A-5 - Definition of support conditions and estimated values for replacement spring

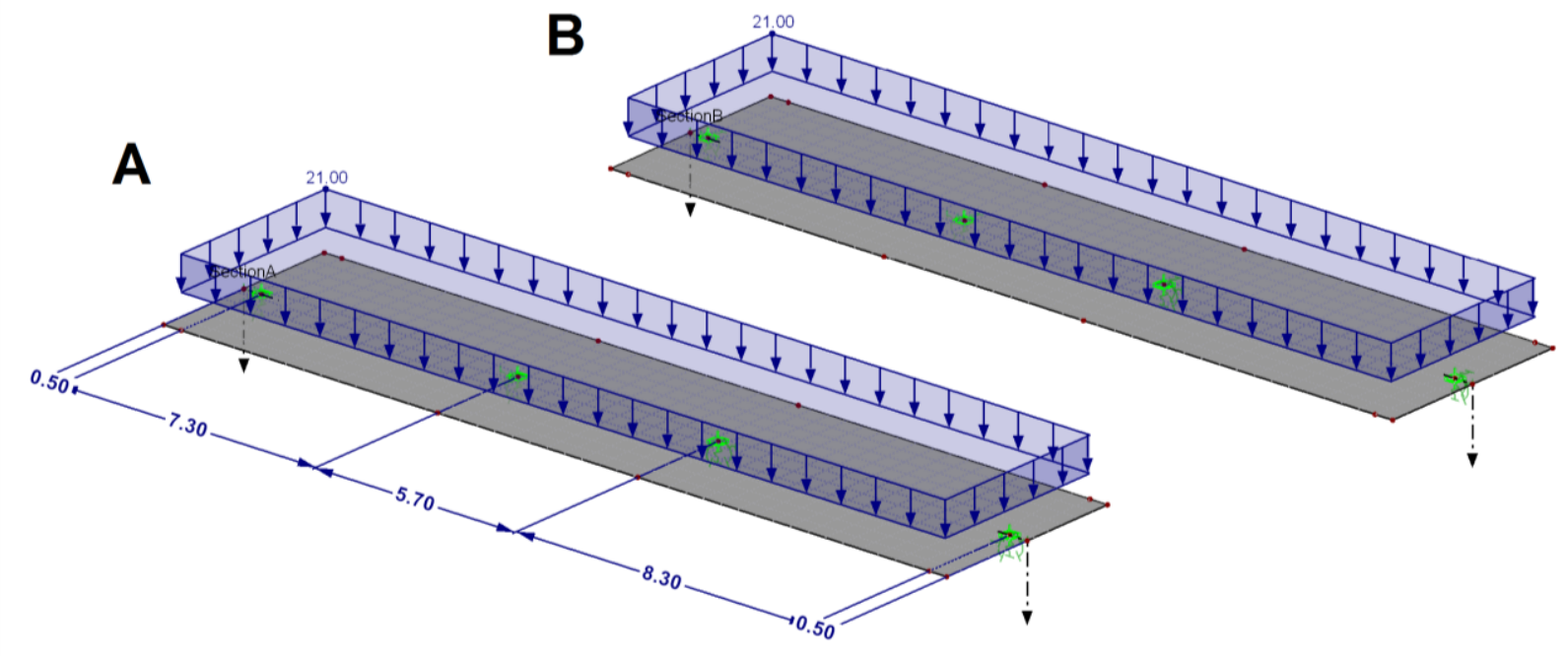

Figure A-6 - FE-model, dimensions, and loading

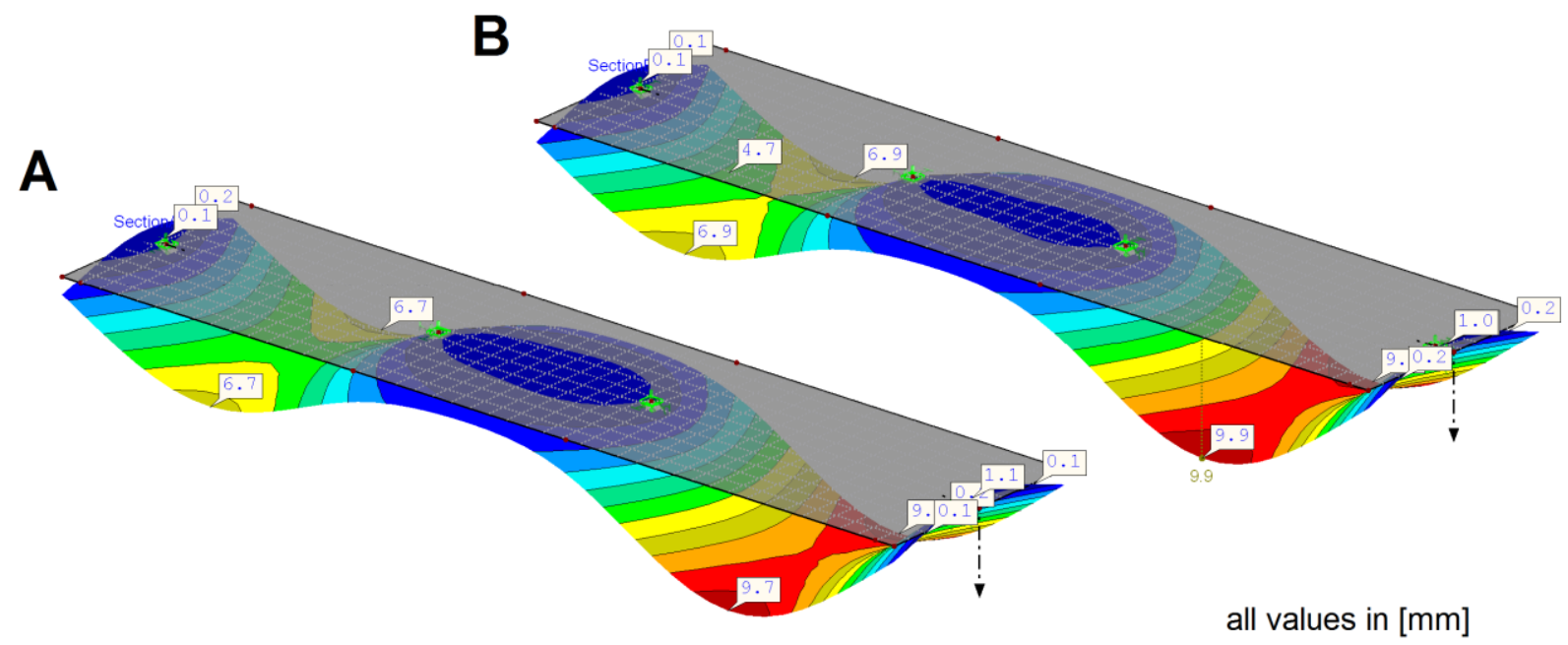

Figure A-7 - Deformation of the slab stripe 


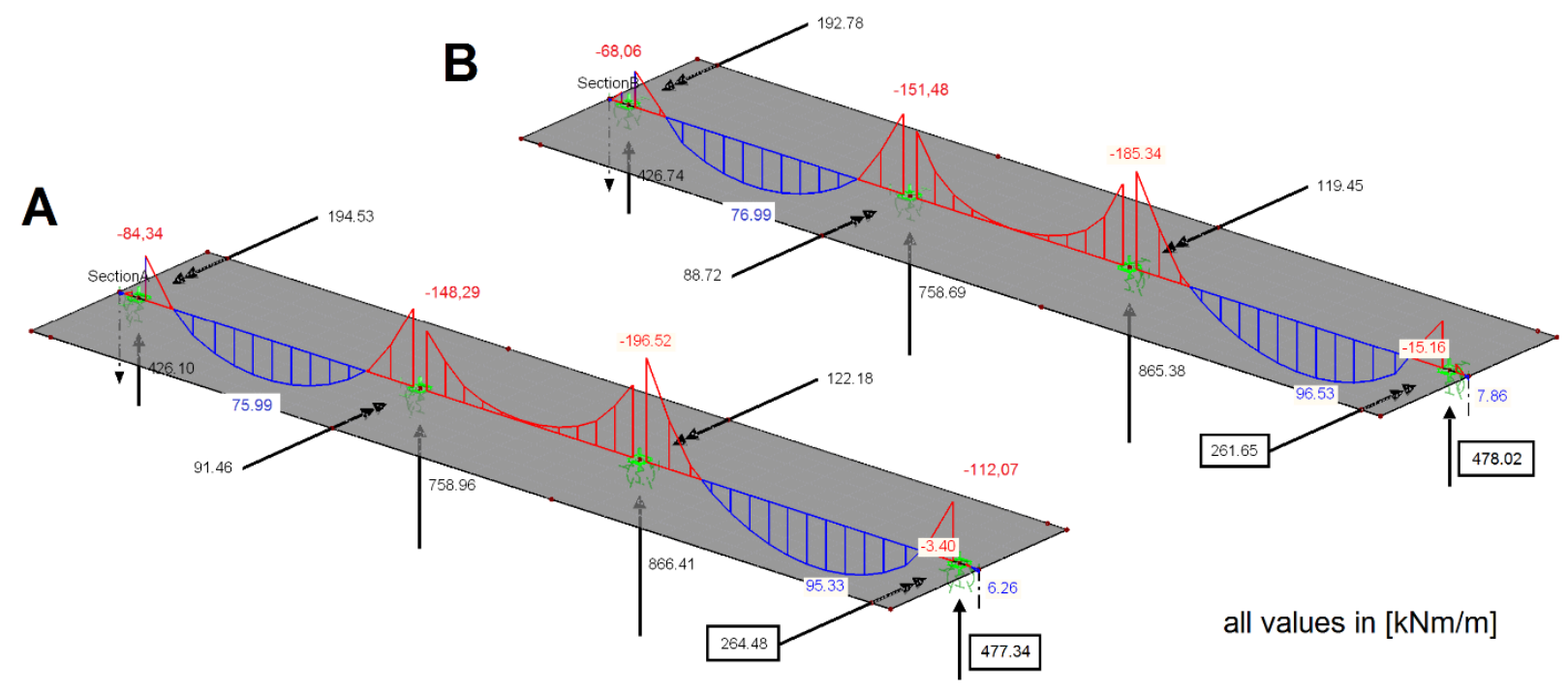

Figure A-8 - Moment diagram in the longitudinal direction and support reactions

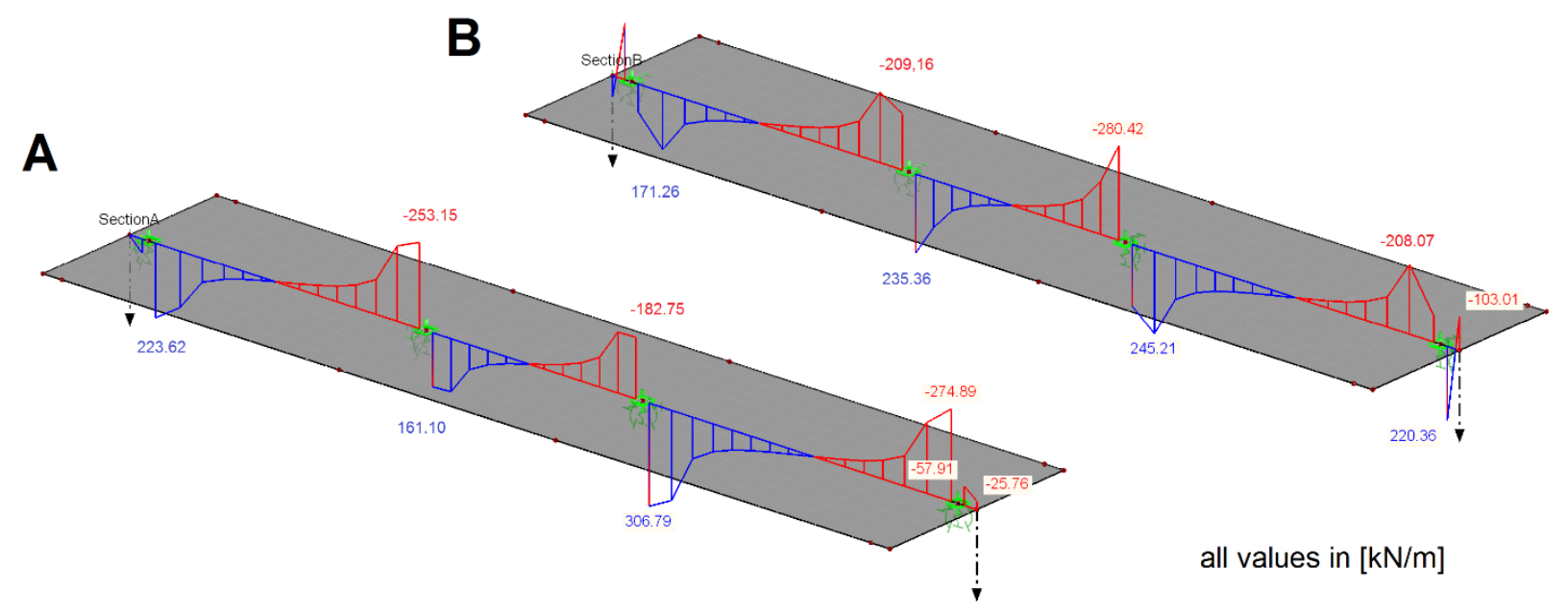

Figure A-9 - Shear diagram in the longitudinal direction

The values of the moment and shear diagrams are not useful as they only represent the path along the sections. The decisive values are the support reactions shown in Figure A-8.

The results within the column area are not displayed (= gap within the diagrams) as the values are not representative due to singularities in that area. 


\section{Comparison of Results}

The results of both calculations are collected in the following table. Remarkably the calculated values only differ slightly. The support moment calculated by the $\mathrm{C}_{0}-\mathrm{C}_{\mathrm{u}}$-method is slightly smaller (less than 4\%) than the moment obtained by the FE-calculation. The difference between the two different FE-models with different support conditions is negligible (1\%).

Table A-1 - Collection of calculated moments and shear forces

\begin{tabular}{|l|c|c|}
\hline & $\mathbf{M}_{\text {slab }}$ & $\mathbf{V}_{\text {slab }}$ \\
\hline $\mathbf{C}_{\mathrm{o}}-\mathbf{C}_{\mathrm{u}}$ method & $250,3 \mathrm{kNm}$ & - \\
\hline FEM (elastic node support) & $264,5 \mathrm{kNm}$ & $477,3 \mathrm{kN}$ \\
\hline FEM (elastic surface foundation) & $261,7 \mathrm{kNm}$ & $478,0 \mathrm{kN}$ \\
\hline Loaded Area $(8.3 \mathrm{~m} / 2+0,5 \mathrm{~m})^{\star} 5,4 \mathrm{~m}^{\star} 21 \mathrm{kN} / \mathrm{m}^{2}$ & - & $527,3 \mathrm{kN}$ \\
\hline
\end{tabular}

Chosen values for strut-and-tie models:

$M_{\text {slab }}=260 \mathrm{kNm}$

$\mathrm{V}_{\text {slab }}=480 \mathrm{kN}$

\section{A.3 STRUT-AND-TIE MODELS AND DIMENSIONING OF REINFORCEMENT}

In the main body of this paper, three strut-and-tie models were presented. In the following, the previously calculated moments and forces will be applied to these models. In a second step the struts, ties and nodes will be verified and specific reinforcement design solutions will be given.

\section{Explanation of Symbols and Illustrations}

The calculation of the forces within struts and ties was carried out with Microsoft Excel. The relevant parts of the calculation sheets are displayed on the following pages.

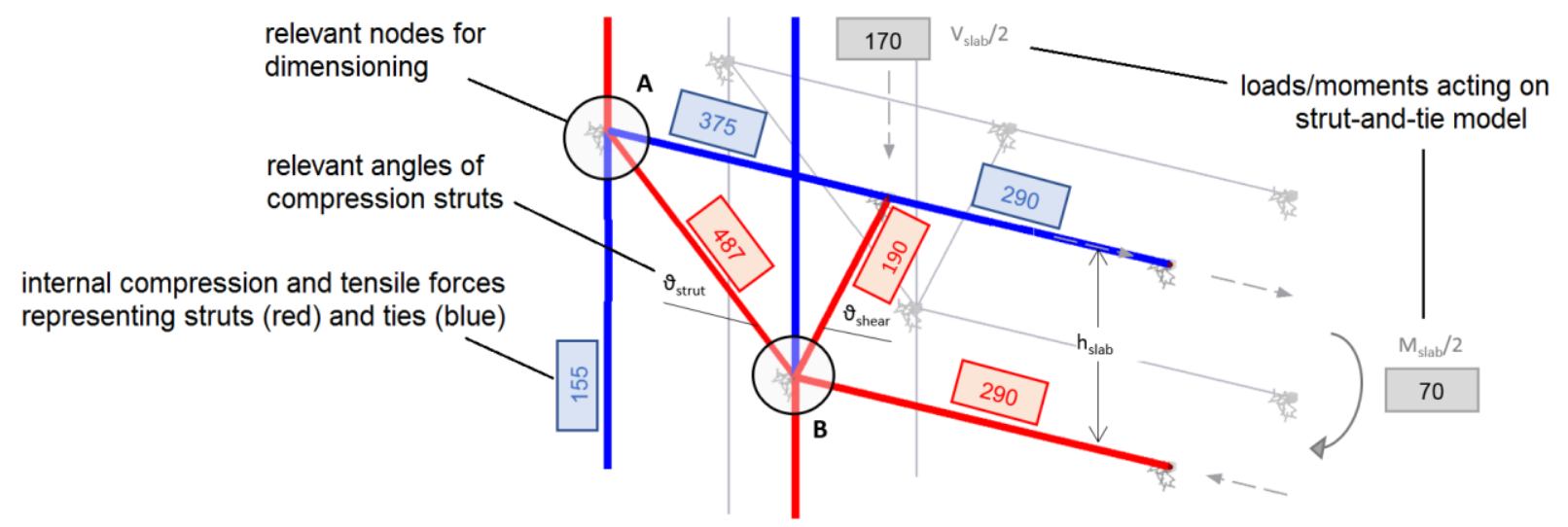

Figure A-10 - Explanations of symbols in strut-and-tie models 
For dimensioning of the complex nodes 3D-graphics were used as an illustration.
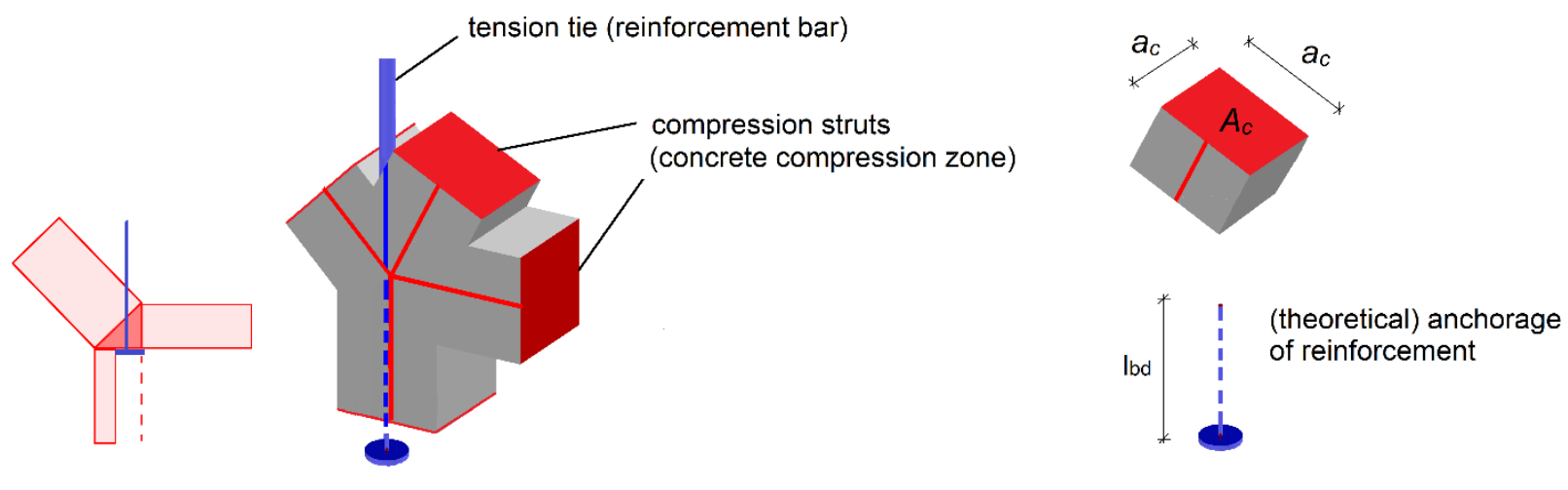

Figure A-11 - Explanation of symbols in nodal areas

The anchorage length of the ties that segue directly into compression struts (illustrated as a blue dashed line ending with an anchor head) is not verified. It is assumed that the tie is sufficiently anchored by verifying the facing compression strut.

Depending on whether we deal with a C-C or a C-T-node the design concrete strength $\sigma_{R d, \max }$ was calculated according to Table 4-1. Based on the design concrete strength and the actual compressive force within the strut the necessary surface area $A_{c}$ is calculated. To simplify the calculations, the three-dimensional strut is assumed to have a squared shape. According to this assumption, the side length $a_{c}$ is obtained by calculating the square root of the surface area.

Due to the fact that the struts do not exactly follow the squared shape, the calculated surface area needs to be evaluated on sound judgment. As a rule of thumb, the width of the compressive area should not exceed half of the present element length. Accordingly, the side length $a_{c}$ should be aimed to be roughly smaller than half of the column width $\left(c_{x}\right.$ and $\left.c_{y}\right)$ respectively half of the slab height $\left(h_{\text {slab }}\right)$. As for the diagonal compression strut, the required surface area can be slightly greater, as the surrounding slab provides greater space to spread out.

Beyond that, the estimated concrete strength $\sigma_{R d, \max }$ as mentioned above is a very conservative approach. As the connection is situated in an area of multiaxial compression, higher concrete strength up to $\sigma_{\mathrm{Rd}, \max } \leq 3,0 \mathrm{f}_{\mathrm{cd}}$ could be used, minimizing the required surface area of the compressive strut many times over. 


\section{General Remarks for the Reinforcement Design}

As for the calculation of the anchorage length, 'good' conditions are assumed for all bars. This is due to the fact that the height of the slab does not exceed the limit of $300 \mathrm{~mm}$ as explained in Chapter 6.1.4. The minimum mandrel diameters $\left(D_{\min }\right)$ are chosen according to Chapter 6.1.2 and the related tables.

The basic required anchorage length is dependent on the bond conditions and can be calculated according to ${ }^{8}: \quad l_{b, r q d}=\varnothing / 4 \times{ }^{\sigma_{s d}} /_{f_{b d}} \quad f_{b d}=2,25 x f_{c t d} \quad$ for $\emptyset \leq 32 \mathrm{~mm}$

For the calculation of the anchorage length in the following, the simplified method using an equivalent anchorage length $\mathrm{l}_{\mathrm{bd} \text {,eq }}$ for hooks and loops was used ${ }^{9}$ :

$l_{b d, e q}=\alpha_{1} \times l_{b, r q d} \times \frac{A_{s, r e q}}{A_{s, p r o v}}$

$\alpha_{1}=1,0$ for a straight bar

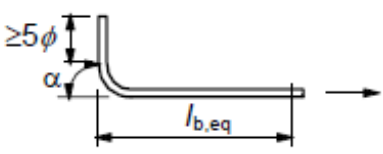

$\alpha_{1}=0,7 \quad$ other than straight bar

The required anchorage length can also be calculated according to ${ }^{10}$ :

$l_{b d}=\alpha_{1} \times \alpha_{3} \times \alpha_{4} \times \alpha_{5} \times l_{b, r q d} \times \frac{A_{s, r e q}}{A_{s, \text { prov }}} \geq \max \left\{0,3 \times \alpha_{1} \times \alpha_{4} \times l_{b, r q d} ; 10 \emptyset\right\}$

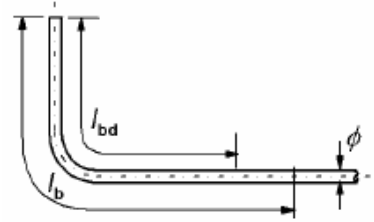

$0,7 \leq \alpha_{3} \leq 1,0$ for confinement by transverse bars not welded to main reinforcement

$\alpha_{4}=0,7 \quad$ for conf inement by welded transverse bars

$0,7 \leq \alpha_{5} \leq 1,0 \quad$ for confinement by transverse pressure

For the following calculations the simplified method is used as a conservative approach. However, for actual design it is recommended to calculate the anchorage length according to the more accurate equation in order to reduce the required anchorage length.

The anchorage length can be further reduced by increasing the cross-section of the reinforcement. This means installing more reinforcement $\left(A_{s, \text { prov }}\right)$ than actually needed to cover the tensile force $\left(A_{s, r e q}\right)$. Although this seems uneconomically at a first glance, this is common

8 DIN EN 1992-1-1 including German National Annex, 8.4.2 (8.2) and 8.4.3 (8.3)

${ }^{9}$ DIN EN 1992-1-1 including German National Annex, 8.4.4 (2)

10 DIN EN 1992-1-1 including German National Annex, 8.4 .4 (1) 
practice to reduce the anchorage length. However, as we are already facing limited space conditions in the area of the connection, it is unlikely that increasing the cross section of reinforcement is possible at all.

The required lap length is calculated according to ${ }^{11}$ :

$$
\begin{aligned}
& l_{0}=\alpha_{1} \times \alpha_{3} \times \alpha_{5} \times \alpha_{6} \times l_{b, r q d} \geq \max \left\{0,3 \times \alpha_{1} \times \alpha_{6} \times l_{b, r q d} ; 15 \emptyset ; 200 \mathrm{~mm}\right\} \\
& \alpha_{6}=2,0 \text { for }>33 \% \text { lapped bars relative to total cross }- \text { section area; } \emptyset>16 \mathrm{~mm}
\end{aligned}
$$

Again the values of $\alpha_{3}$ and $\alpha_{5}$ are set to zero, as a conservative approach.

Another rule that has to be taken into account with regard to the detailing of reinforcement is the spacing of bars. According to the EC the clear distance between two bars should be ${ }^{12}$ :

$$
a \geq\{\varnothing ; 20 m m\}
$$

Lapped bars may be allowed to touch each other within the lap length.

${ }^{11}$ DIN EN 1992-1-1 including German National Annex, 8.7 .3 (1)

12 DIN EN 1992-1-1 including German National Annex, 8.2 (2) 


\section{SIMPLE MODEL CHARGED WITH BENDING MOMENT AND SHEAR}

Strut-and-tie model: $\quad$ all forces in [kN], all moments in [kNm]

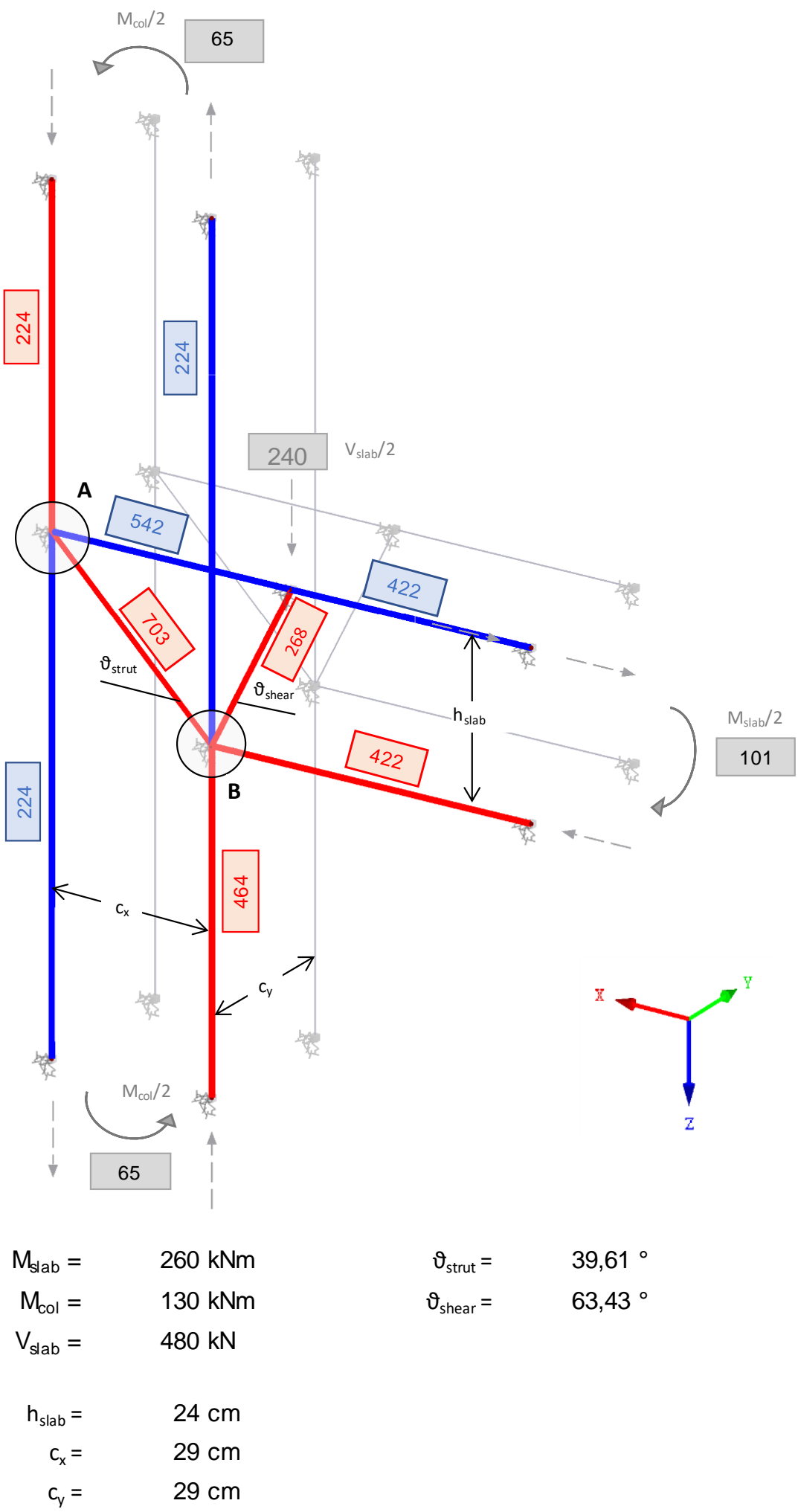




\section{Dimensioning of node A}

$\mathrm{k}_{3, \mathrm{t}}=0,75 \quad$ for C-T-nodes

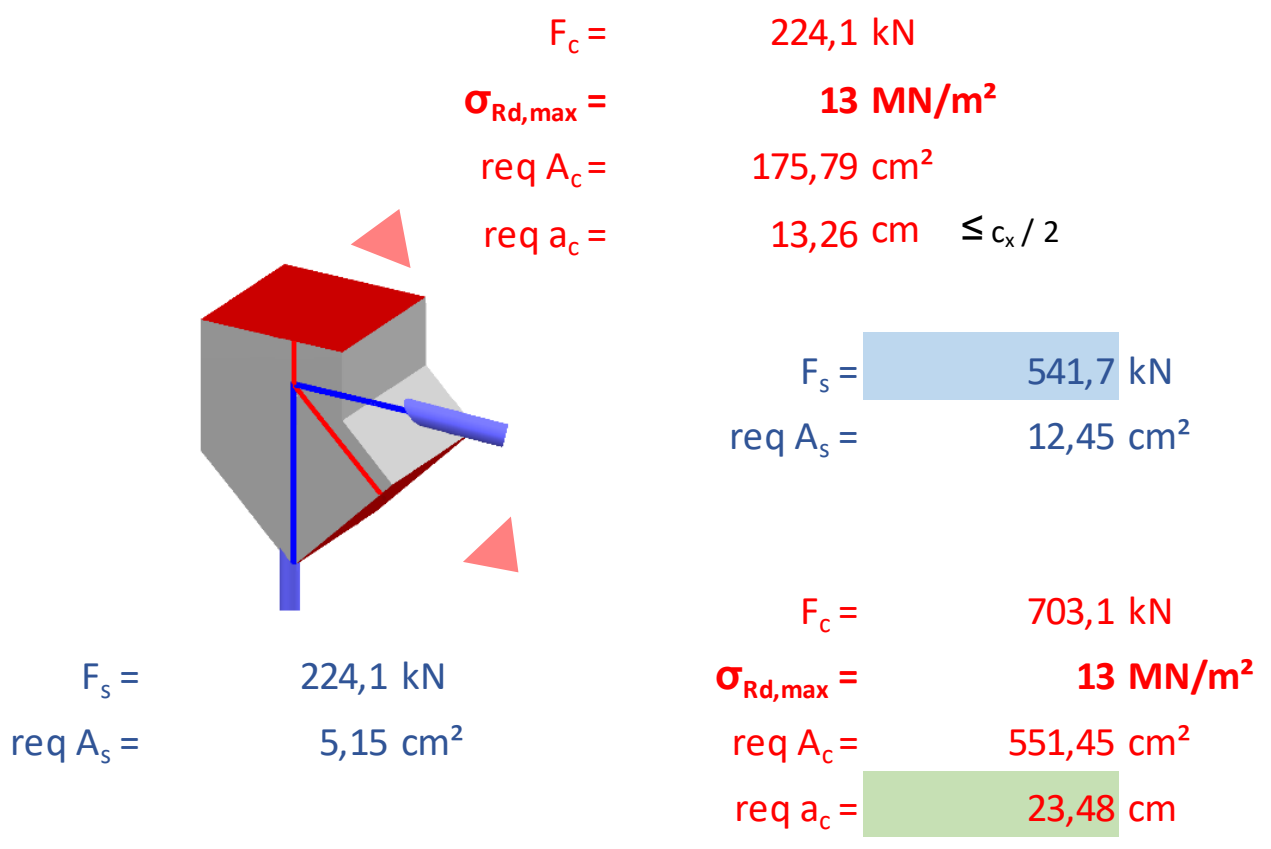

\section{Dimensioning of node B}

$$
\begin{aligned}
& k_{3, c}=1,10 \quad \text { for C-C-nodes } \\
& F_{s d}=\quad 224,1 \mathrm{kN} \quad F_{c}=268,3 \mathrm{kN} \\
& \text { req } A_{s d}=\quad 5,15 \mathrm{~cm}^{2} \quad \sigma_{\mathrm{R}, \max }=19 \mathrm{MN} / \mathrm{m}^{2} \\
& \mathrm{~F}_{\mathrm{c}}=703,1 \mathrm{kN} \quad \text { req } \mathrm{a}_{\mathrm{c}}=11,98 \mathrm{~cm} \\
& \sigma_{\mathrm{Rd}, \max }=19 \mathrm{MN} / \mathrm{m} \\
& \text { req } A_{c}=375,99 \mathrm{~cm}^{2} \\
& \text { req } \mathrm{a}_{\mathrm{c}}=19,39 \mathrm{~cm} \\
& \mathrm{~F}_{\mathrm{c}}=\quad 464,1 \mathrm{kN} \\
& \sigma_{\mathrm{Rd}, \max }=19 \mathrm{MN} / \mathrm{m} \\
& \text { req } A_{c}=248,20 \mathrm{~cm}^{2} \\
& \text { req } \mathrm{a}_{\mathrm{c}}=\quad 15,75 \mathrm{~cm} \quad \mathrm{c}_{\mathrm{x}} / 2
\end{aligned}
$$

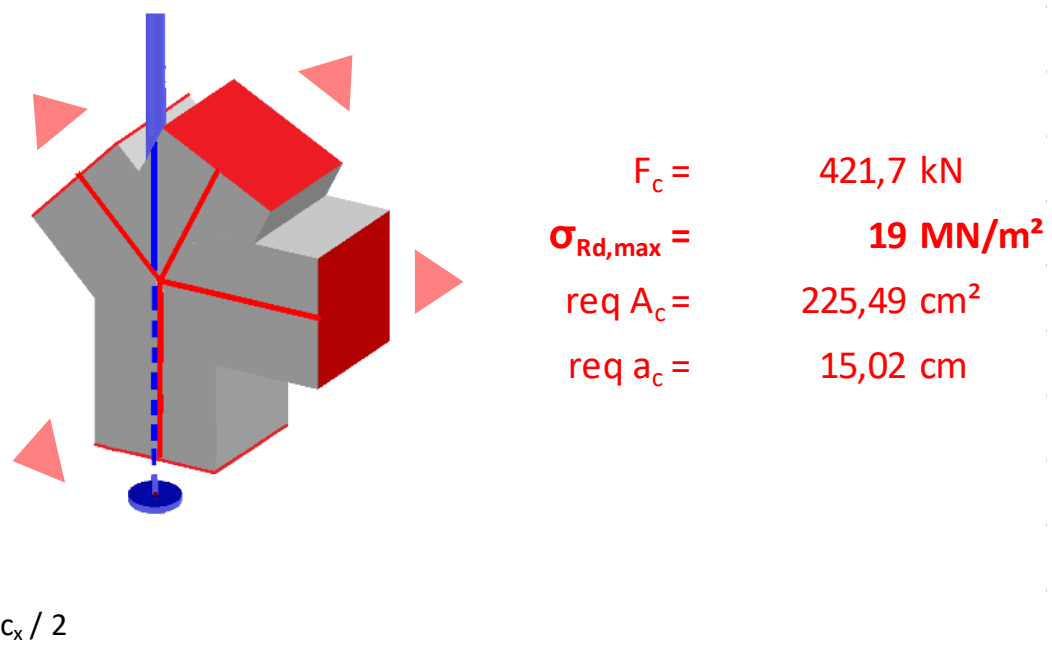




\section{Verification of the diagonal compression strut}

As the strut lies within the slab a full discontinuity region is assumed.

$$
\begin{array}{rr}
\mathrm{F}_{\mathrm{c}}= & \quad 703 \mathrm{kN} \\
\mathrm{h}= & 18,82 \mathrm{~cm} \\
\mathrm{a}= & 23,48 \mathrm{~cm} \\
\mathrm{~b}_{\mathrm{ef}}= & 34,09 \mathrm{~cm}
\end{array}
$$

Transverse tensile force in compression field:

$$
\begin{aligned}
T & = & 22,3 \mathrm{kN} \\
\text { req } A_{s}= & & 0,51 \mathrm{~cm}^{2}
\end{aligned}
$$

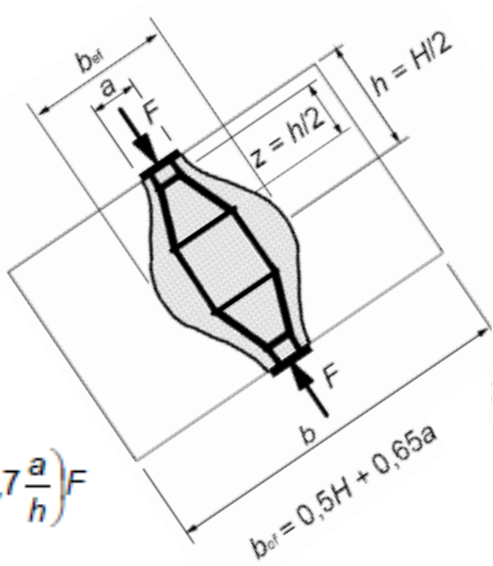

As the transverse tensile forces, which result from the spread of the concrete strut, are relatively small, it can be assumed that they are absorbed by the slab reinforcement.

Determination of the mandrel diameter, anchorage length and lap length (Node A)

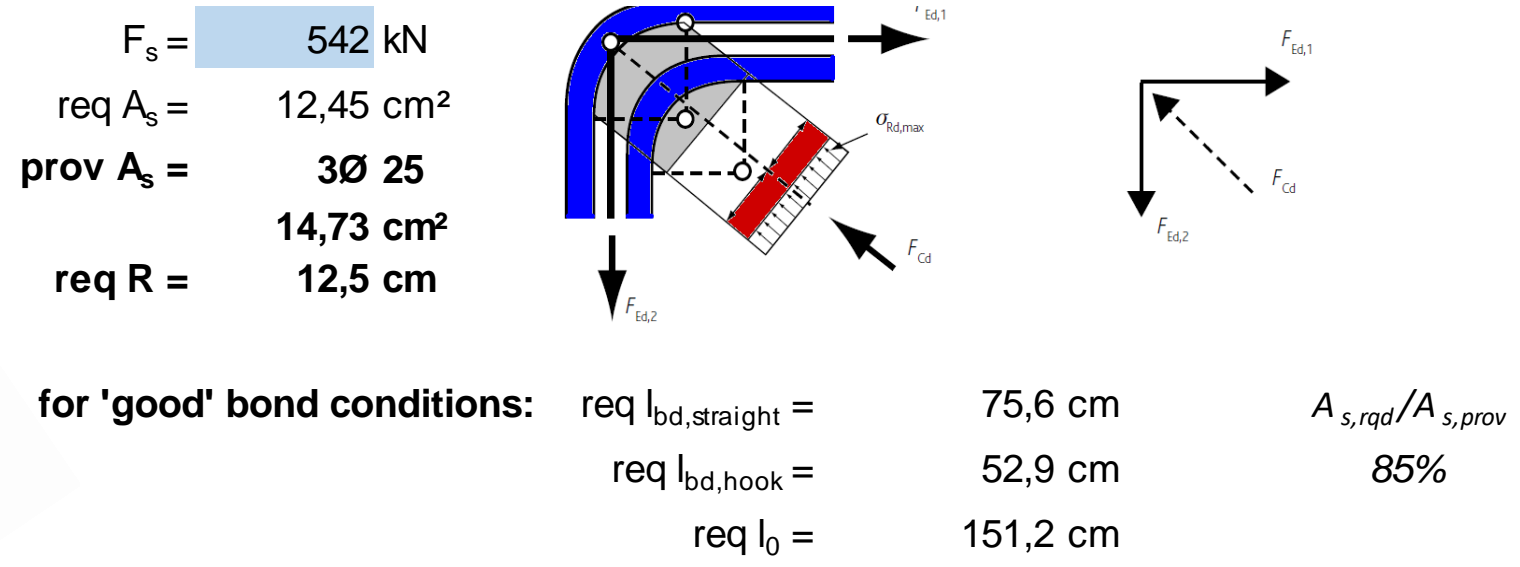

\begin{tabular}{|c|c|c|c|c|c|c|}
\hline $\boldsymbol{Ø}_{\text {bar }}$ & $\mathbf{A}_{\mathbf{s , \text { bar }}}$ & req D (10Ø) & req $\mathbf{R}$ & req $_{\mathbf{b d}, \text { straight }}$ & req $\mathbf{~}_{\text {bd,hook }}$ & req $\mathbf{I}_{\mathbf{0}}$ \\
\hline$[\mathrm{mm}]$ & {$\left[\mathrm{cm}^{2}\right]$} & {$[\mathrm{mm}]$} & {$[\mathrm{cm}]$} & {$[\mathrm{cm}]$} & {$[\mathrm{cm}]$} & {$[\mathrm{cm}]$} \\
\hline $\mathbf{1 6}$ & 2,01 & 160 & 8 & 57,2 & 40,1 & 114,5 \\
\hline $\mathbf{2 0}$ & 3,14 & 200 & 10 & 71,5 & 50,1 & 143,1 \\
\hline $\mathbf{2 5}$ & 4,91 & 250 & 13 & 89,4 & 62,6 & 178,9 \\
\hline $\mathbf{2 8}$ & 6,16 & 280 & 14 & 100,2 & 70,1 & 200,3 \\
\hline
\end{tabular}



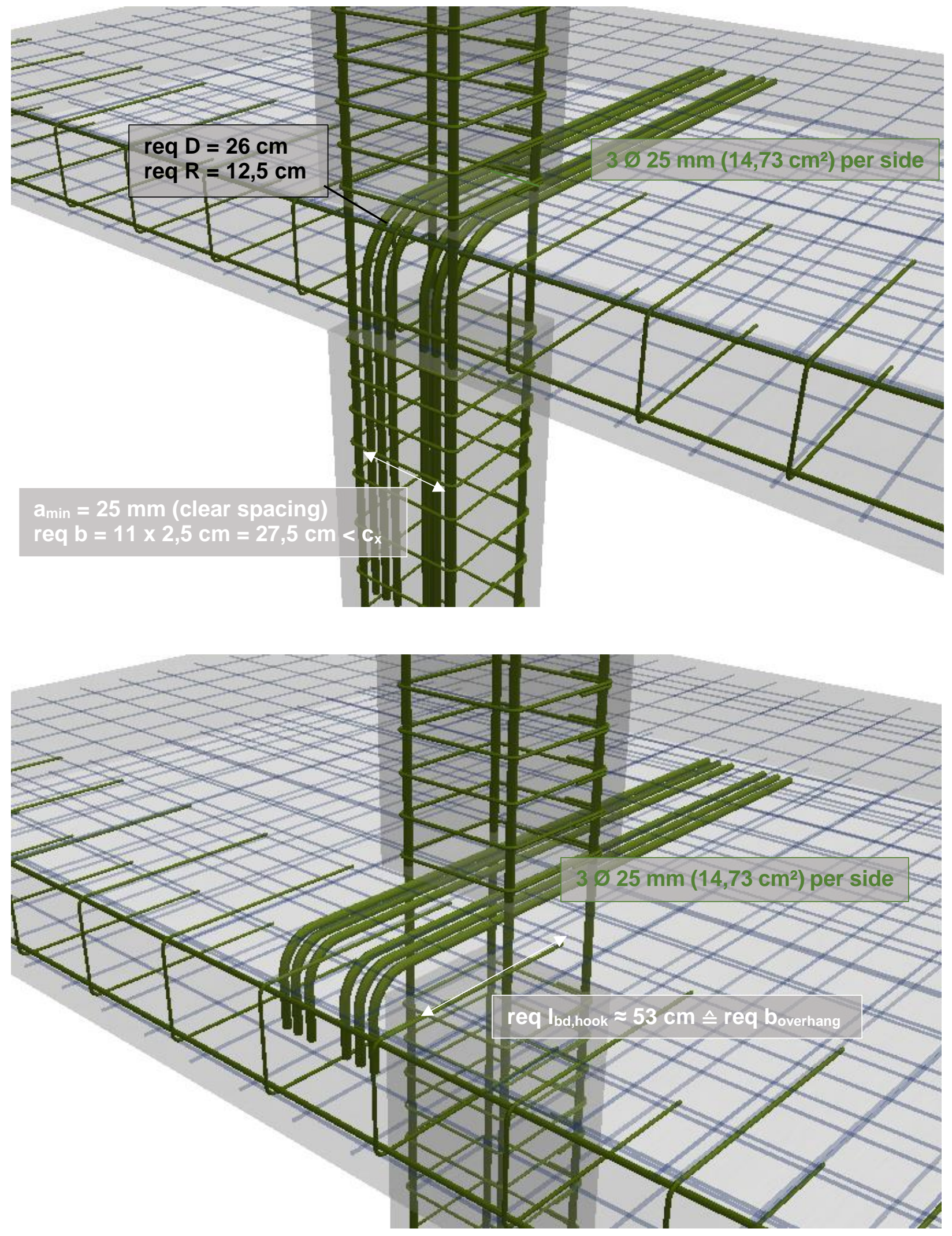

Due to the required anchorage length the overhang must be at least $53 \mathrm{~cm}$ long. 
MODEL WITH HORIZONTAL REINFORCEMENT LOOP

Strut-and-tie model: all forces in [kN], all moments in [kNm]

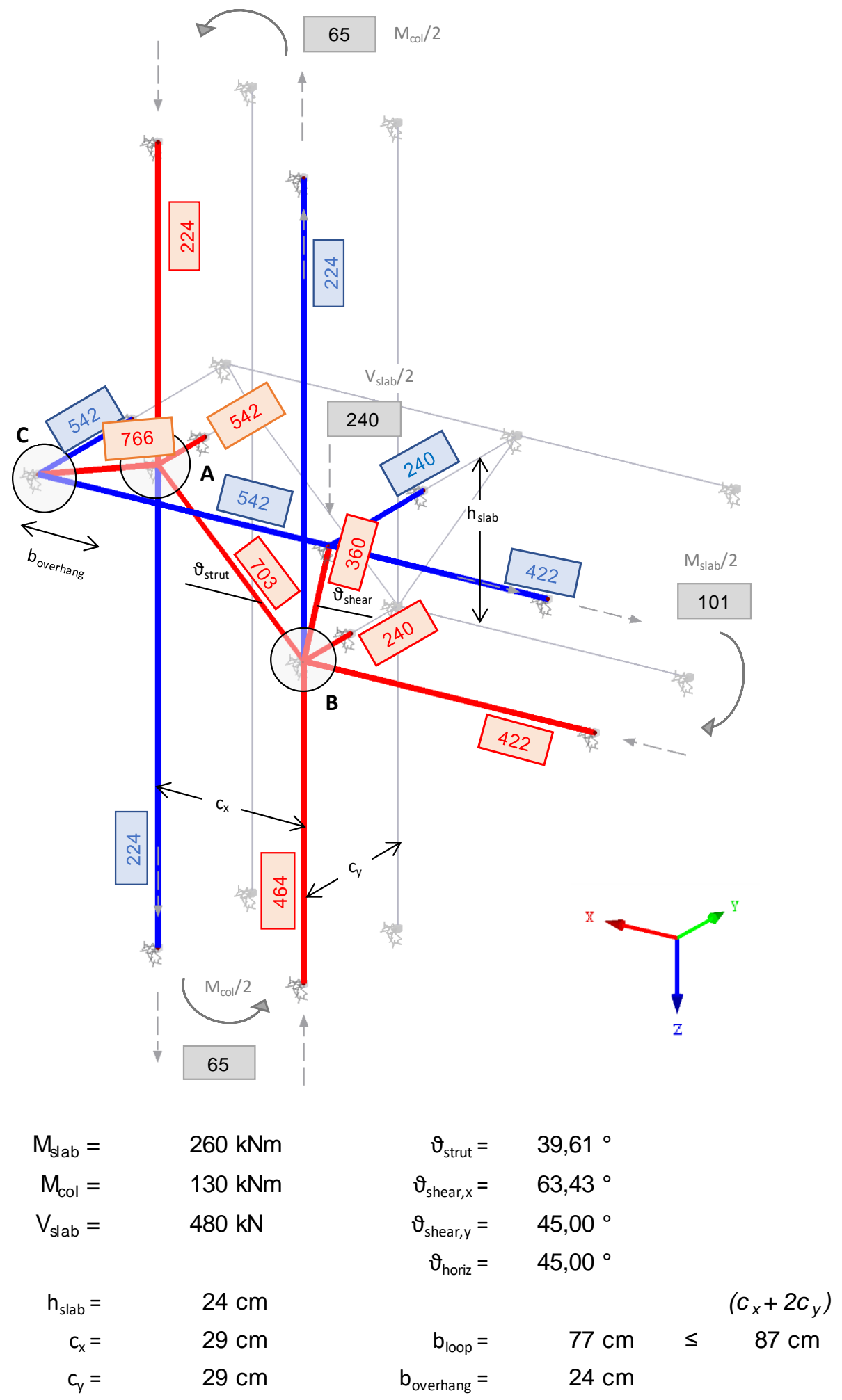

69 


\section{Dimensioning of node A}

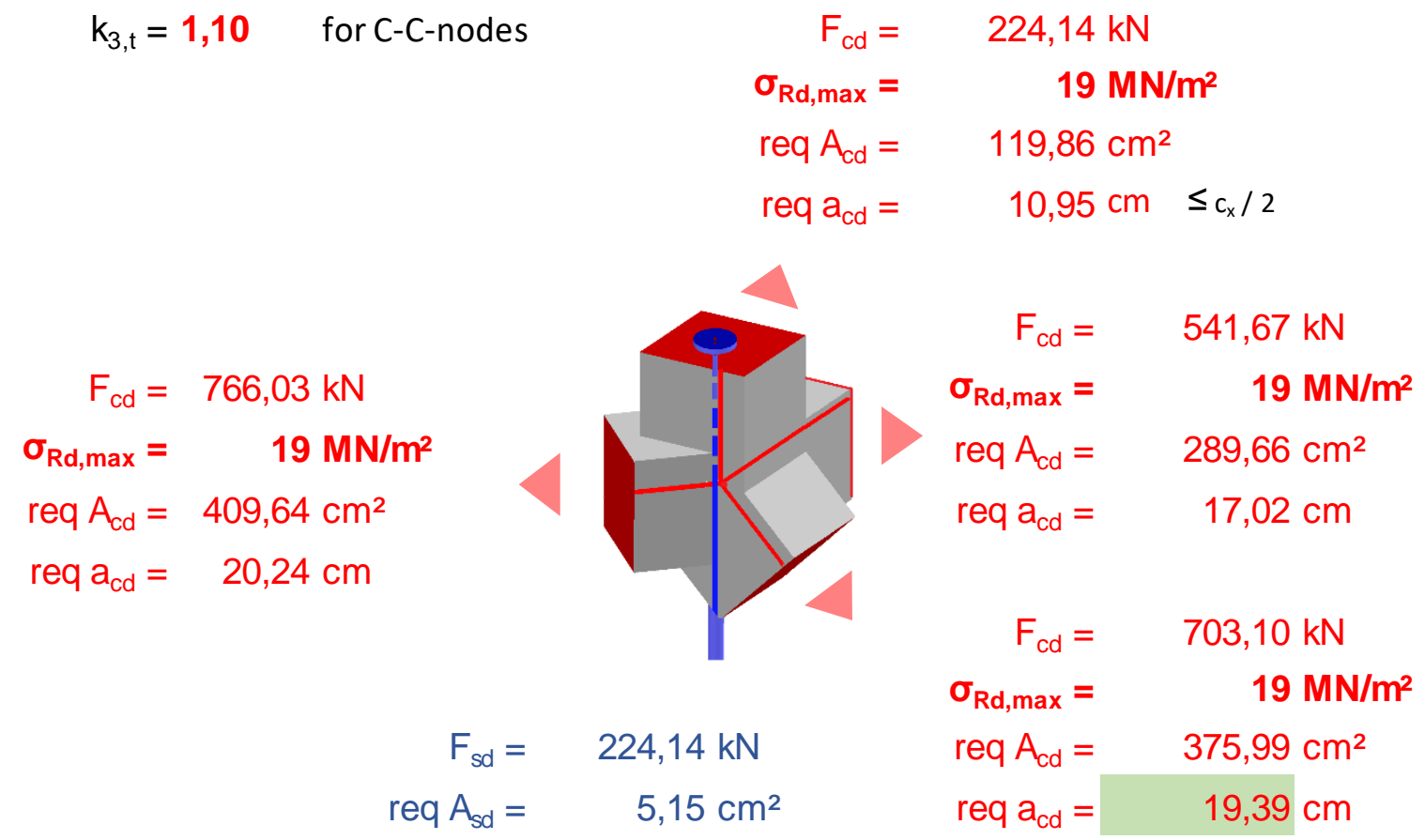

\section{Dimensioning of node B}

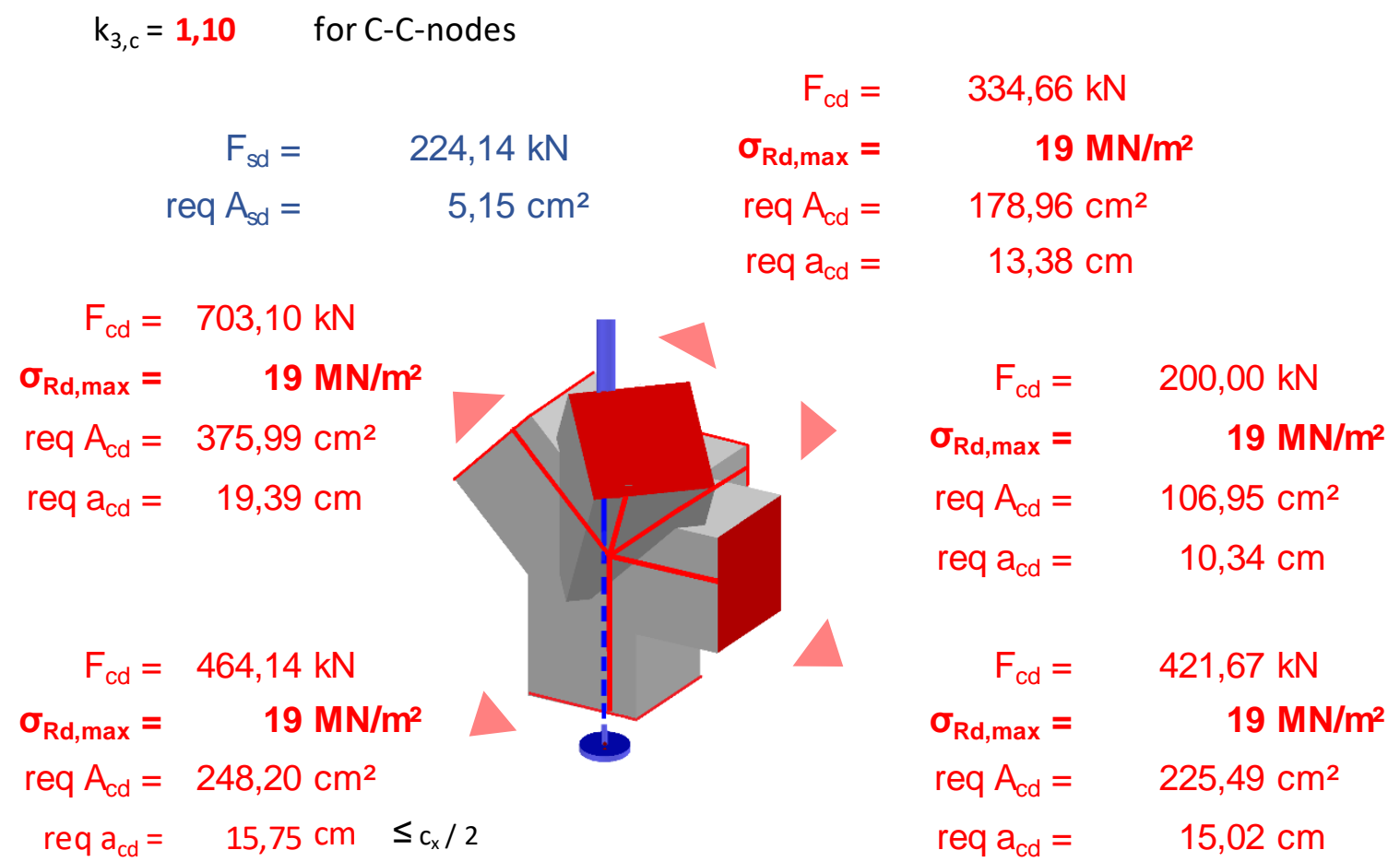


Verification of the diagonal compression strut

As the strut lies within the slab a full discontinuity region is assumed.

$$
\begin{aligned}
\mathrm{F}_{\mathrm{c}}= & & 703 \mathrm{kN} \\
\mathrm{h}= & & 18,82 \mathrm{~cm} \\
\mathrm{a}= & & 19,39 \mathrm{~cm} \\
\mathrm{~b}_{\mathrm{ef}}= & & 31,43 \mathrm{~cm}
\end{aligned}
$$

Transverse tensile force in compression field:

$$
\begin{aligned}
\mathrm{T} & = & & 49,0 \mathrm{kN} \\
\text { req } \mathrm{A}_{\mathrm{s}} & = & & 1,13 \mathrm{~cm}^{2}
\end{aligned}
$$

$$
T=\frac{1}{4}\left(1-0,7 \frac{a}{h}\right) F
$$

Determination of the mandrel diameter (Dimensioning of node C)

$$
\begin{aligned}
& F_{\mathrm{s}}=\quad 542 \mathrm{kN} \\
& \text { req } A_{s}=12,45 \mathrm{~cm}^{2} \\
& \text { prov } A_{s}=4 \varnothing 20 \\
& \text { req } R=\begin{array}{r}
12,56 \mathrm{~cm}^{2} \\
20 \mathrm{~cm}
\end{array} \\
& \text { ( } \wedge \text { req } b_{\text {overhang }} \text { ) }
\end{aligned}
$$
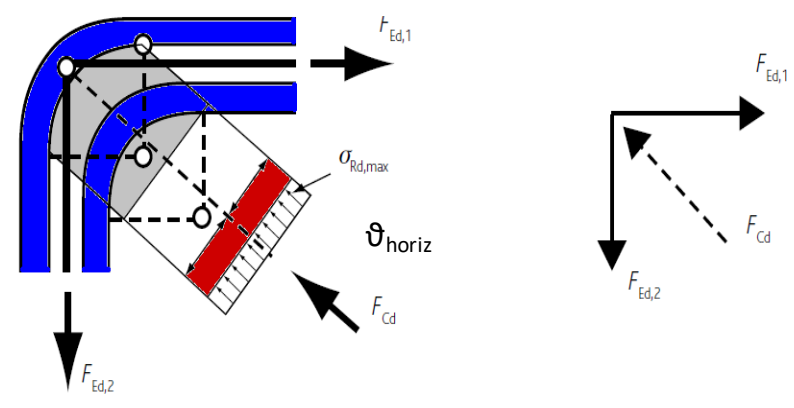

\begin{tabular}{|c|c|c|c|}
\hline $\boldsymbol{\varnothing}_{\text {bar }}$ & $\mathbf{A}_{\text {s,bar }}$ & req D (20Ø) & req R \\
\hline$[\mathrm{mm}]$ & {$\left[\mathrm{cm}^{2}\right]$} & {$[\mathrm{mm}]$} & {$[\mathrm{cm}]$} \\
\hline $\mathbf{1 6}$ & 2,01 & 320 & 16 \\
\hline $\mathbf{2 0}$ & 3,14 & 400 & 20 \\
\hline $\mathbf{2 5}$ & 4,91 & 500 & 25 \\
\hline $\mathbf{2 8}$ & 6,16 & 560 & 28 \\
\hline
\end{tabular}




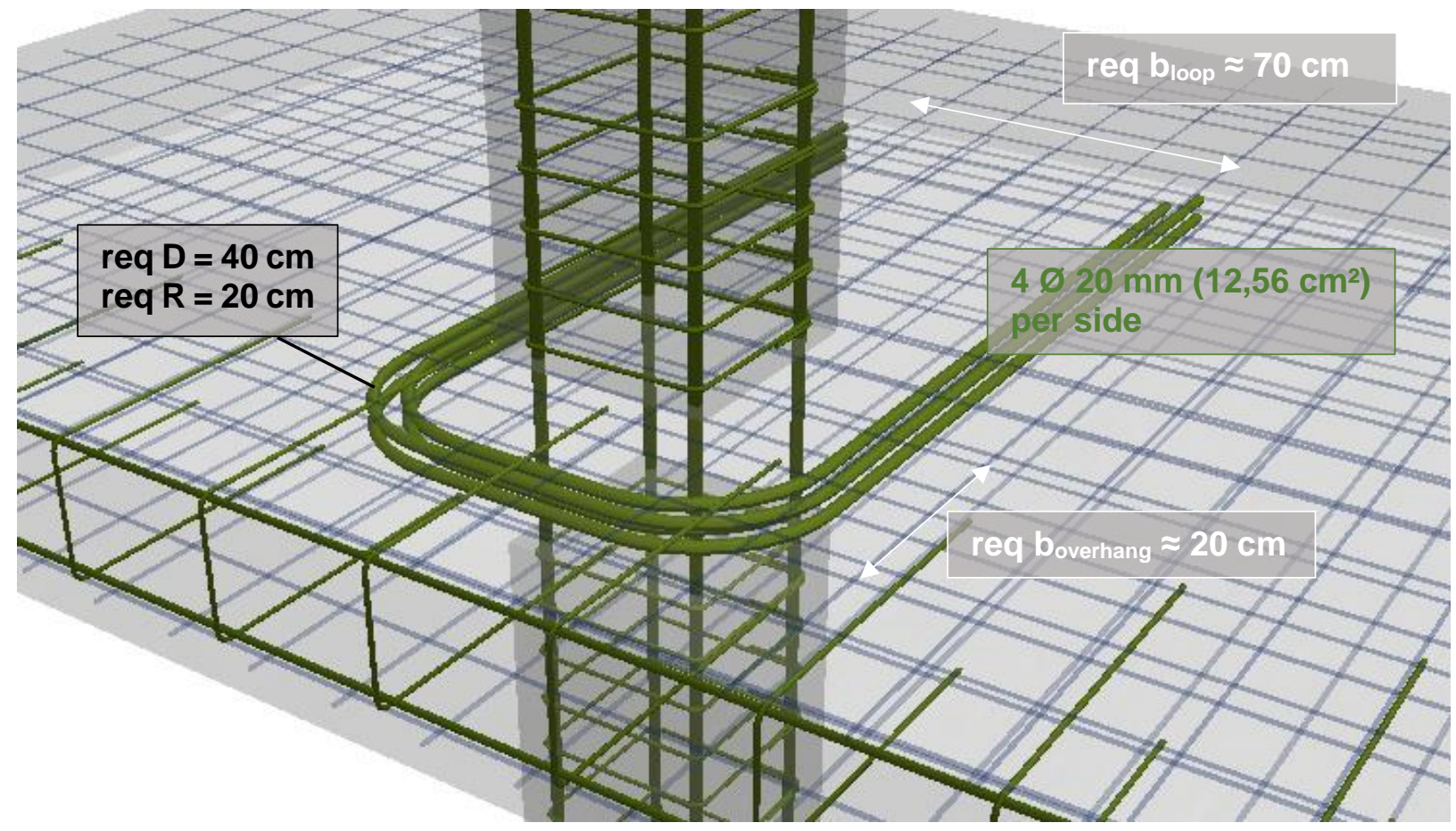

The required length of the overhang is only about $20 \mathrm{~cm}$, which is much less than the length required for anchoring the bars in the first model $(\approx 53 \mathrm{~cm})$. 


\section{COMBINED MODEL WITH OUTSOURCED REINFORCEMENT}

Strut-and-tie model: $\quad$ all forces in [kN], all moments in [kNm]

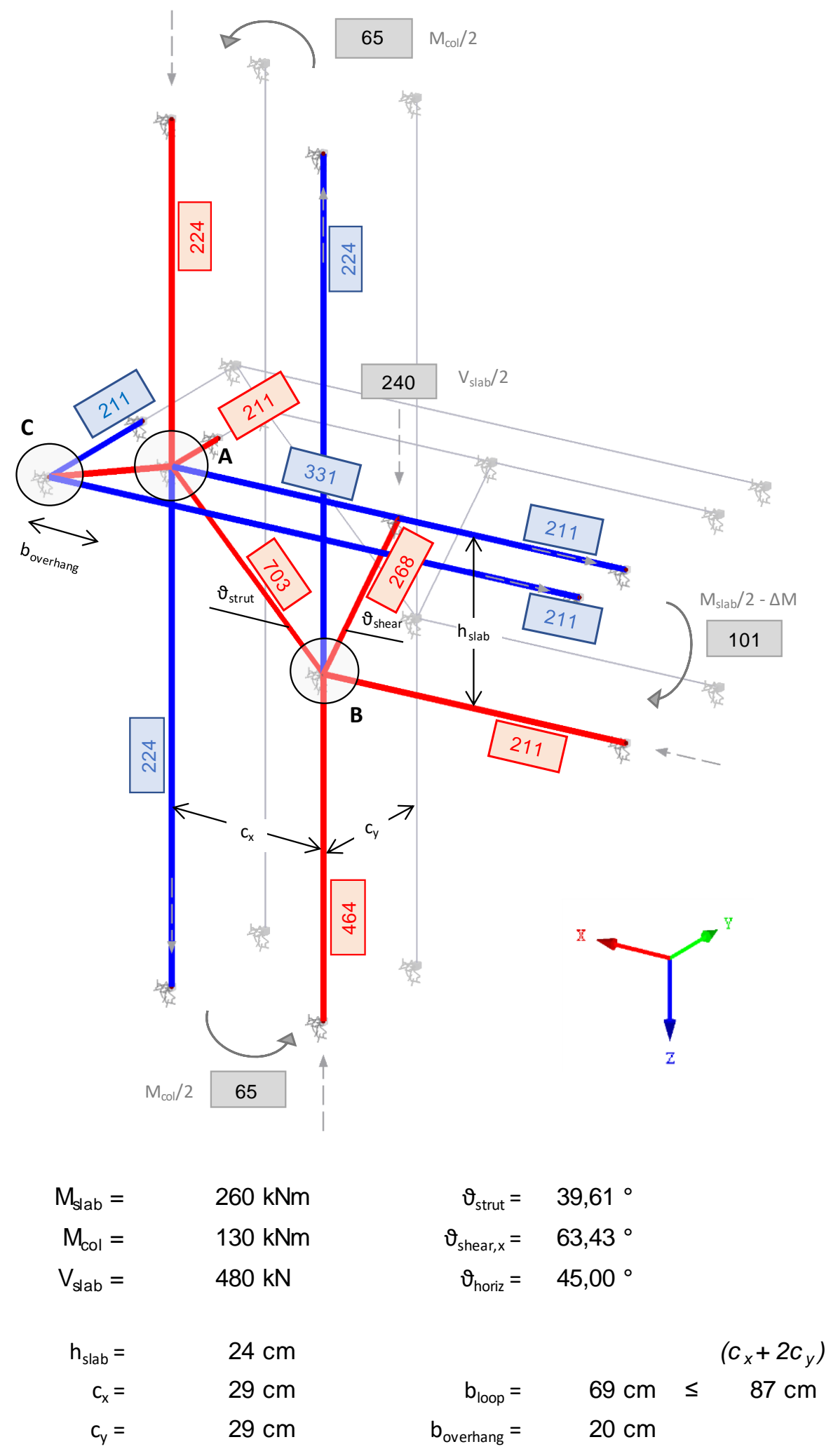




\section{Dimensioning of node A}

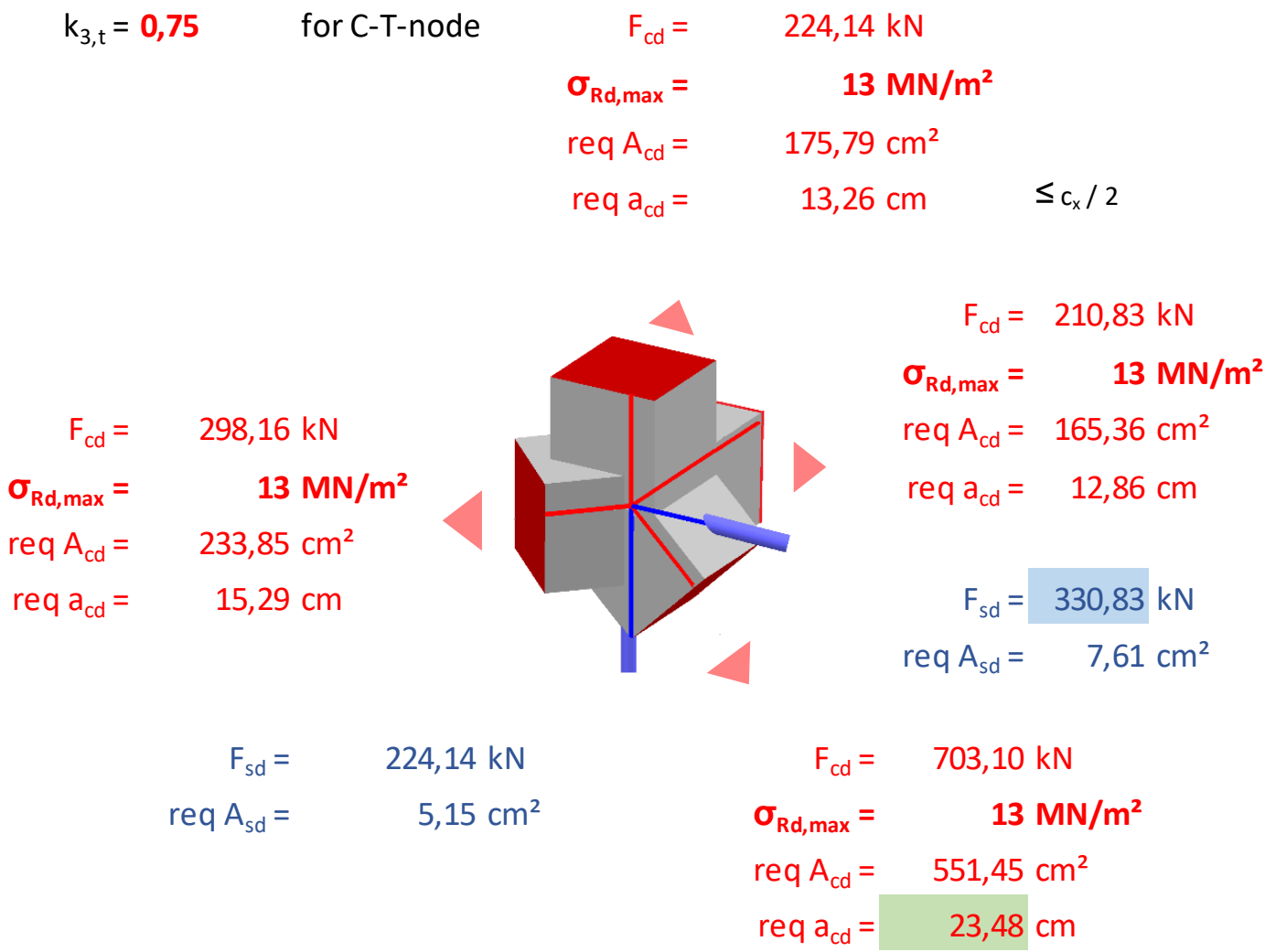

\section{Dimensioning of node B}

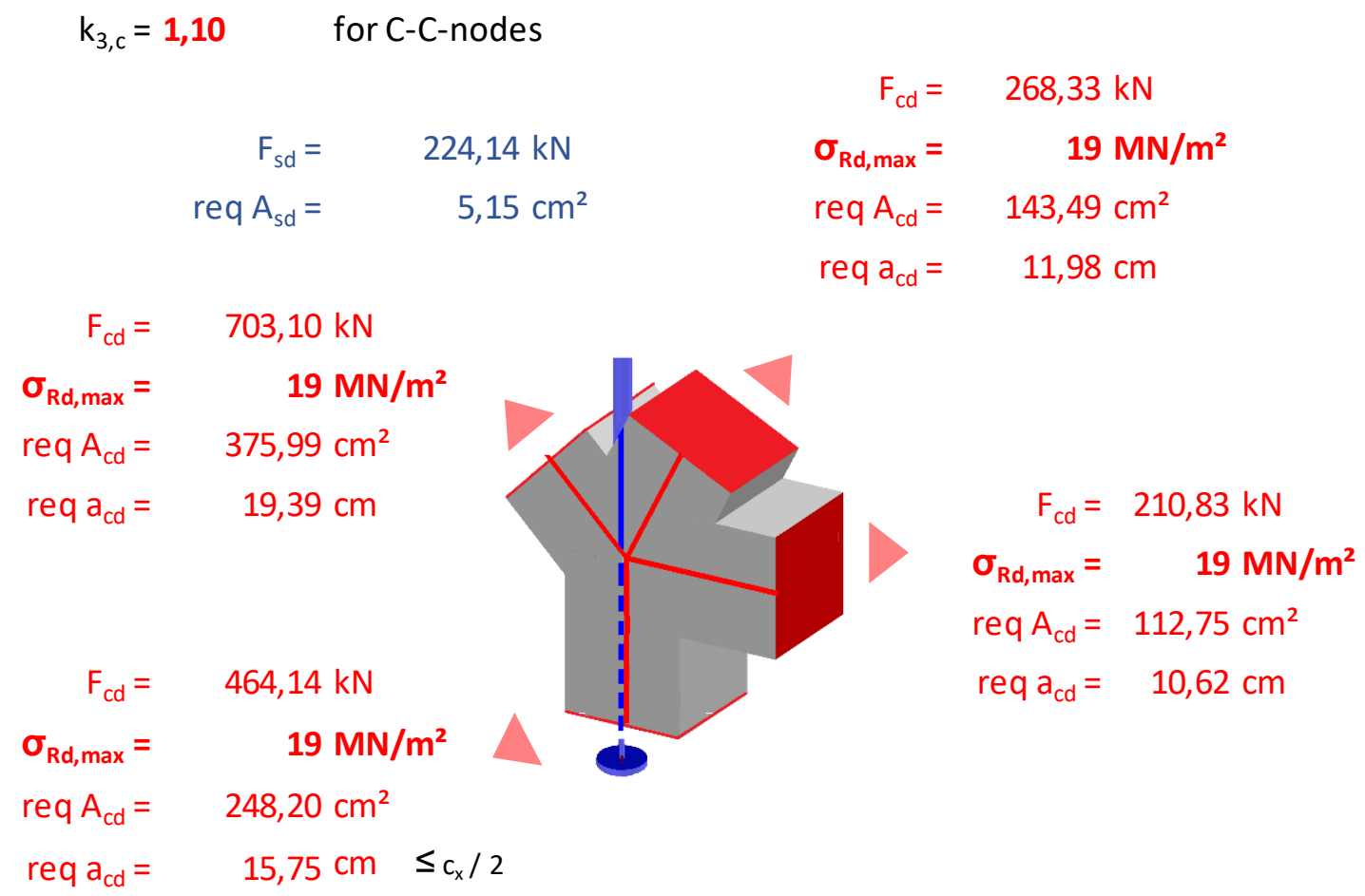


Verification of the diagonal compression strut

As the strut lies within the slab a full discontinuity region is assumed.

$$
\begin{array}{rrr}
\mathrm{F}_{\mathrm{c}}= & & 703 \mathrm{kN} \\
\mathrm{h}= & & 18,82 \mathrm{~cm} \\
\mathrm{a}= & 23,48 \mathrm{~cm} \\
\mathrm{~b}_{\mathrm{ef}}= & & 34,09 \mathrm{~cm}
\end{array}
$$

Transverse tensile force in compression field:

$$
\begin{array}{rlrl}
\mathrm{T} & = & 22,3 \mathrm{kN} & \\
\text { req } \mathrm{A}_{\mathrm{s}}= & & 0,51 \mathrm{~cm}^{2} & T=\frac{1}{4}\left(1-0,7 \frac{\mathrm{a}}{h}\right) \mathrm{F}
\end{array}
$$

Determination of the mandrel diameter (Dimensioning of node C)

$$
\begin{aligned}
& \mathrm{F}_{\mathrm{s}}=\quad 211 \mathrm{kN} \\
& \text { req } A_{s}=\quad 4,85 \mathrm{~cm}^{2} \\
& \text { prov } A_{s}=\quad 2020 \\
& \text { req } R=\begin{array}{r}
6,28 \mathrm{~cm}^{2} \\
20 \mathrm{~cm}
\end{array} \\
& \left(\leq b_{\text {overhang }}\right)
\end{aligned}
$$
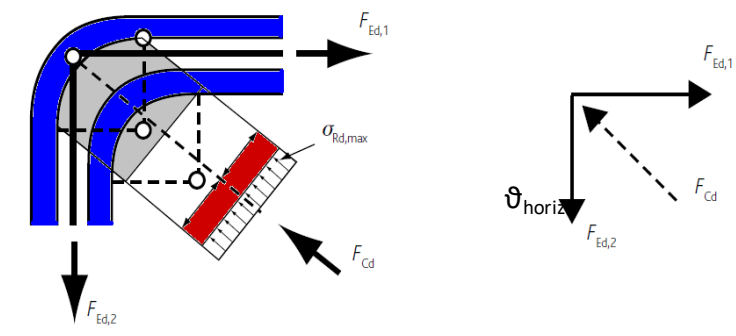

\begin{tabular}{|c|c|c|c|}
\hline $\boldsymbol{Ø}_{\text {bar }}$ & $\mathbf{A}_{\text {s,bar }}$ & req D (20Ø) & req R \\
\hline$[\mathrm{mm}]$ & {$\left[\mathrm{cm}^{2}\right]$} & {$[\mathrm{mm}]$} & {$[\mathrm{cm}]$} \\
\hline $\mathbf{1 6}$ & 2,01 & 320 & 16 \\
\hline $\mathbf{2 0}$ & 3,14 & 400 & 20 \\
\hline $\mathbf{2 5}$ & 4,91 & 500 & 25 \\
\hline $\mathbf{2 8}$ & 6,16 & 560 & 28 \\
\hline
\end{tabular}


Determination of the mandrel diameter, anchorage length and lap length (Node A)

$\begin{aligned} F_{s}= & 331 \mathrm{kN} \\ \text { req } A_{s}= & 7,61 \mathrm{~cm}^{2} \\ \text { prov } A_{s}= & \quad 30 \mathbf{2 0} \\ \text { req } \mathbf{R}= & 9,42 \mathrm{~cm}^{2} \\ & \mathbf{1 0} \mathbf{c m}\end{aligned}$
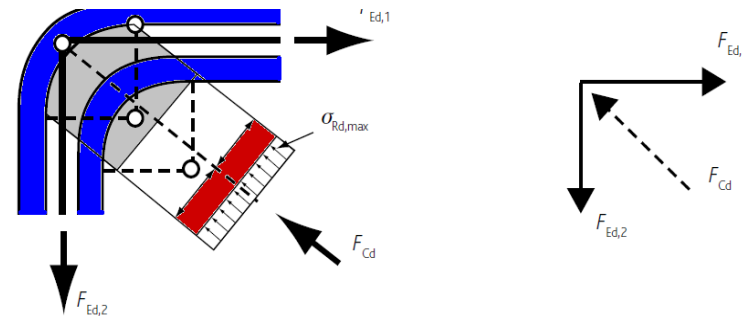

for 'good' bond conditions:

$$
\begin{array}{r}
\text { req } I_{b d, \text { straight }}= \\
\text { req } l_{b d, \text { hook }}= \\
\text { req } I_{0}=
\end{array}
$$

$A_{s, \text { rqd }} / A_{s, \text { prov }}$

$57,8 \mathrm{~cm}$

\begin{tabular}{|c|c|c|c|c|c|c|}
\hline$\varnothing_{\text {bar }}$ & $A_{s, \text { bar }}$ & req D (10Ø) & req $R$ & req $I_{b d, \text { straight }}$ & req $I_{\text {bd,hook }}$ & req $I_{0}$ \\
\hline [mm] & {$\left[\mathrm{cm}^{2}\right]$} & {$[\mathrm{mm}]$} & {$[\mathrm{cm}]$} & {$[\mathrm{cm}]$} & {$[\mathrm{cm}]$} & {$[\mathrm{cm}]$} \\
\hline 16 & 2,01 & 160 & 8 & 57,2 & 40,1 & 114,5 \\
\hline 20 & 3,14 & 200 & 10 & 71,5 & 50,1 & 143,1 \\
\hline 25 & 4,91 & 250 & 13 & 89,4 & 62,6 & 178,9 \\
\hline 28 & 6,16 & 280 & 14 & 100,2 & 70,1 & 200,3 \\
\hline
\end{tabular}

$81 \%$

$115,5 \mathrm{~cm}$

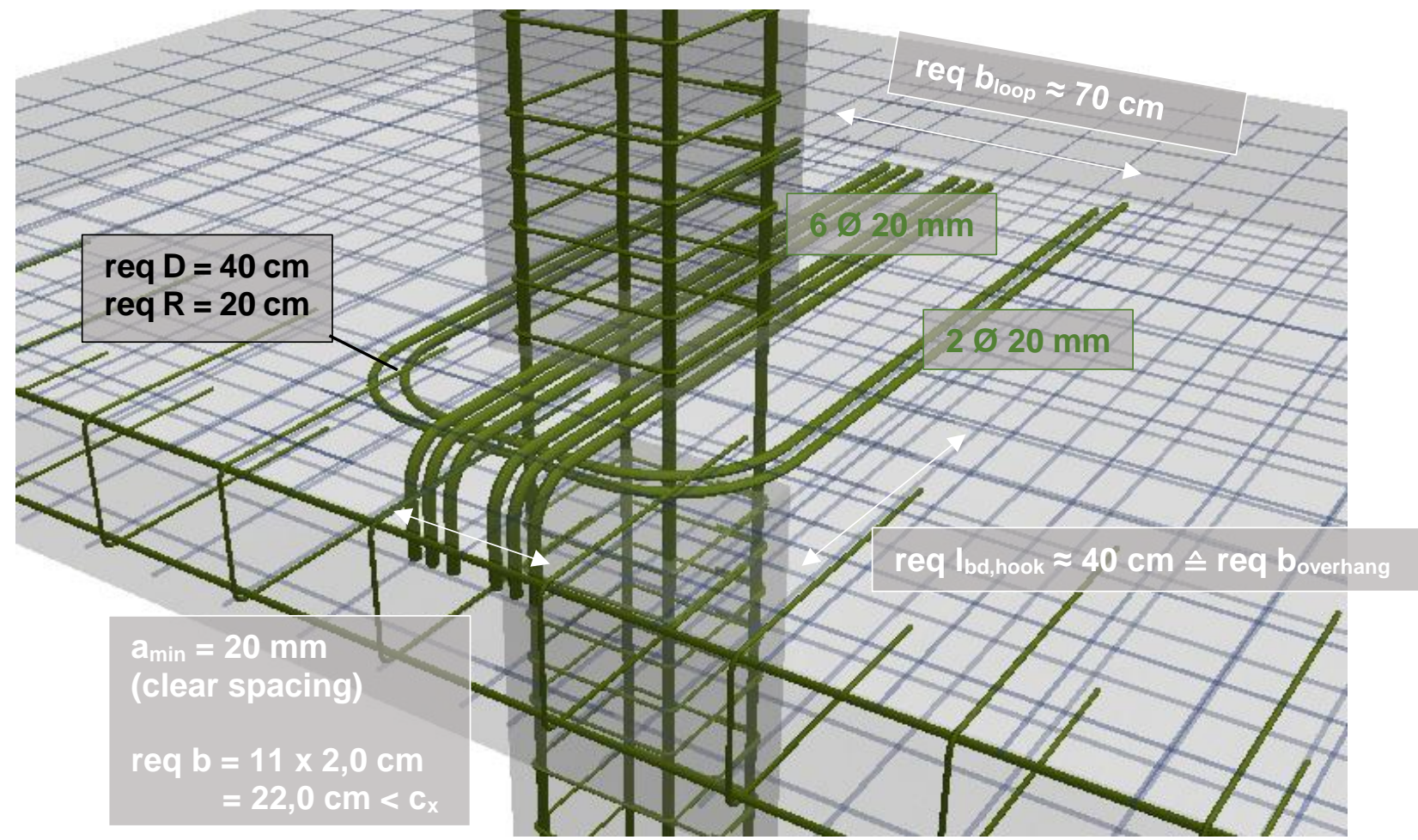




\section{A.4 RELATION TO SHEAR SLENDERNESS}

In Chapter 1.1.2 a limit value set by the $\mathrm{ACl}$ for the consideration of moment transfer was presented. This limit value is based on the shear slenderness of the slab, which shall be used as a reference value for the magnitude of the moments in the following.

The EC gives the following equation to calculate the shear slenderness ${ }^{13}$.

$$
\lambda=\frac{M_{d}}{V_{d} \times d}
$$

As for the purpose of using the shear slenderness $\lambda$ as a reference value for the choice of a suitable reinforcement arrangement in Chapter 7.2, the equation is linked (simplistically) to a simply fixed end beam charged with a uniformly distributed load, as shown in Figure A-12 . .

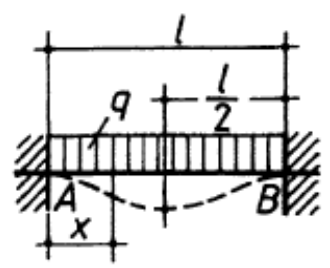

$$
A=B=\frac{q l}{2}
$$

$$
\begin{aligned}
& M(x)=-\frac{q l^{2}}{2}\left(\frac{1}{6}-\frac{x}{l}+\frac{x^{2}}{l^{2}}\right) \\
& \min M=M_{\mathrm{A}}=M_{\mathrm{B}}=-\frac{q l^{2}}{12}
\end{aligned}
$$

Figure A-12 - Moment and shear distribution in a simply fixed end beam [29]

Replacing the moment $\mathrm{M}_{d}$ and shear $\mathrm{V}_{d}$ by the given values, we obtain the following interrelation between shear slenderness, the span length and the effective depth of the slab.

$$
\lambda=\frac{M_{d}}{V_{d} \times d}=\frac{\left(q l^{2} / 12\right)}{(q l / 2) \times d}=\frac{(l / 6)}{d}
$$

The just developed interrelation is used to link the required reinforcement cross-section to a certain value of shear slenderness reflecting the magnitude of moments and shear acting on the connection. In order to determine the reference values of $\lambda$ for the reinforcement design, it is necessary to set limit values for the required cross-section of reinforcement for each individual reinforcement arrangement, which will be done in the following.

${ }^{13}$ DIN EN 1992-1-1 including German National Annex, 5.6.3 (5.12N) 
The following table shows the provided cross sectional area (prov $A_{s}$ ) of different reinforcement arrangements. Taking into account the number of bars and the minimum clear spacing (req a), the required width (req w) can be calculated, representing the total length that is needed for placing the bars next to each other.

Table A-2 - Different reinforcement arrangements, required cross sectional area and width

\begin{tabular}{|l|c|c|c|c|c|c|c|c|c|c|c|c|}
\hline & $2 \varnothing 16$ & $2 \varnothing 20$ & $4 \varnothing 16$ & $2 \varnothing 25$ & $6 \varnothing 16$ & $4 \varnothing 20$ & $8 \varnothing 16$ & $6 \varnothing 20$ & $4 \varnothing 25$ & $8 \varnothing 20$ & $6 \varnothing 25$ & $8 \varnothing 25$ \\
\hline $\begin{array}{c}\text { prov } \mathbf{A}_{\mathbf{s}} \\
{\left[\mathbf{c m}^{2} \text { ] }\right.}\end{array}$ & 4,02 & 6,28 & 8,04 & 9,82 & 12,1 & 12,6 & 16,1 & 18,8 & 19,6 & 25,1 & 29,5 & 39,3 \\
\hline $\begin{array}{c}\text { req a } \\
\text { [mm] }\end{array}$ & 20 & 20 & 20 & 25 & 20 & 20 & 20 & 20 & 25 & 20 & 25 & 25 \\
\hline $\begin{array}{c}\text { req w } \\
{[\mathbf{c m}]}\end{array}$ & - & - & 12,4 & - & 19,6 & 14,0 & 26,8 & 22,0 & 17,5 & 30,0 & 27,5 & 34,0 \\
\hline
\end{tabular}

The limit value for using the two overlapping loops was set to $A_{s} \approx 10,0 \mathrm{~cm}^{2}$ (green column). Beyond this value, it is likely that either the required lap length gets too large (when using greater diameters) to accommodate it within the connection.

The limit value for the installation of $90^{\circ}$ bent bars was set to $A_{s} \approx 20,0 \mathrm{~cm}^{2}$ (red column). Beyond this value, it would be necessary to install $8 \varnothing 20$ bars, which would be hard to accommodate within the provided column width. In this case, the solution using the horizontal reinforcement loop should be taken into consideration.

\section{Exemplary Calculations for Different Loadings, Slab Depths and Widths}

The parameters and dimensions used for the first calculation (loading, slab depth and width) are based on those used for the exemplary calculation in the previous chapter. For the two following calculations random values were chosen. 


\begin{tabular}{|c|c|c|c|c|c|c|c|c|c|}
\hline Loading & $q=$ & & $\mathrm{kN} / \mathrm{m}^{2}$ & & 9,0 & & & & \\
\hline Shear Force V: & & & & & 7,0 & & & & \\
\hline Width slab & $b_{L}=$ & & & & $\begin{array}{l}6,0 \\
5,0\end{array}$ & & & & \\
\hline & $q_{v}=$ & 105 & $\mathrm{~N} / \mathrm{m}$ & & 4,0 & & & & \\
\hline Bending moment $\mathrm{M}$ : & & & & & $\begin{array}{l}\bar{\omega} 3,0 \\
\overline{\text { के } 2,0}\end{array}$ & & & & \\
\hline Effective depth slab & $d=$ & 24 & $\mathrm{~cm}$ & & $\underset{一}{\Phi} 1,0$ & & & & \\
\hline Effective width slab & $b_{m}=$ & 2,5 & & & 0,0 & & & & \\
\hline & $\mathrm{q}_{\mathrm{m}}=$ & 52,5 & $\mathrm{~s} / \mathrm{m}$ & & & & $\begin{array}{l}26,833, \\
\text { req As [cm }\end{array}$ & $\begin{array}{l}y \\
y\end{array}$ & $0,7 \quad 60,3$ \\
\hline & & & & & & & & & \\
\hline Span width slab I & {$[\mathrm{m}]$} & 5,0 & 6,0 & 7,0 & 8,0 & 9,0 & 10,0 & 11,0 & 12,0 \\
\hline Shear slenderness $\lambda$ & {$[-]$} & 3,5 & 4,2 & 4,9 & 5,6 & 6,3 & 6,9 & 7,6 & 8,3 \\
\hline Shear force V & {$[\mathrm{kN}]$} & 262,5 & 315,0 & 367,5 & 420,0 & 472,5 & 525,0 & 577,5 & 630,0 \\
\hline Bending moment $\mathrm{M}$ & {$[\mathrm{kNm}]$} & 109,4 & 157,5 & 214,4 & 280,0 & 354,4 & 437,5 & 529,4 & 630,0 \\
\hline Tensile Force T & {$[\mathrm{kN}]$} & 455,7 & 656,3 & 893,2 & 1166,7 & 1476,6 & 1822,9 & 2205,7 & 2625, \\
\hline req $A_{s}$ & {$\left[\mathrm{~cm}^{2}\right]$} & 10,5 & 15,1 & 20,5 & 26,8 & 33,9 & 41,9 & 50,7 & 60,3 \\
\hline e.g. & & $4 \varnothing 20$ & $4 \varnothing 25$ & $4 \varnothing 25$ & $6 \varnothing 25$ & 8025 & $8 \varnothing 28$ & $8 \varnothing 28$ & - \\
\hline
\end{tabular}

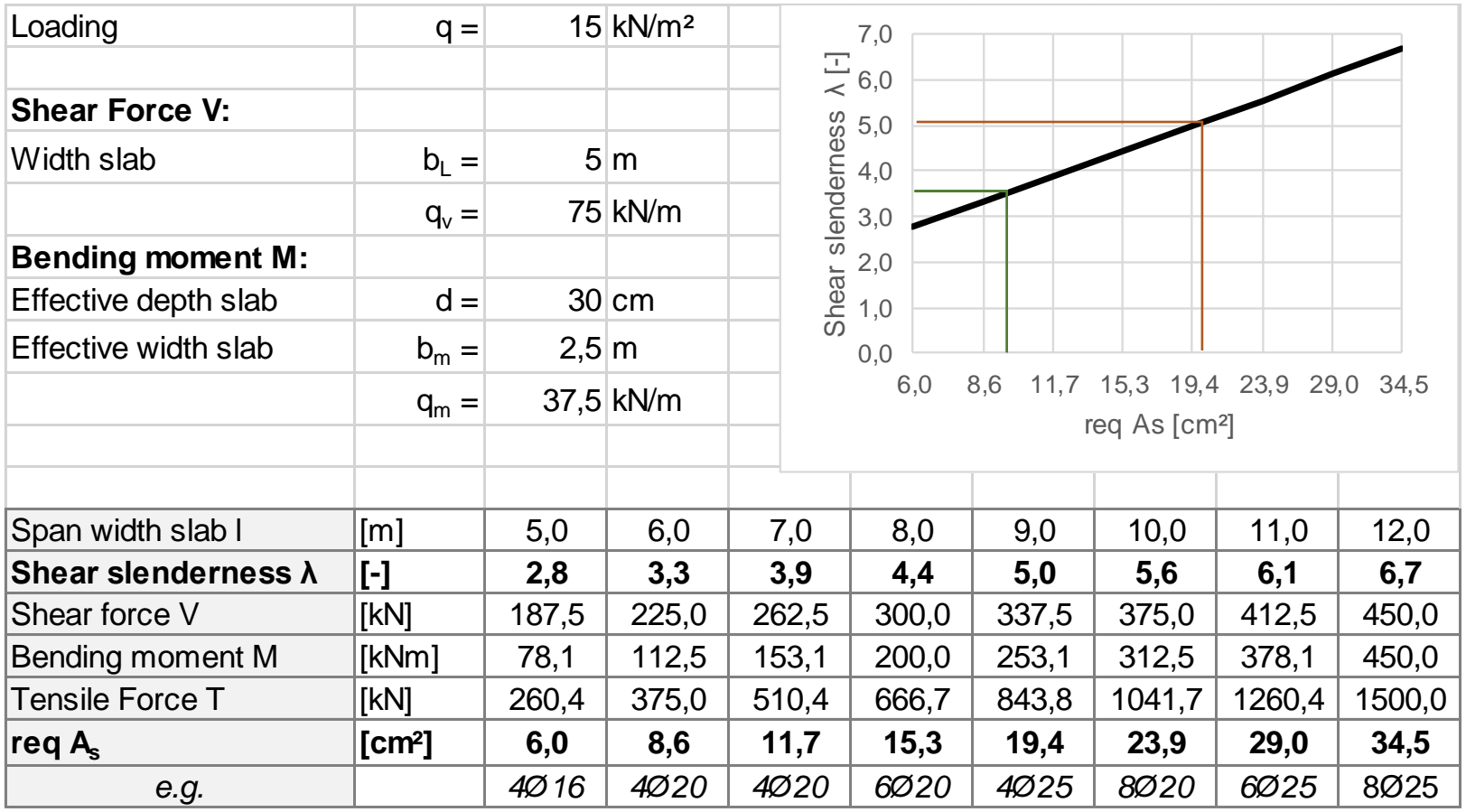




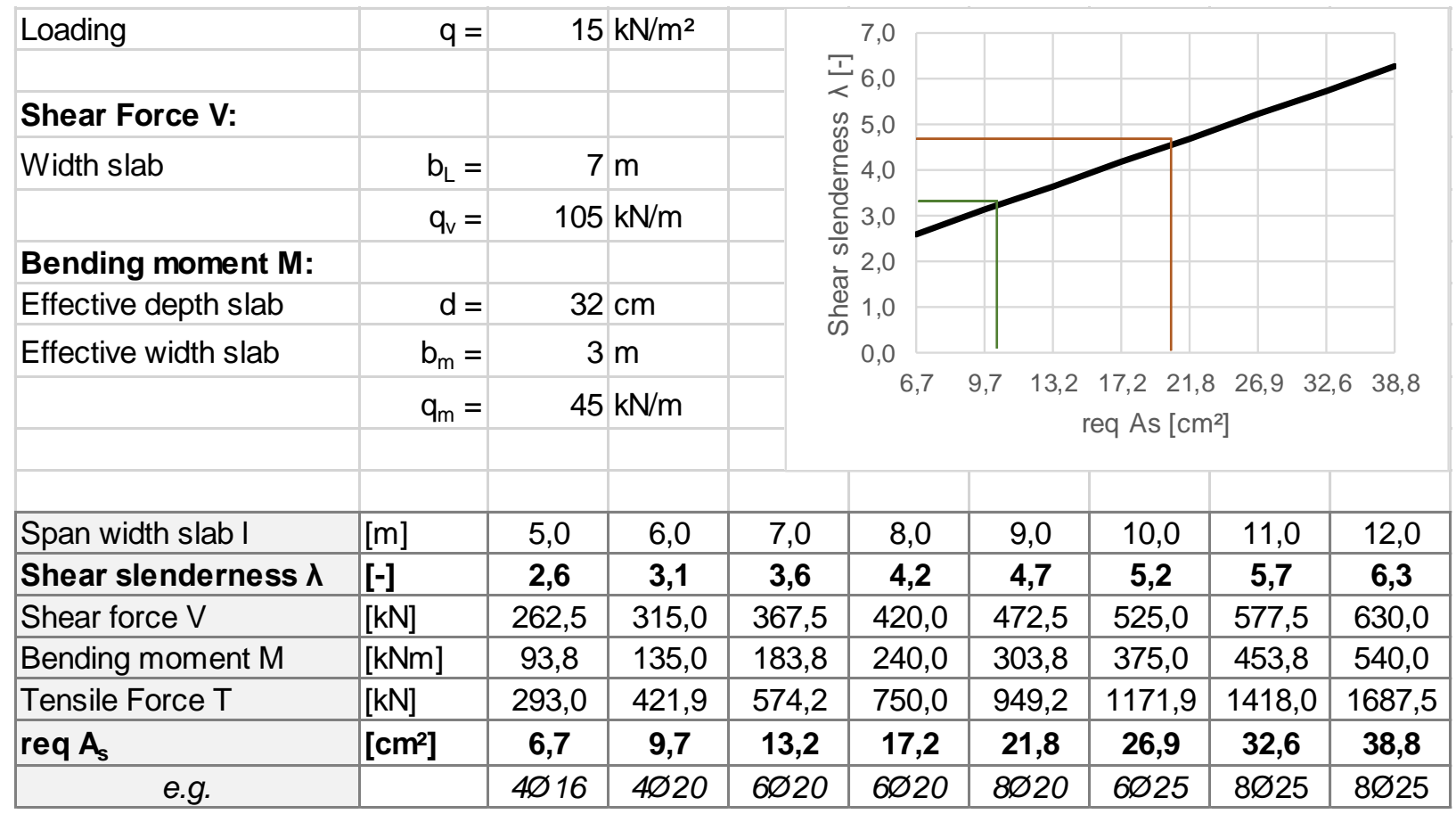

Although the parameters for loading, slab depth and width were chosen randomly for the three exemplary calculations, the ratio of required $A_{s}$ and shear slenderness $\lambda$ stays in the same range. Therefore, it can be noted that the limit value corresponding to a sectional area of $A_{s}=10 \mathrm{~cm}^{2}$ is reached at a value of the shear slenderness of about $\lambda \approx 3,5$, the limit value of req $A_{s}=20 \mathrm{~cm}^{2}$ corresponds to a value of approximately $\boldsymbol{\lambda} \approx \mathbf{5 , 0}$. 


\section{REFERENCES}

[1] T. S. Urban and M. M. Goldyn, "Behaviour of Eccentrically Loaded High-Strength Concrete Columns Intersected by Lower-Strength Concrete Slabs," Structural Concrete 16, pp. 480495, 2015.

[2] 352, ACl-ASCE Commitee, Recommendations for Design of Slab-Column Connections in Monolithic Reinforced Concrete Structures, 1997.

[3] Europoles, "Product Sheet (Construction Details)," February 2018. [Online]. Available: http://www.europoles.de/fileadmin/user_upload/media/stuetzen/Konstruktionsdetails _exklusive_Stuetzen_de.pdf. [Accessed 15 May 2018].

[4] J. Hegger, J. Walraven and F. Häusler, "Zum Durchstanzen von Flachdecken nach Eurocode 2," Beton- und Stahlbetonbau 105, pp. 206-215, 2010.

[5] L. Soares and R. Vollum, "Influence of Continuity on Punching Resistance at Edge Columns," Magazine of Concrete Research, pp. 1225-1239, 2016.

[6] DIN Deutsches Institut für Normung e.V., Eurocode 2: Design Of Concrete Structures, Berlin: Beuth Verlag GmbH, October 2005.

[7] F. S. Häusler, "Zum Maximalen Durchstanzwiderstand von Flachdecken mit und ohne Vorspannung," Rheinisch-Westfälische Technische Hochschule Aachen, Aachen, 2009.

[8] J. Minnert and G. Günther, "Bemessungsvorschlag für die verstärkte Querbewehrung bei mehrgeschossigen Ortbetonstützen ohne Übergreifungsstoß der Längsbewehrung," Beton- und Stahlbetonbau 102, pp. 88-97, 2007.

[9] S. Lutz, "Vorlesungsskiptum aus Betonbau," Technische Universität Graz, 2004.

[10] M. Cyllok, "Bemessung der Lastdurchleitung hochfester Stahlbetonstützen durch normalfeste Flachdecken nach EN 1992-1-1," Beton- und Stahlbetonbau 106, pp. 672-684, 2011. 
[11] G. Rinnhofer, S. Burtscher and J. Kollegger, "Berechnung von Stützen-Deckenknoten für Schleuderbetonstützen," Beton- und Stahlbetonbau 104, pp. 599-608, 2009.

[12] K. Kordina, "Bewehrungsführung in Ecken und Rahmenendknoten [Heft 354]," Wilhelm Ernst \& Sohn, Berlin, 1984.

[13] J. G. MacGregor and F. M. Barlett, Reinforced Concrete, Mechanics and Design, First Canadian Edition, Scarborough, Ontario: Prentice Hall Canada Inc., 2000.

[14] J. Hegger and W. Roeser, "Die Bemessung und Konstruktion von Rahmenknoten Grundlagen und Beispiele gemäß DIN 1045-1 [Heft 532]," Beuth Verlag, Berlin, 2002.

[15] K. Kordina, M. Teutsch and E. Wegener, "Trag- und Verformungsverhalten von Rahmenknoten," Braunschweig, 1995.

[16] J. Schlaich and K. Schäfer, "Konstruieren im Stahlbetonbau," in Betonkalender 1993, Ernst \& Sohn Verlag, 1993, pp. 327-486.

[17] E. Grasser and G. Thielen, "Hilfsmittel zur Berechnung der Schnittgrößen und Formänderungen von Stahlbetontragwerken (Heft 240)," Beuth Verlag GmbH, Berlin, 1988.

[18] F. Hartmann and C. Katz, Structural Analysis With Finite Elements, 2nd ed., Berlin: Springer, 2007.

[19] C. Barth and W. Rustler, Finite Elemente in der Baustatik-Praxis, 2nd ed., Berlin: Beuth, 2013.

[20] C. H. Goodchild, J. Morrison and R. I. Vollum, "Strut-and-Tie Models," MPA The Concrete Centre, London, 2014.

[21] G. Chantelot and A. Mathern, "Strut-and-Tie Modelling of Reinforced Concrete Pile Caps," Göteborg, 2010.

[22] J. Hegger, Vorlesung Massivbau III - Rahmenknoten, Aachen: Lehrstuhl und Institut für Massivbau, 2011.

[23] L. Sparowitz, "Vorlesungsskript aus Betonbau," Institut für Betonbau, Technische Universität Graz, 2004. 
[24] M. Jennewein and K. Schäfer, "Standartisierte Nachweise von häufigen D-Bereichen [Heft 430]," Beuth Verlag, Berlin, 1992.

[25] J. Schlaich, K. Schäfer and M. Jennewein, "Toward a Consistent Design of Structural Concrete," PCl Journal, pp. 74-150, May 1987.

[26] Pentair, "Product Sheet Mechanical Anchors including LENTON TERMINATOR," 2018. [Online]. Available: https://www.erico.com/catalog/categories/R2073?pdf=1\&language $=$ en\&country=CA. [Accessed 22 July 2018].

[27] M. Bruckner, "Anwendung von Ankerstäben in Rahmenecken, Rahmenendknoten und Stütze-Fundament-Verbindungen," Institut für Werkstoffe im Bauwesen der Universität Stuttgart, Stuttgart, 2006.

[28] Held, Schnellenbach-Held and Welsch, "Konstruktive Ausbildung und Bemessung des Knotens Flachdecke - Verbundstütze," Bauingenieur, February 2011.

[29] U. Vismann, Wendehorst Bautechnische Zahlentafeln, Wiesbaden: Springer, 2015.

[30] A. Hörmann, "Ermittlung optimierter Stabwerkmodelle auf Basis des Kraftflusses als Anwendung plattformunabhängiger Prozesskopplung," Munich, 2005.

[31] F. Leonhardt, Vorlesungen über Massivbau Teil 1-6, Springer.

[32] H. Trost, "Punktförmig gestützte Platten; Nachweis der Biegebewehrung," in Erläuterungen zu DIN 1045, vol. Heft 400, Berlin, Beuth Verlag, 1994, pp. 131-133. 